\title{
Lactonization of 2-Alkynylbenzoates for the Assembly of Isochromenones Mediated by $\mathrm{BF}_{3} \cdot \mathrm{Et}_{2} \mathrm{O}$
}

Xiang Zhang, ${ }^{\dagger}$ Xintong Wan, ${ }^{\dagger}$ Ying Cong, ${ }^{\dagger}$ Xiaohua Zhen, ${ }^{\dagger}$ Qiao Li ${ }^{\dagger}$ Daisy Zhang-Negrerie ${ }^{\dagger}$ Yunfei Du*,+, and Kang Zhao ${ }^{*}$,

† Tianjin Key Laboratory for Modern Drug Delivery \& High-Efficiency, School of Pharmaceutical Science and Technology, Tianjin University,

Tianjin 300072, P. R. China

Collaborative Innovation Center of Chemical Science and Engineering (Tianjin), Tianjin 300072, P. R. China.

\section{duyunfeier@tju.edu.cn;kangzhao@tju.edu.cn}

Supporting Information

I. ${ }^{1} \mathrm{H}-\mathrm{NMR}$ and ${ }^{13} \mathrm{C}-\mathrm{NMR}$ Spectra of Substrates 1

Page

II. ${ }^{1} \mathrm{H}-\mathrm{NMR}$ and ${ }^{13} \mathrm{C}-\mathrm{NMR}$ Spectra of Products $\mathbf{2}$ and $\mathbf{3}$

III. ${ }^{1} \mathrm{H}-\mathrm{NMR}$ and ${ }^{13} \mathrm{C}-\mathrm{NMR}$ Spectra of Products 4

IV. ${ }^{1} \mathrm{H}-\mathrm{NMR}$ and ${ }^{13} \mathrm{C}-\mathrm{NMR}$ Spectra of Compounds 6 and 7 


\section{I. ${ }^{1} \mathrm{H}-\mathrm{NMR}$ and ${ }^{13} \mathrm{C}-\mathrm{NMR}$ Spectra of Substrates 1}

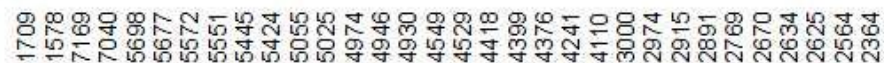

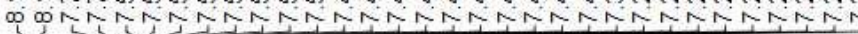
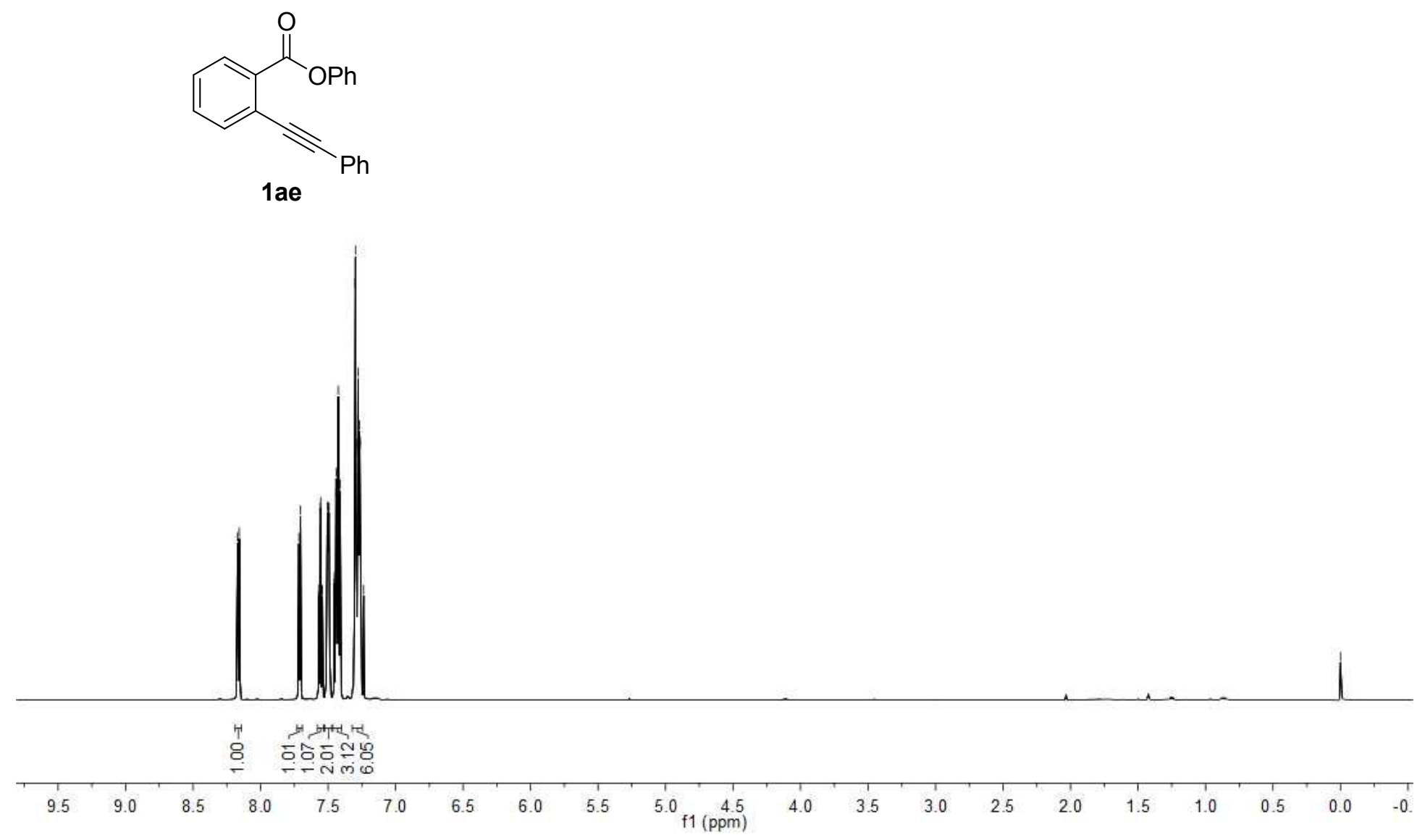

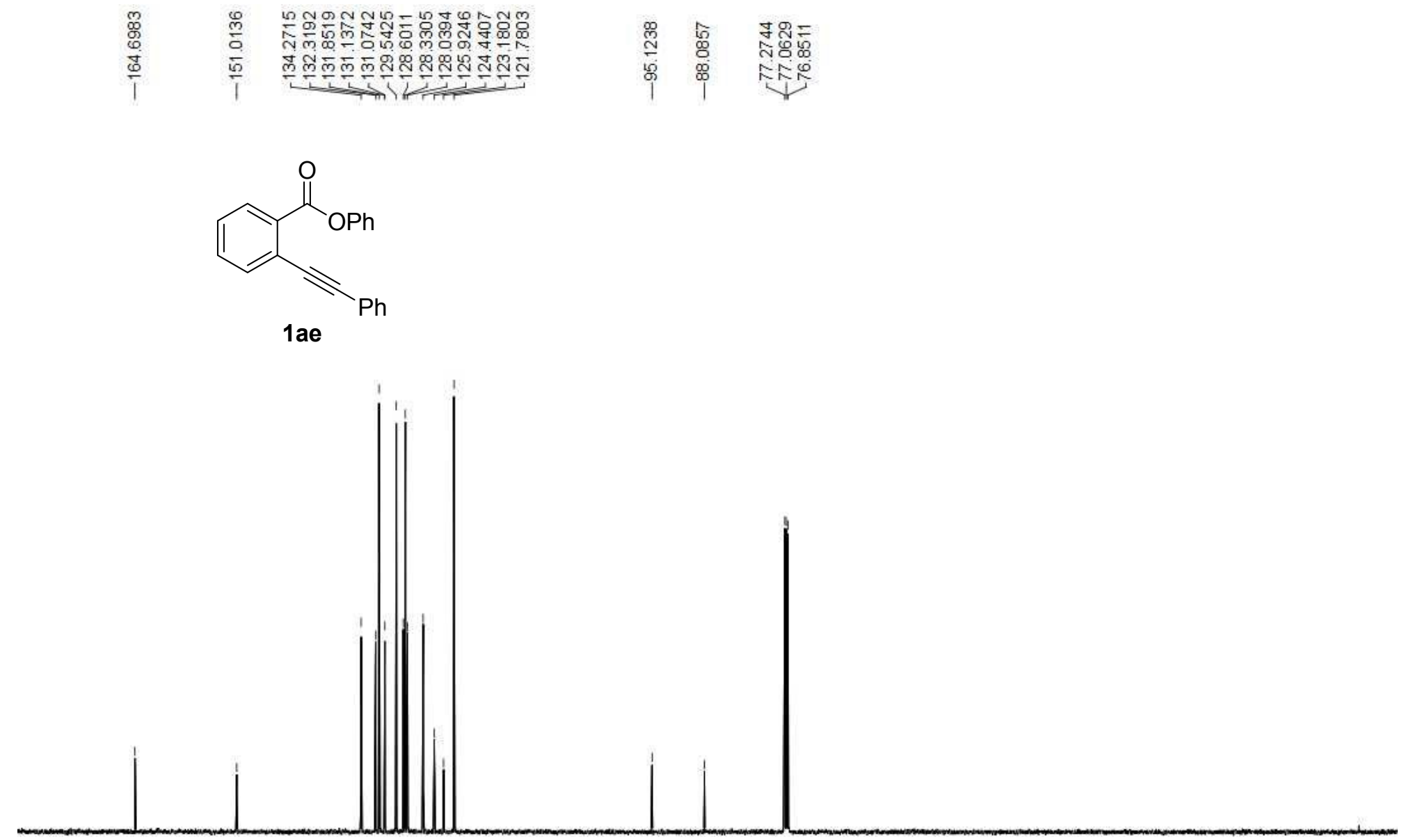

$80+170$

$150 \quad 140$

130

$120 \quad 110$

100

$\mathrm{f1}^{90}(\mathrm{ppm})$

S3 


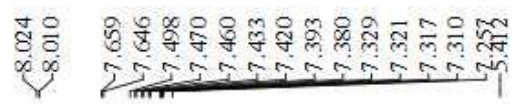

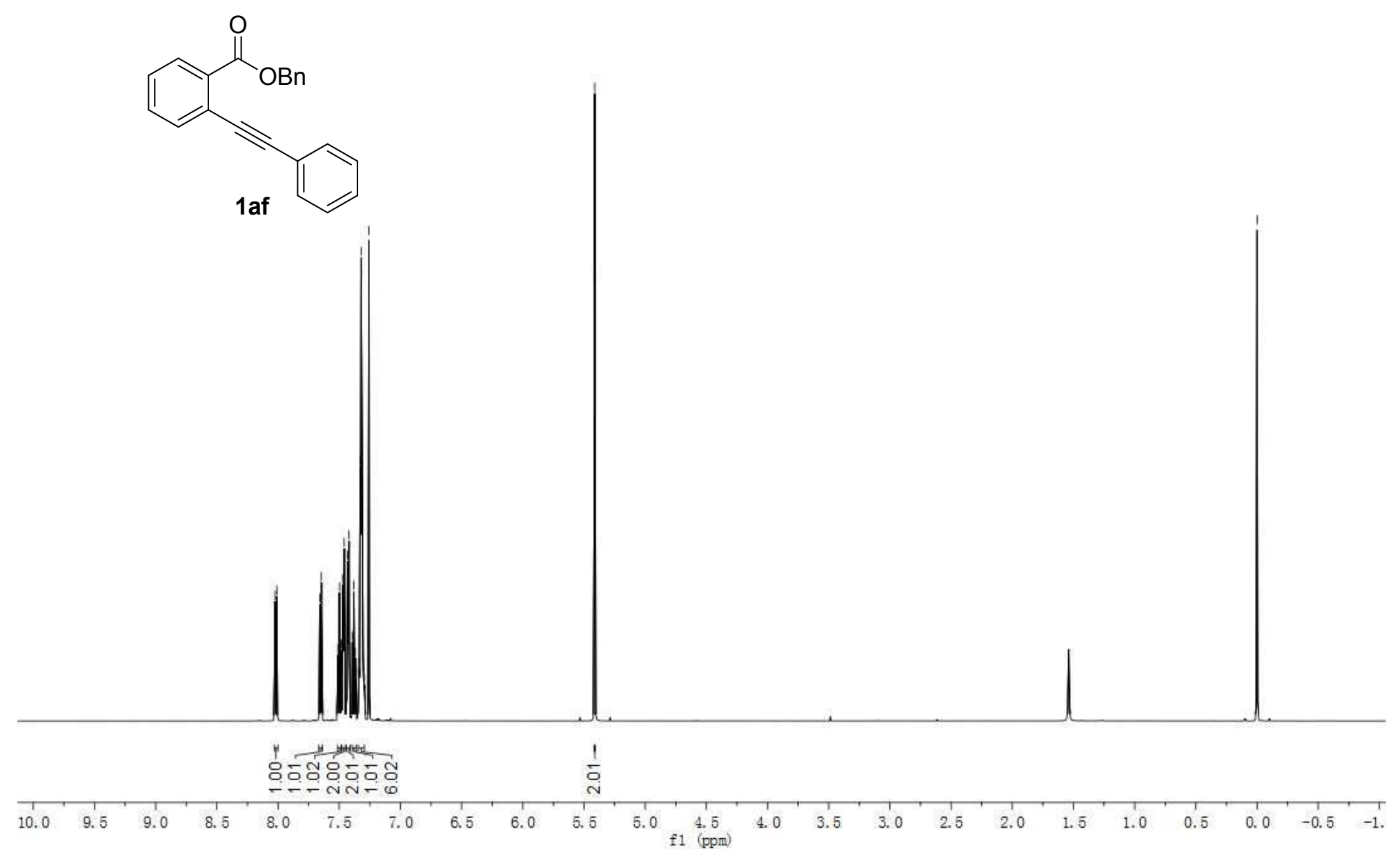



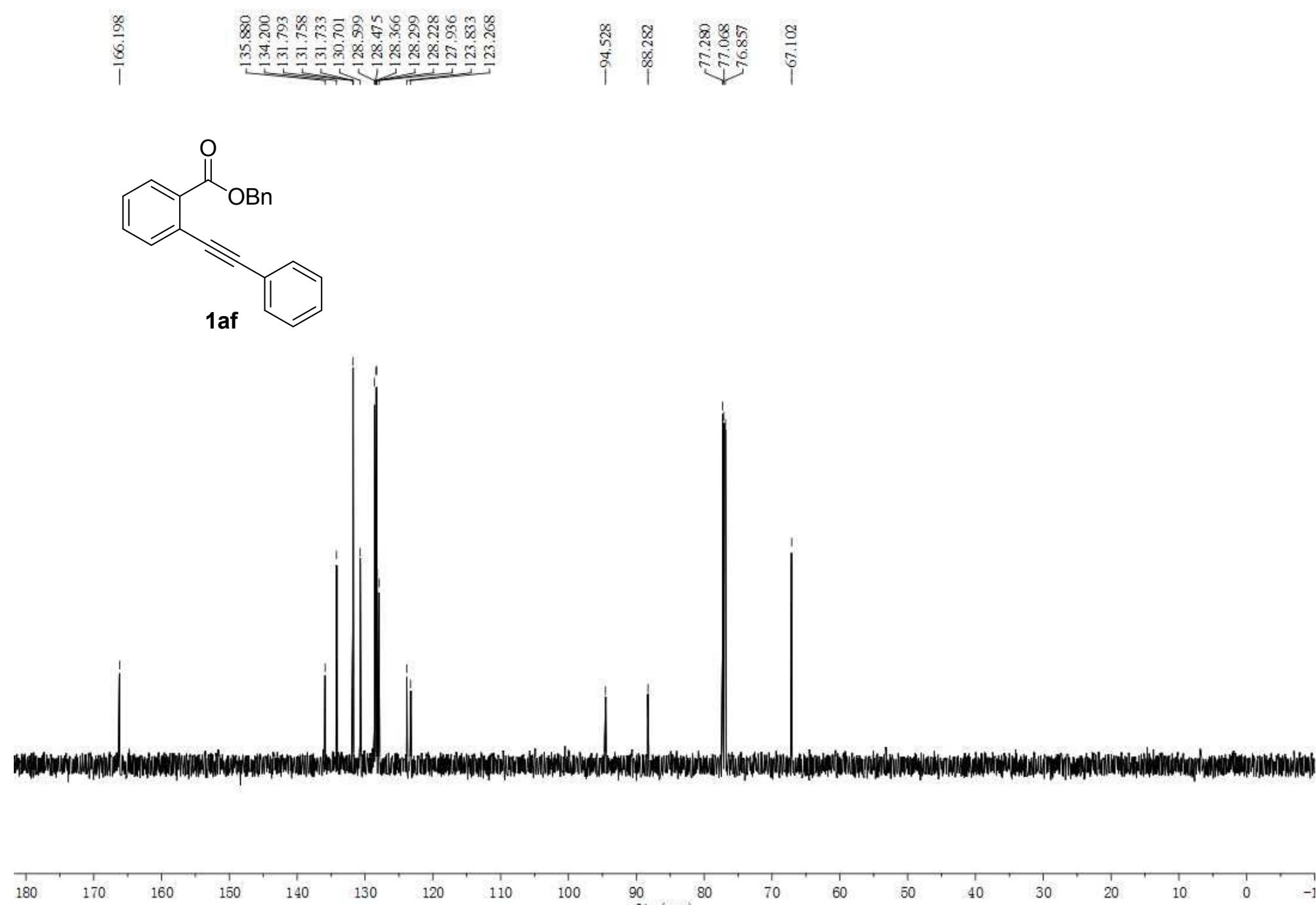

$130 \quad 120$

$110 \quad 100$

$90 \quad 80$ 


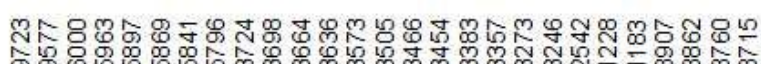

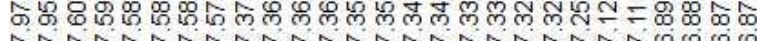

సู่产

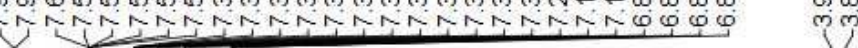

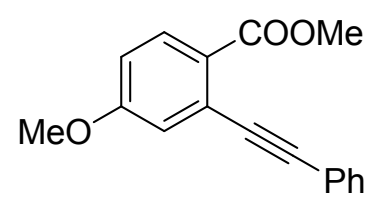

$1 b$

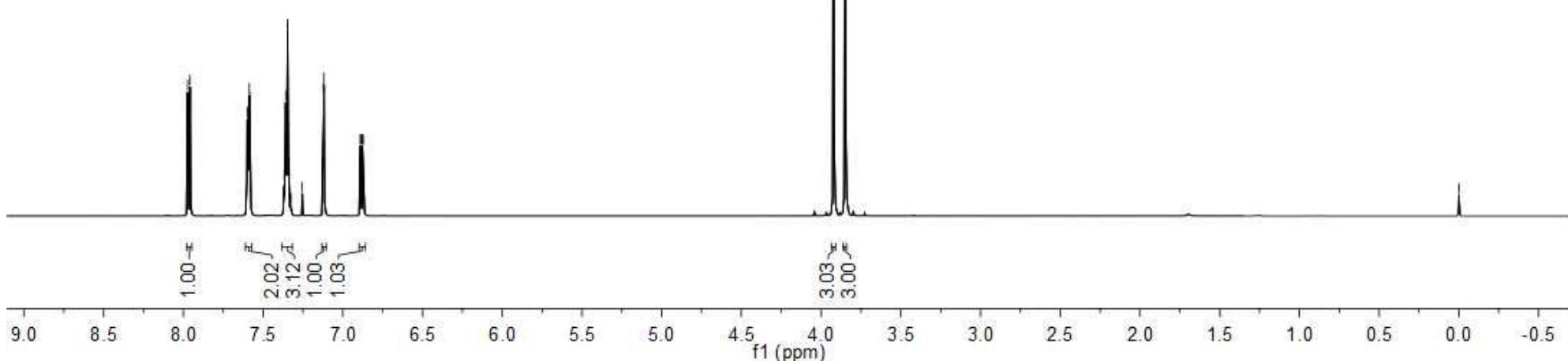




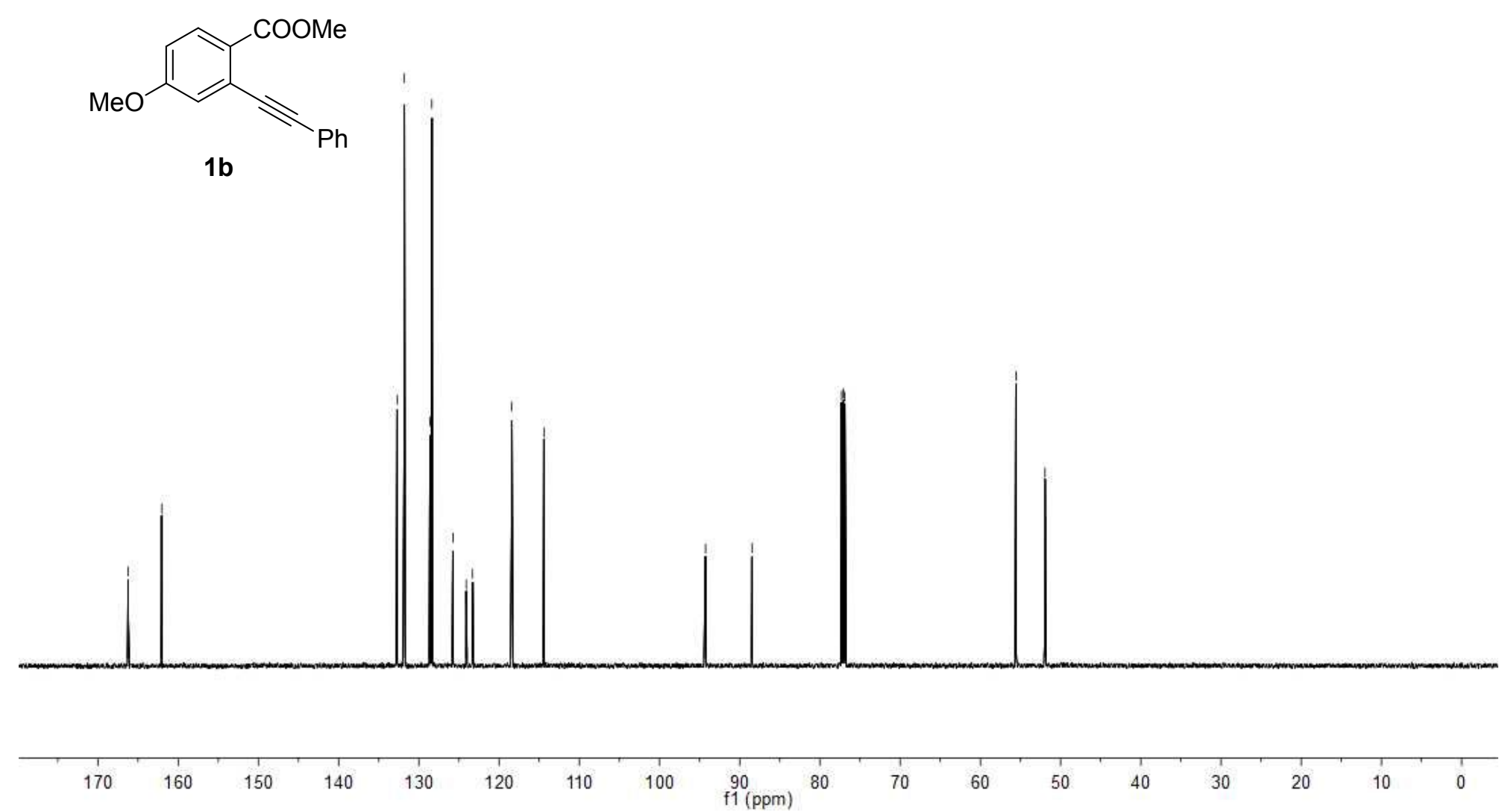




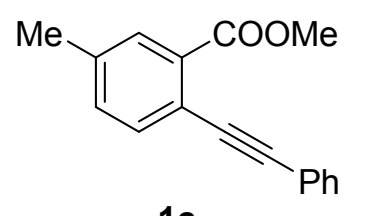

$1 c$

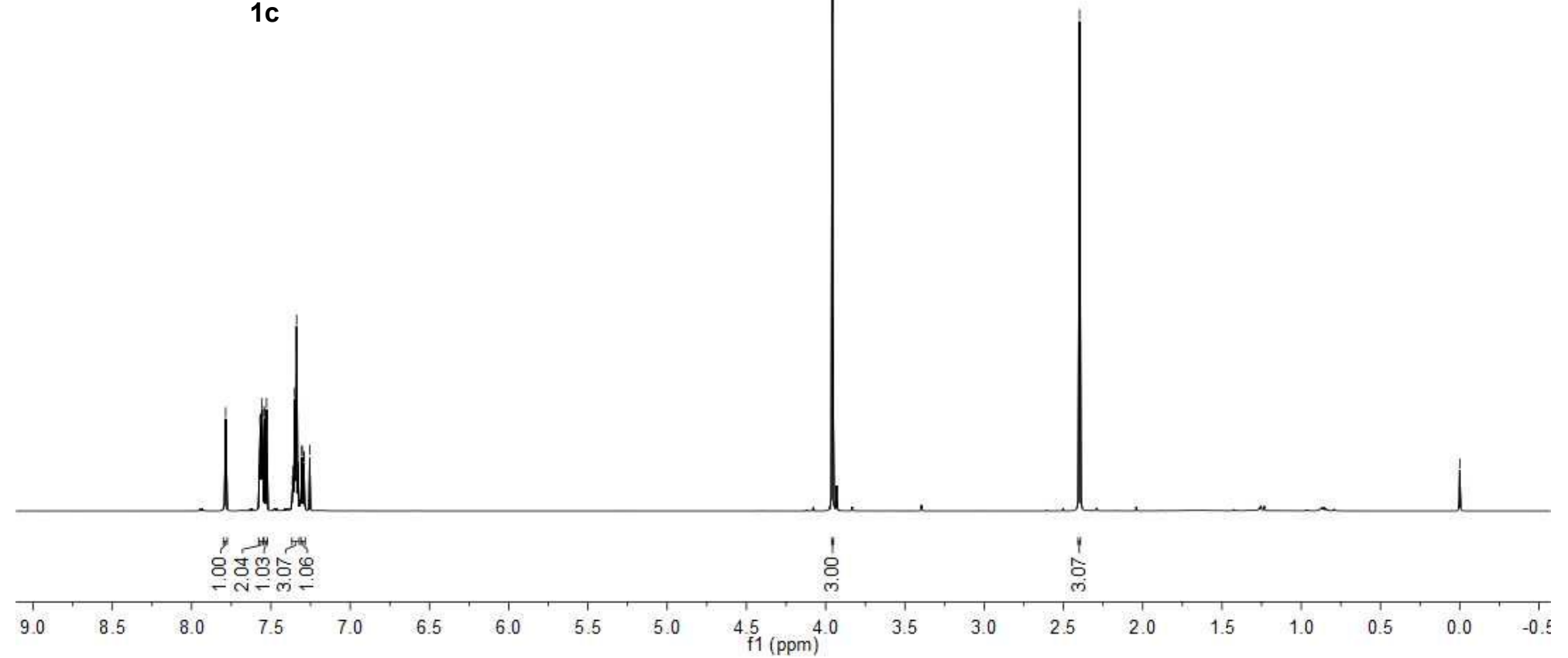




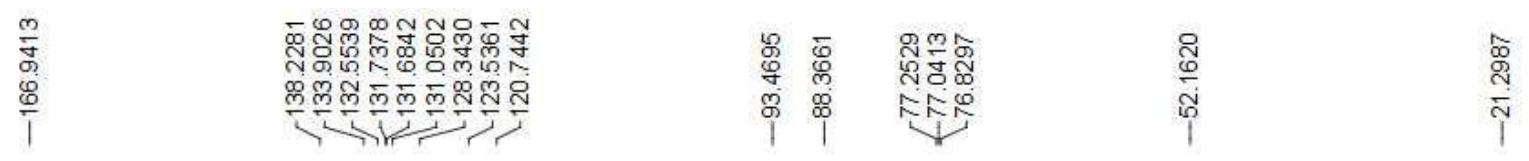

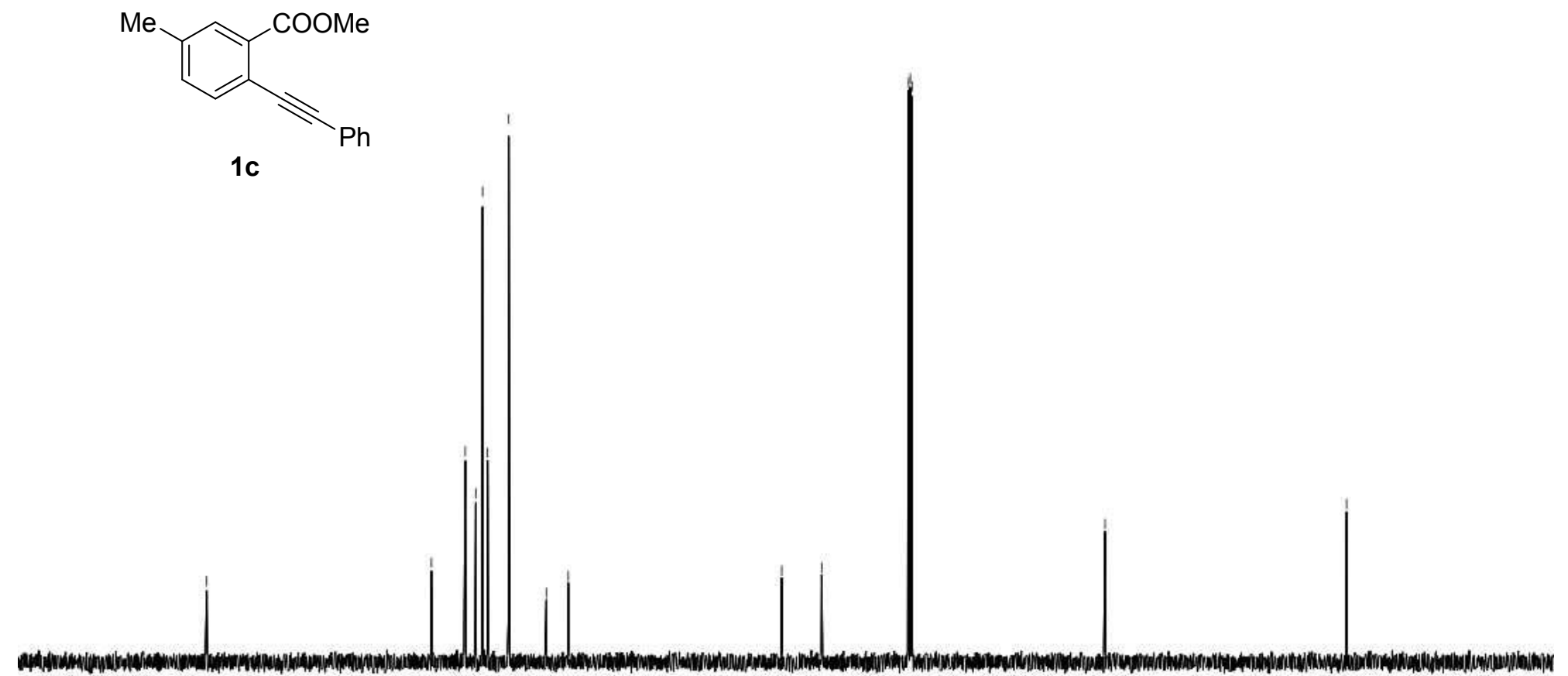

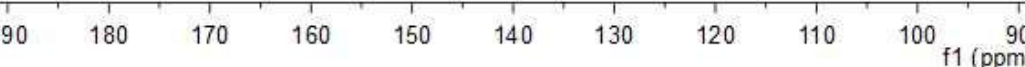



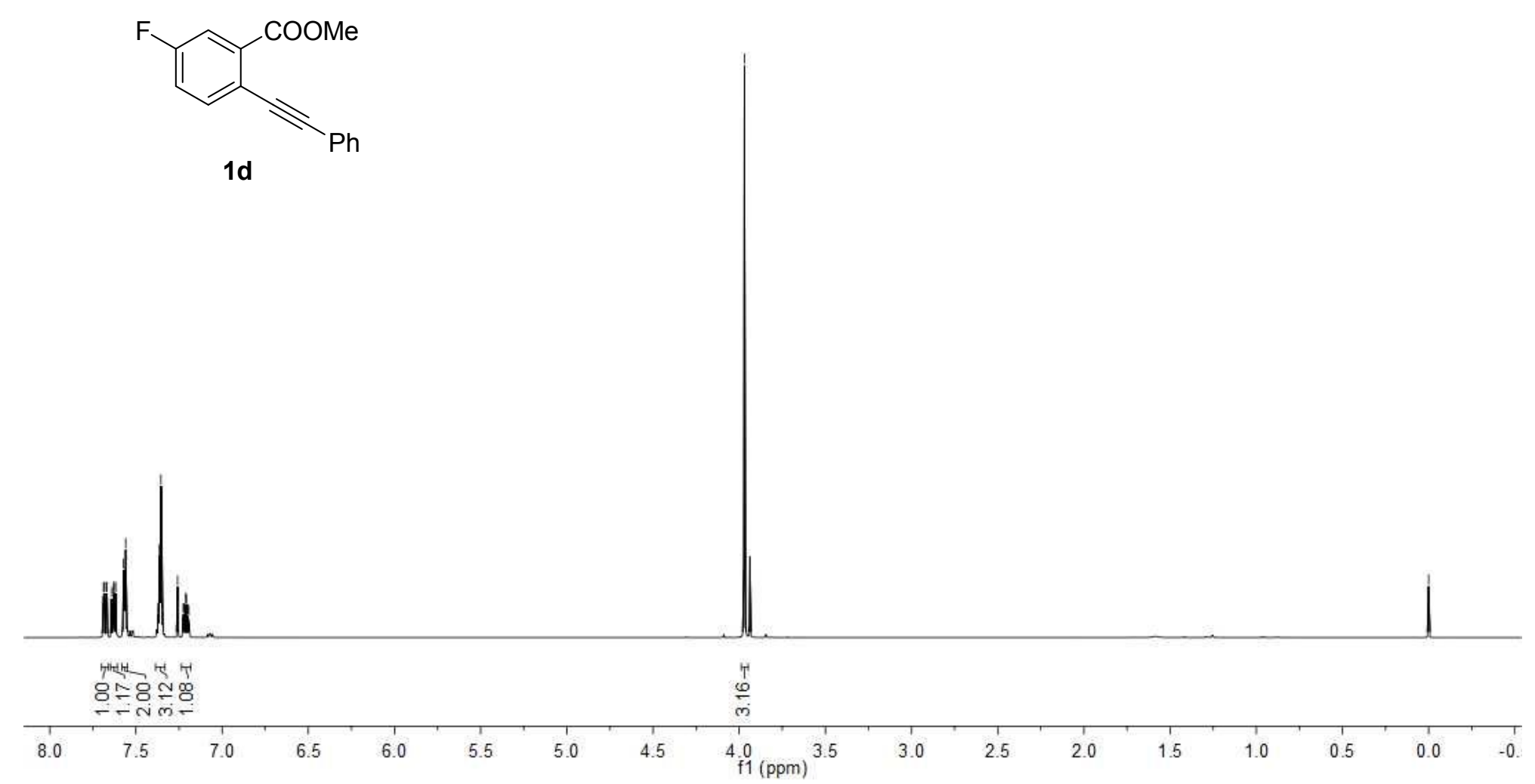

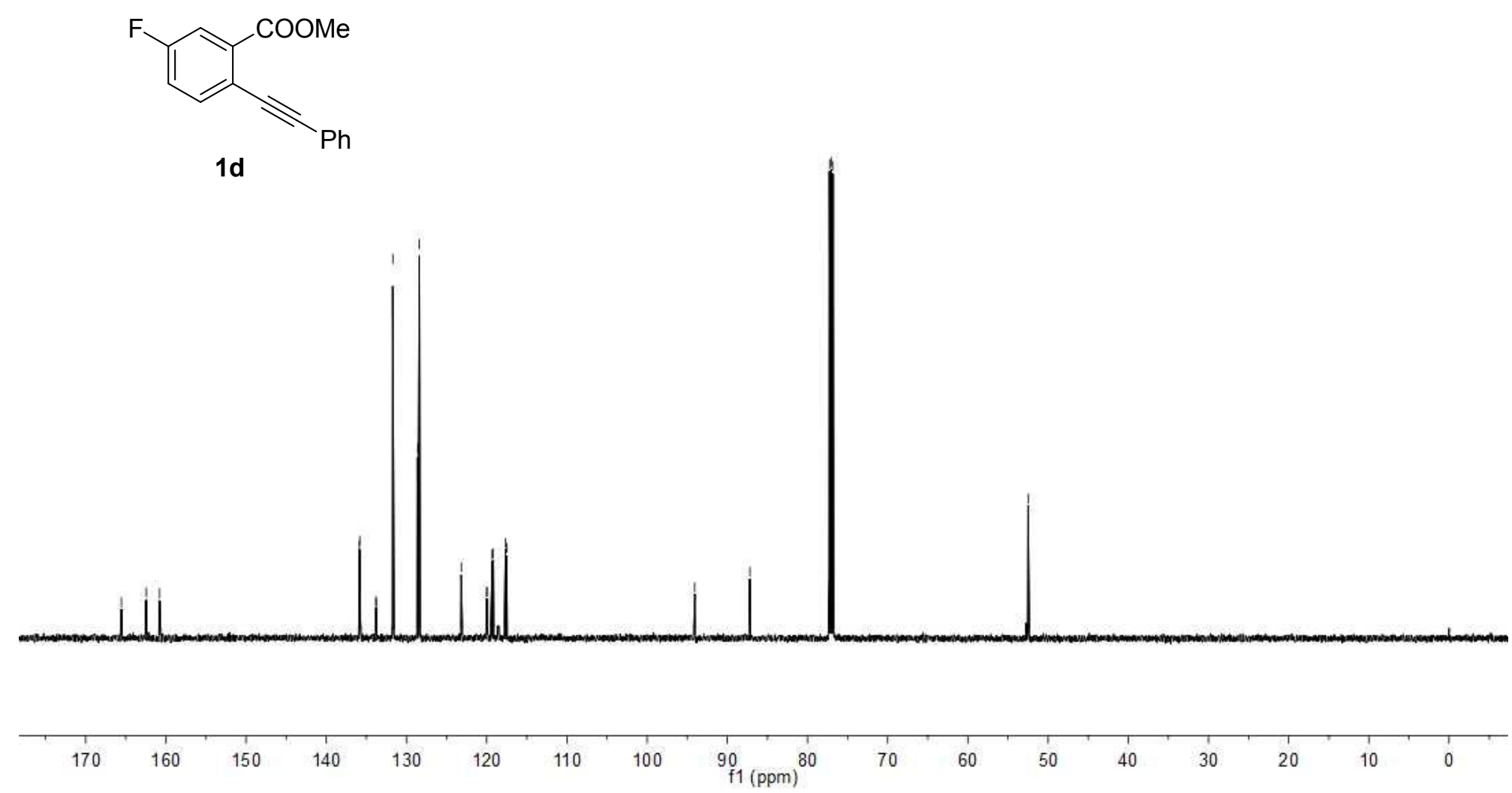


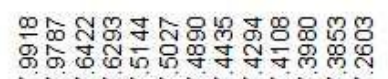

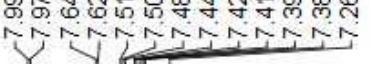

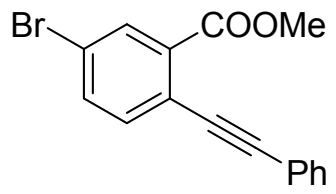

$1 e$

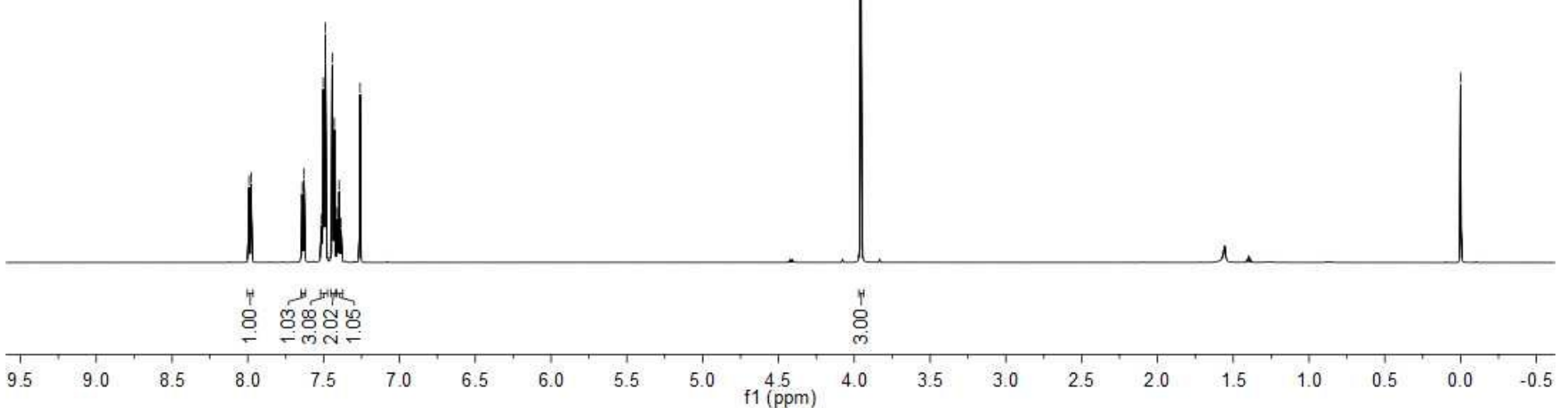




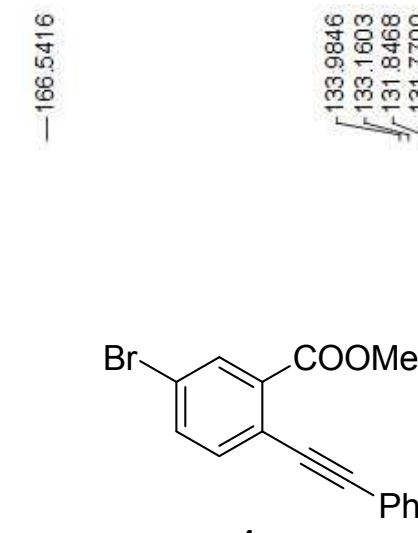

$1 e$

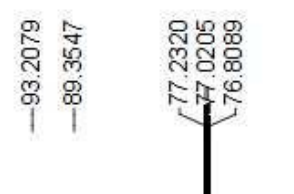

ำ

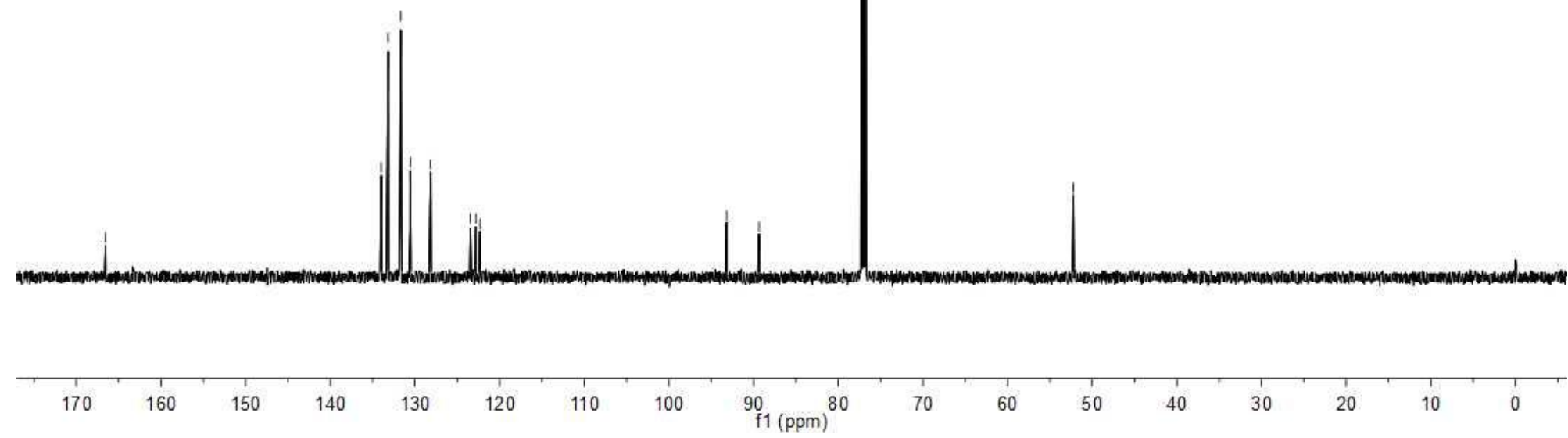




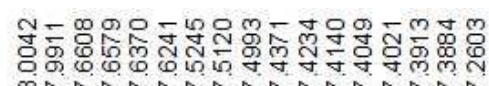

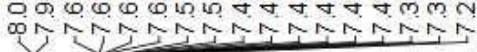
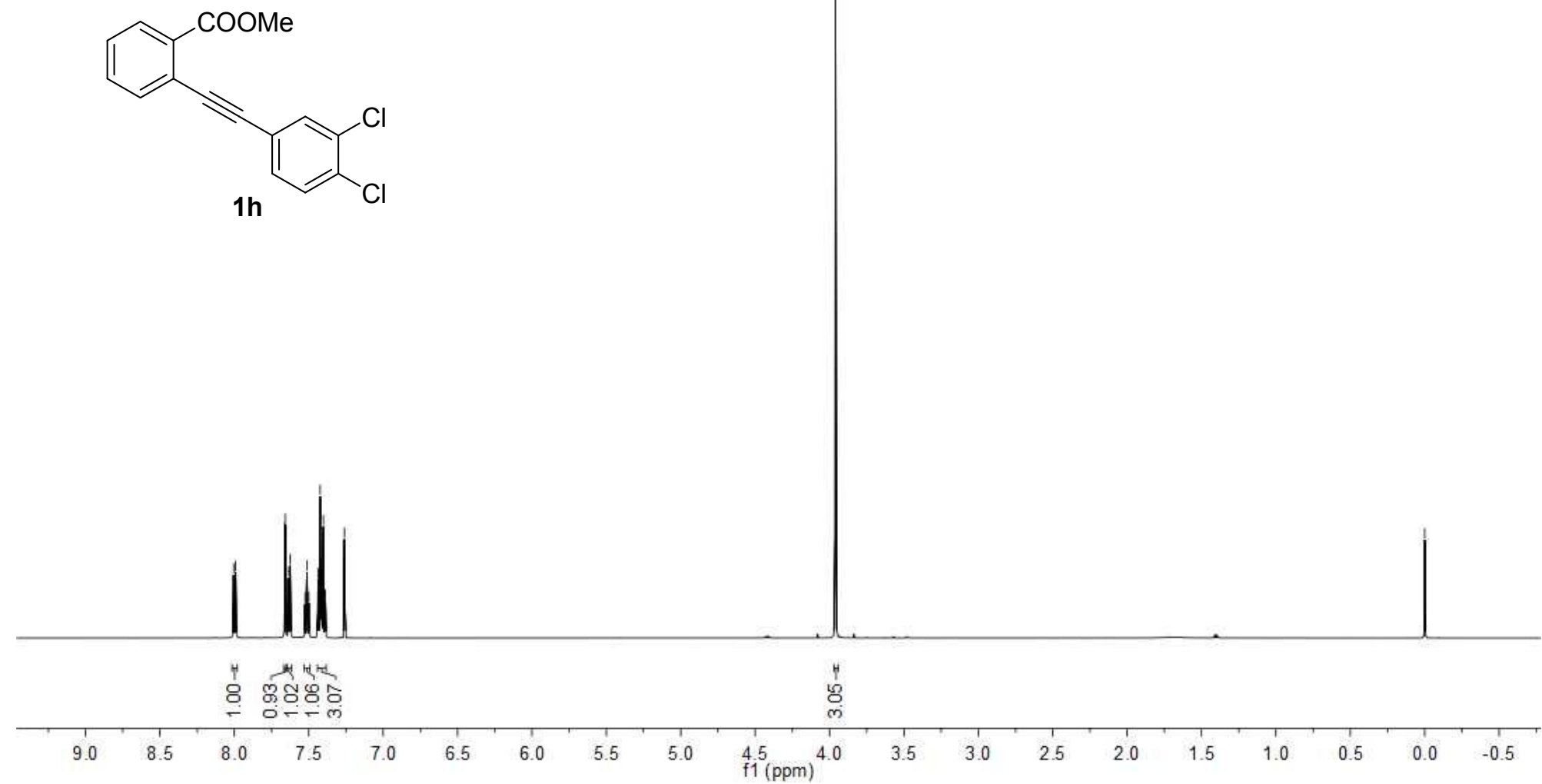


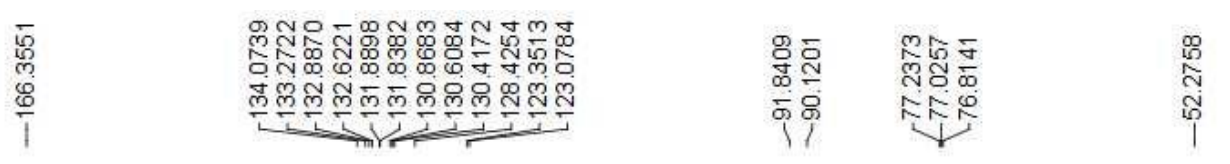

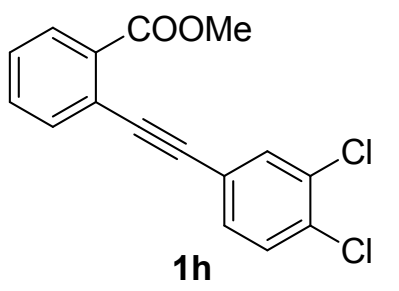

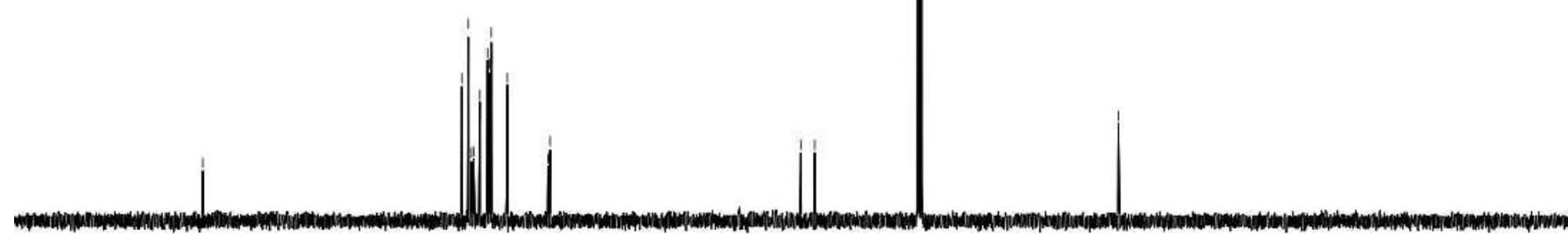

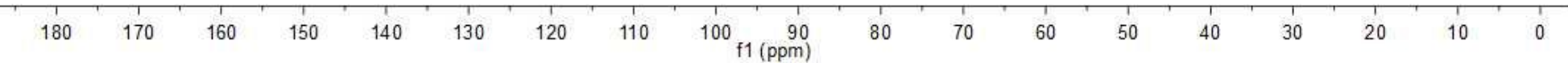



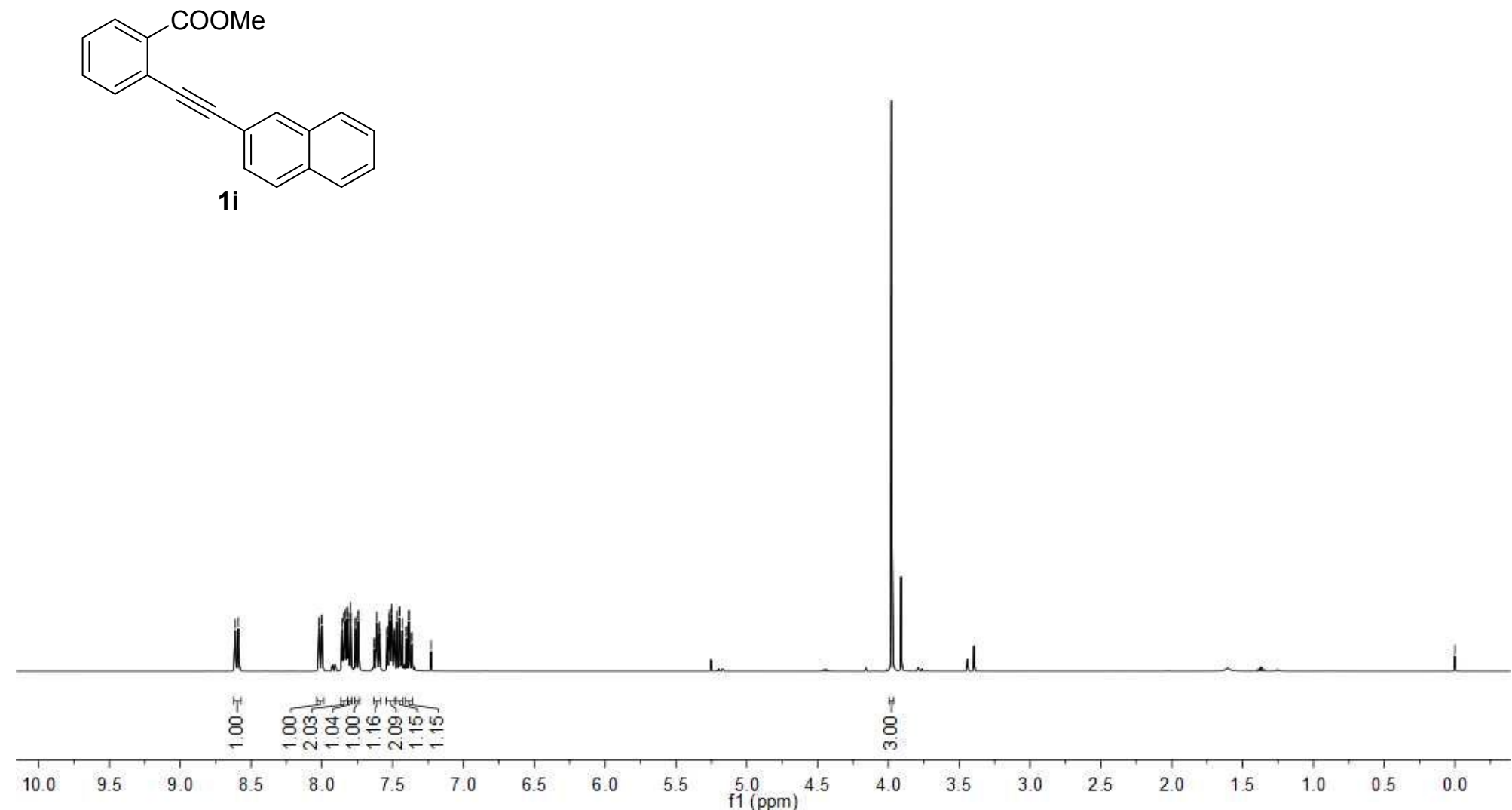


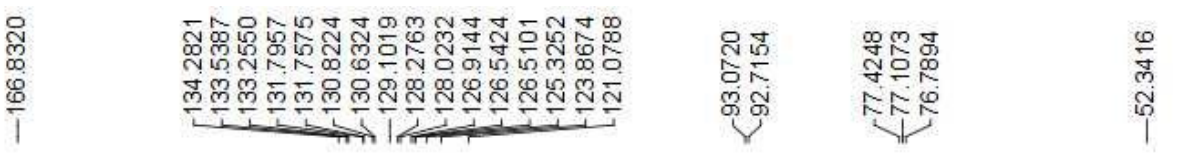
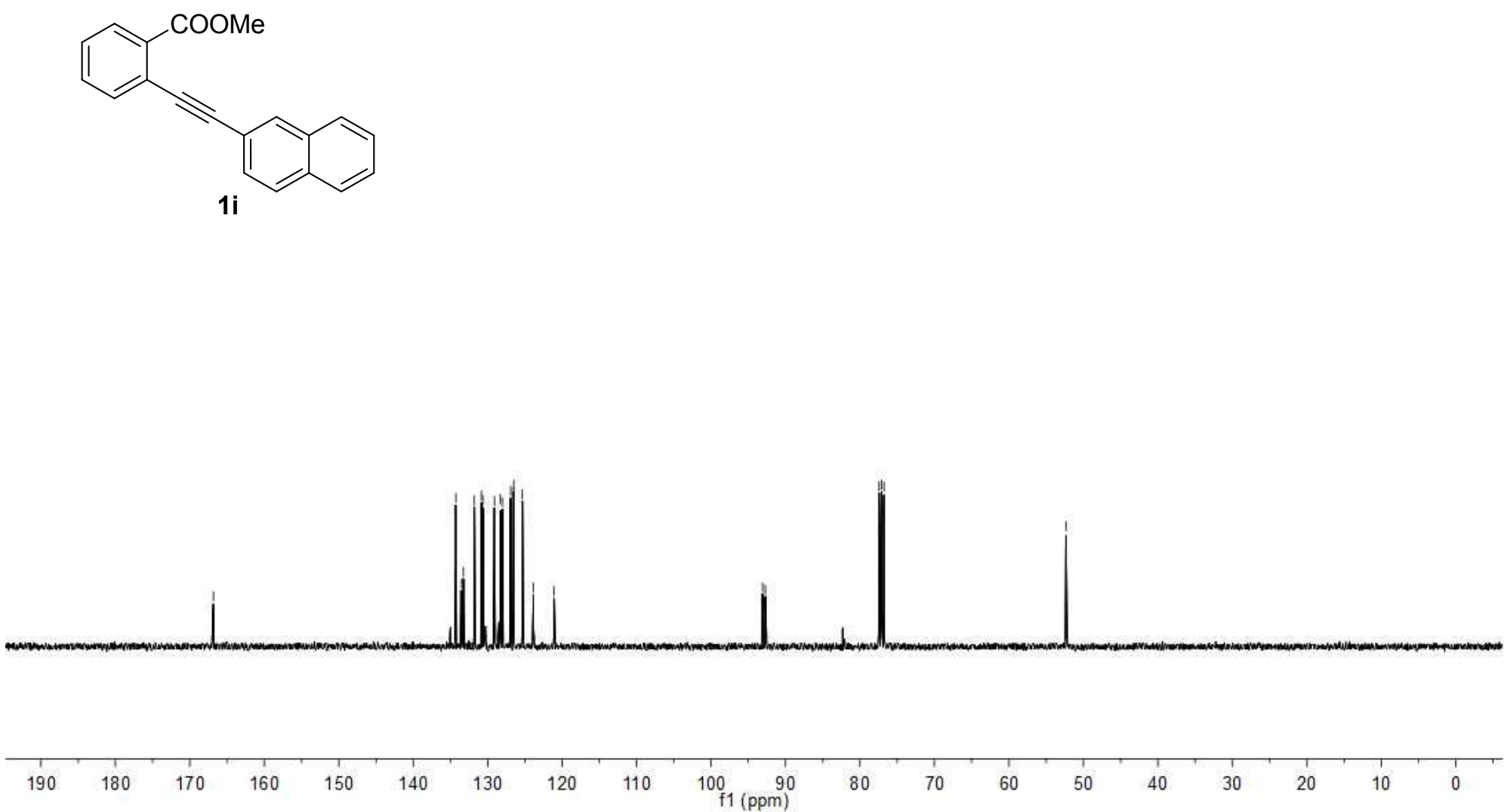

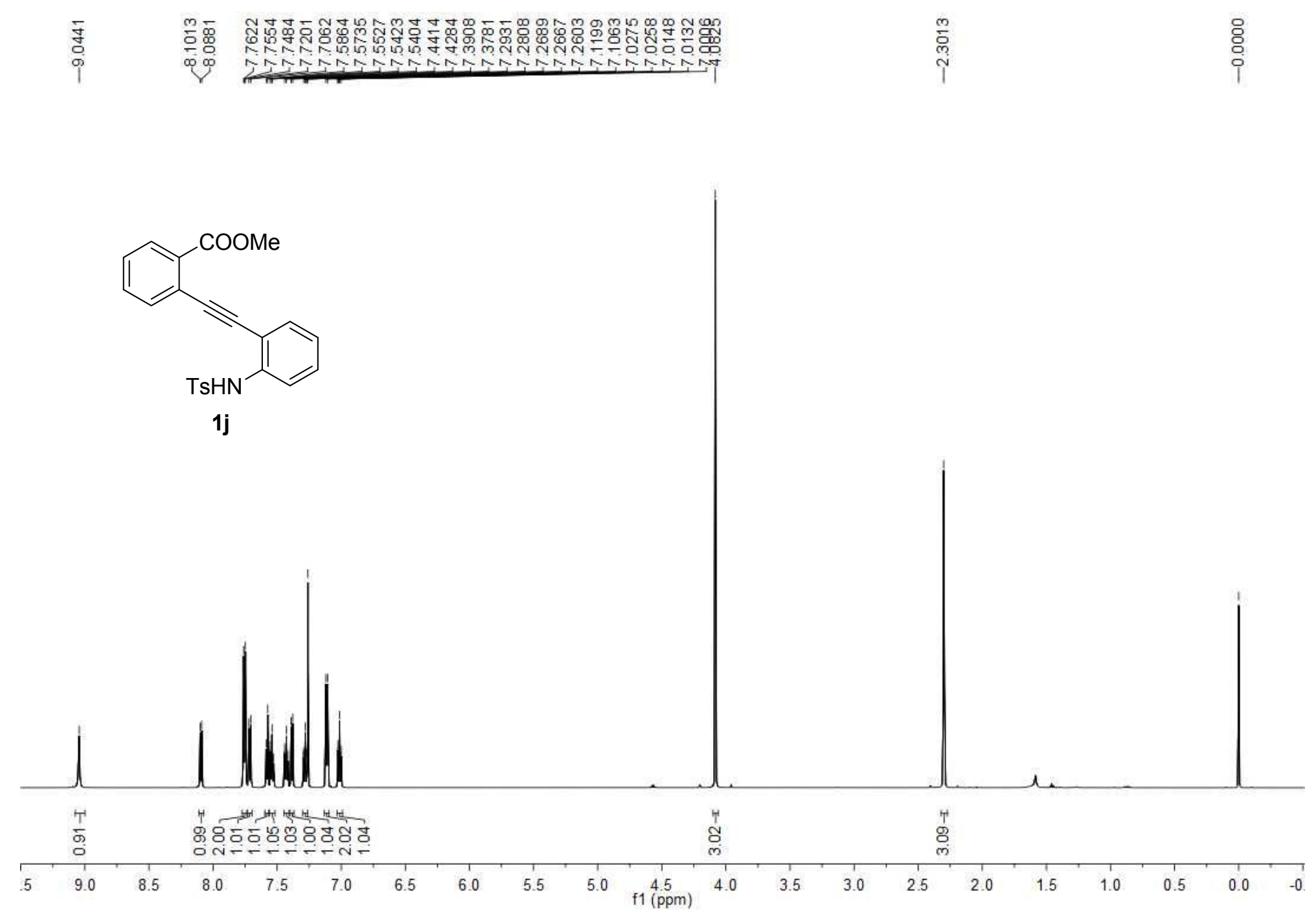

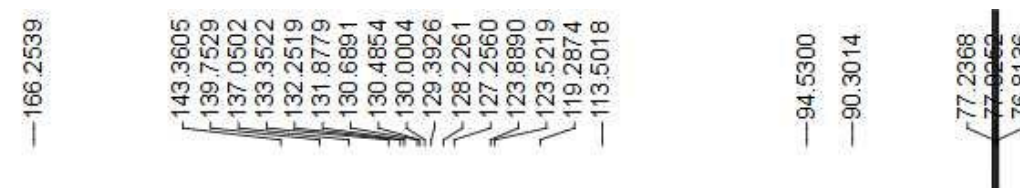

员

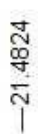
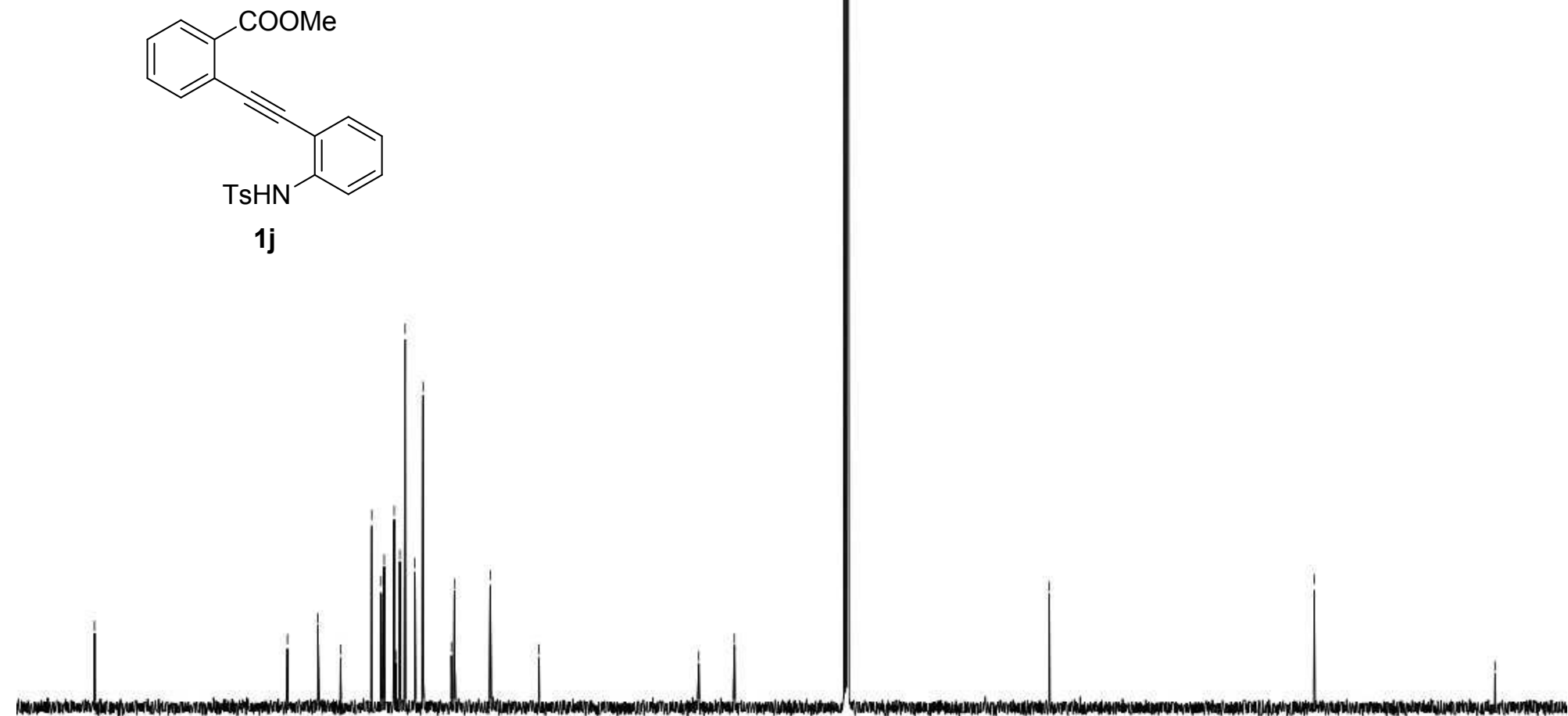

$\begin{array}{lllllllll}170 & 160 & 150 & 140 & 130 & 120 & 110 & 100 & 90 \\ \mathrm{f} 1(\mathrm{ppm}) & 80\end{array}$ 

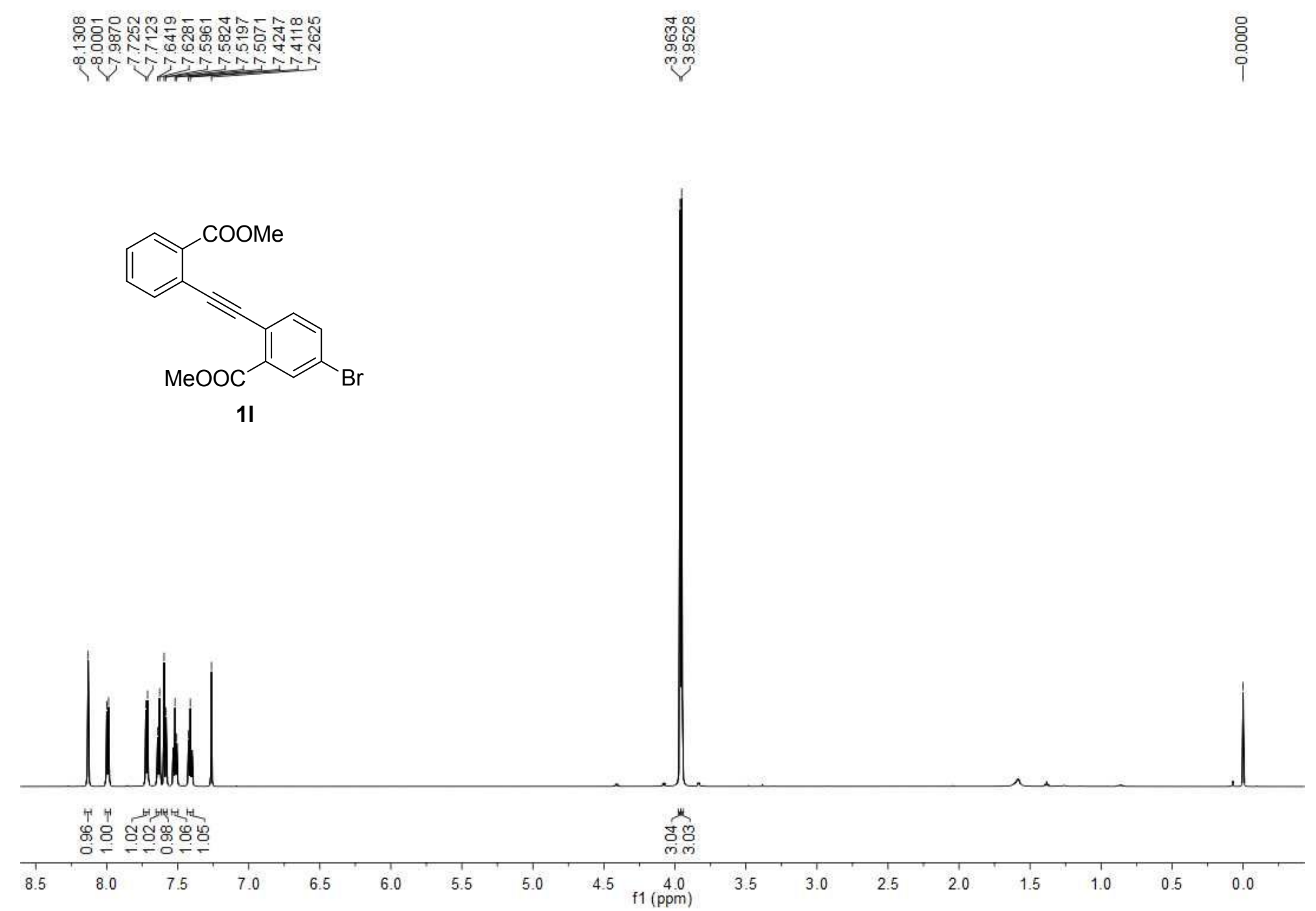


\begin{tabular}{|c|c|c|}
\hline 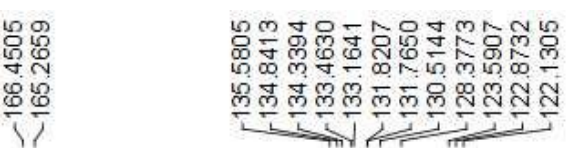 & 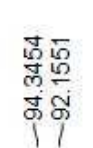 & 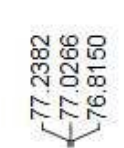 \\
\hline
\end{tabular}

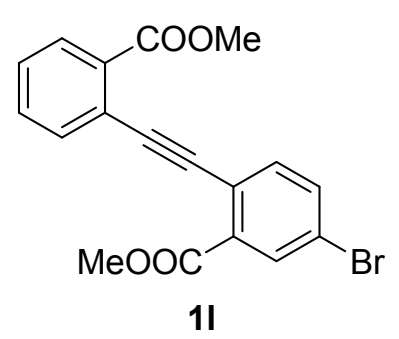

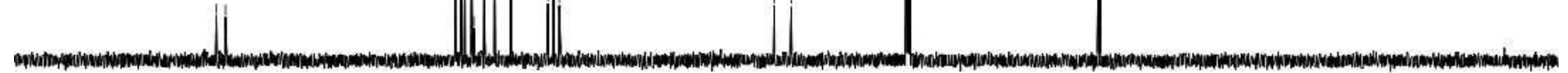

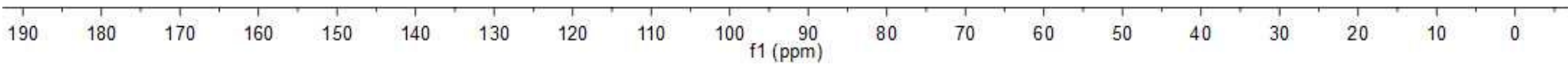




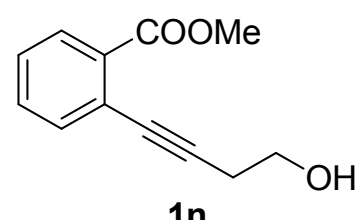

1n

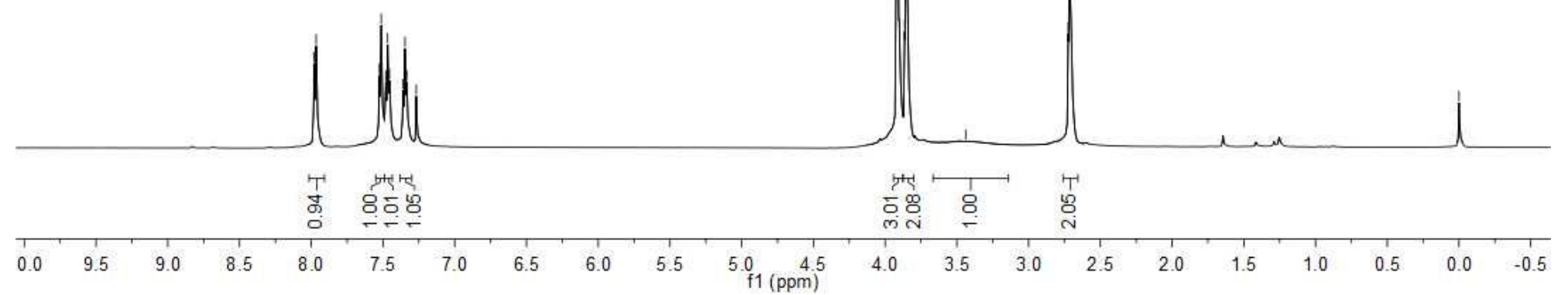



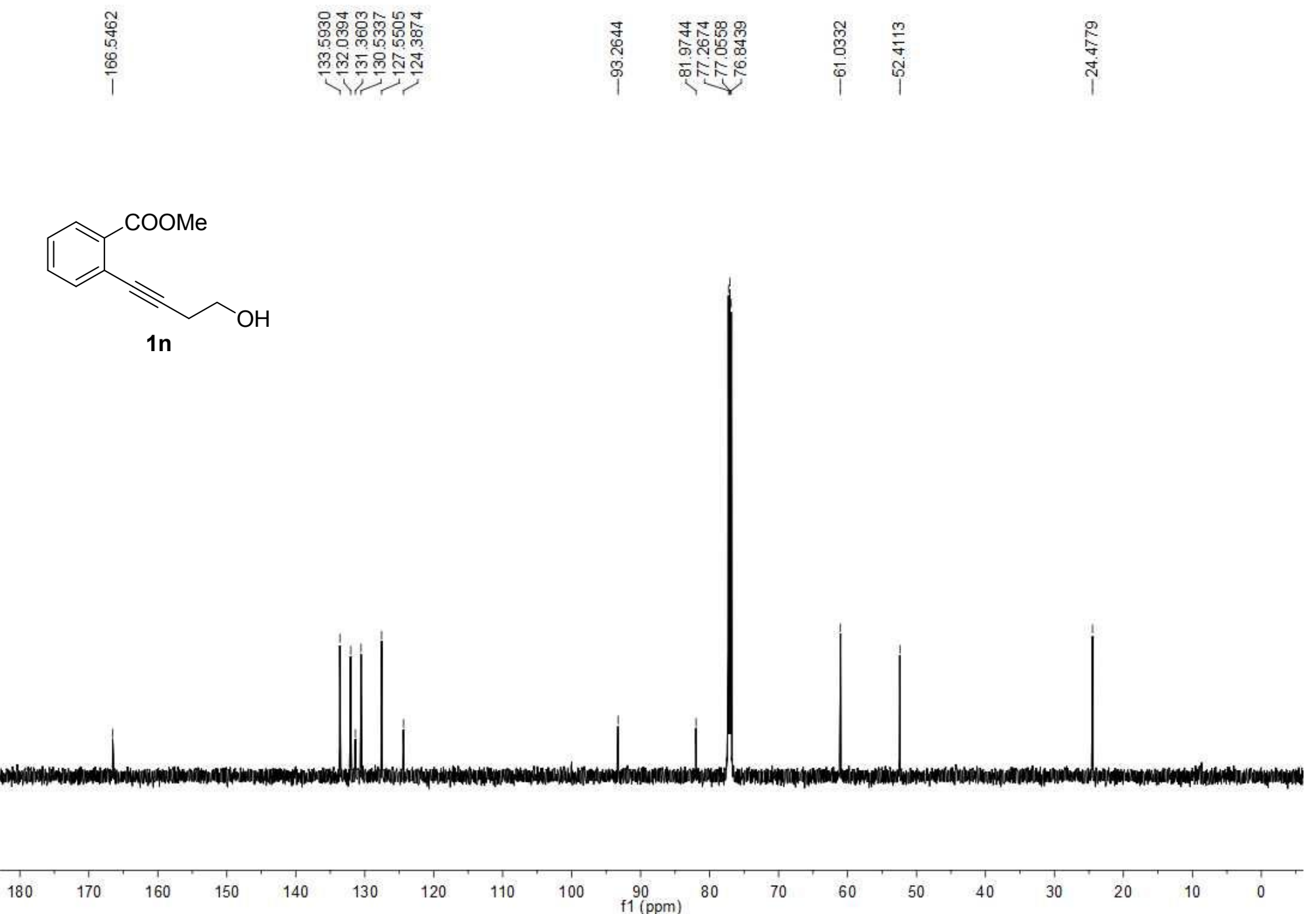

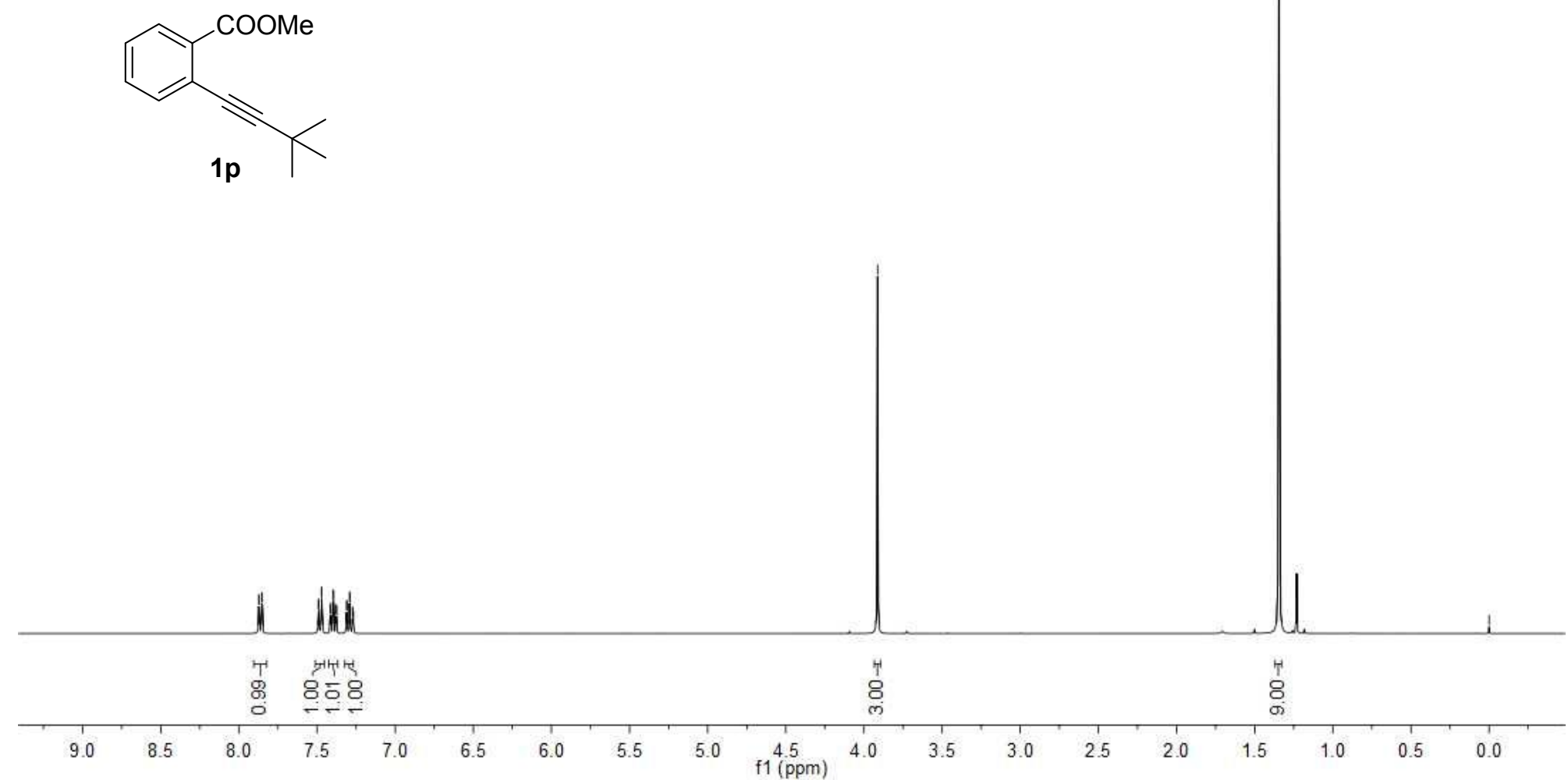

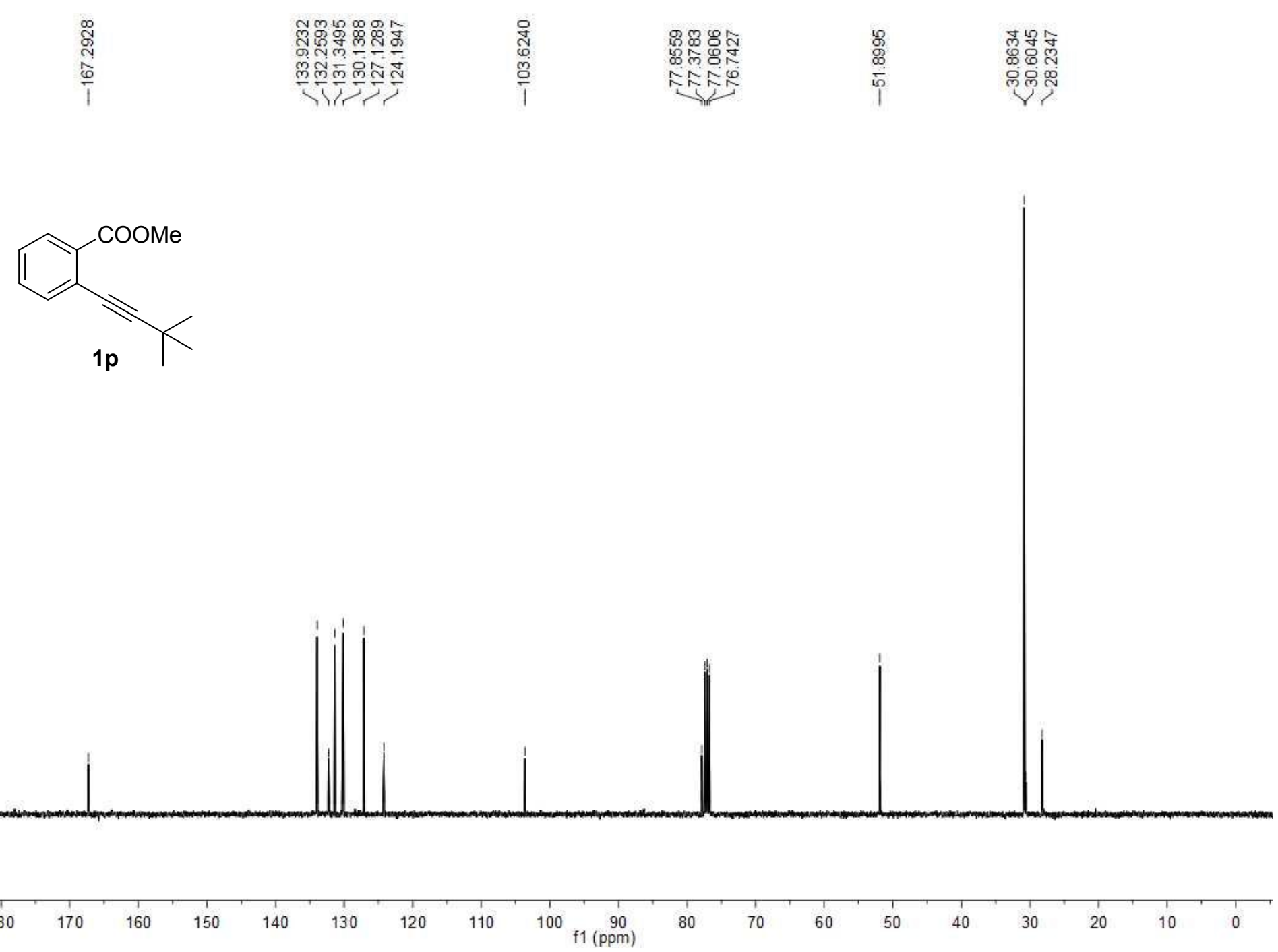


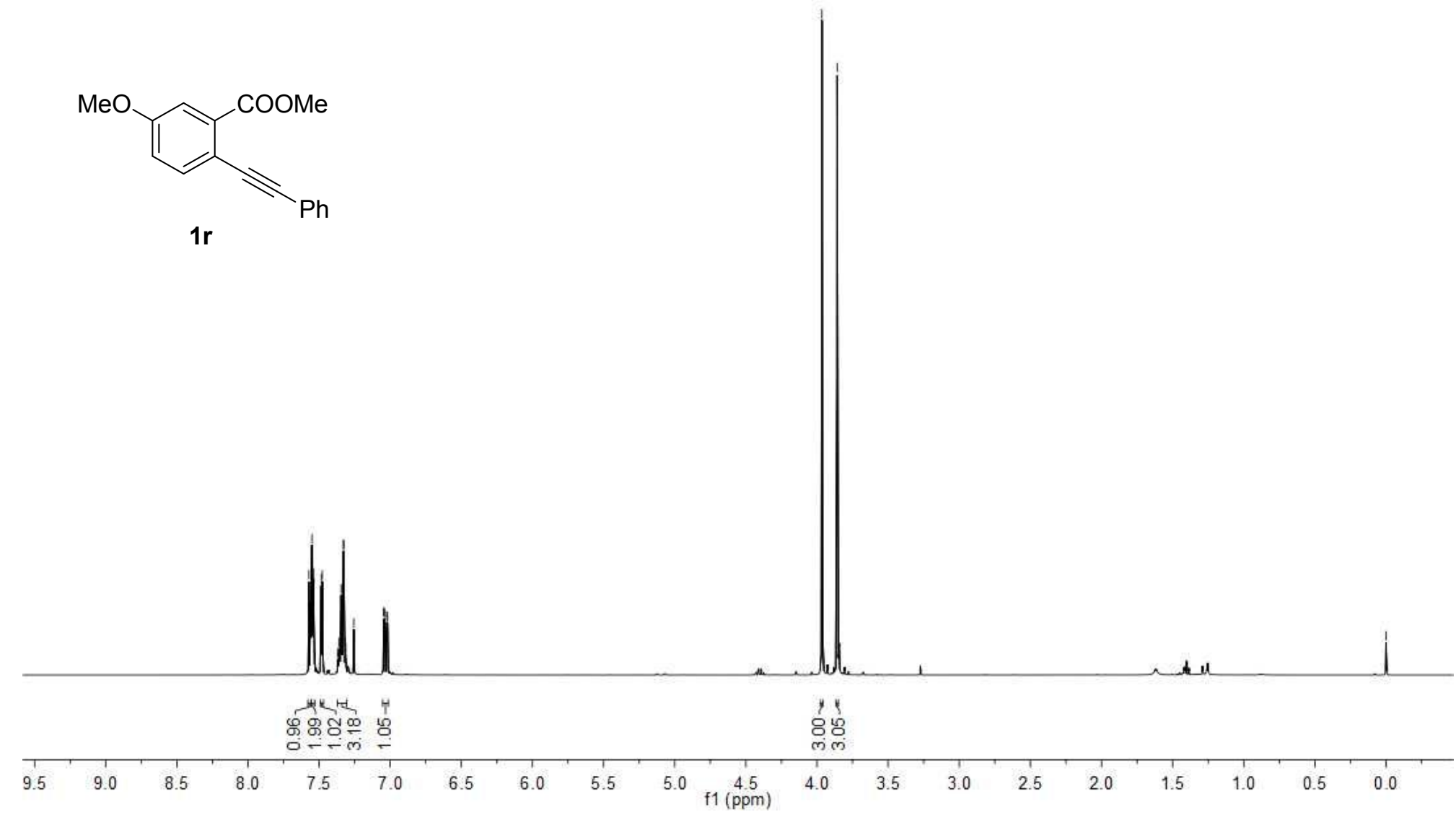




\begin{tabular}{|c|c|c|c|}
\hline$\frac{0}{0}$ & 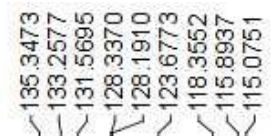 & 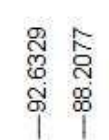 & 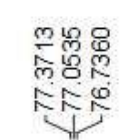 \\
\hline
\end{tabular}
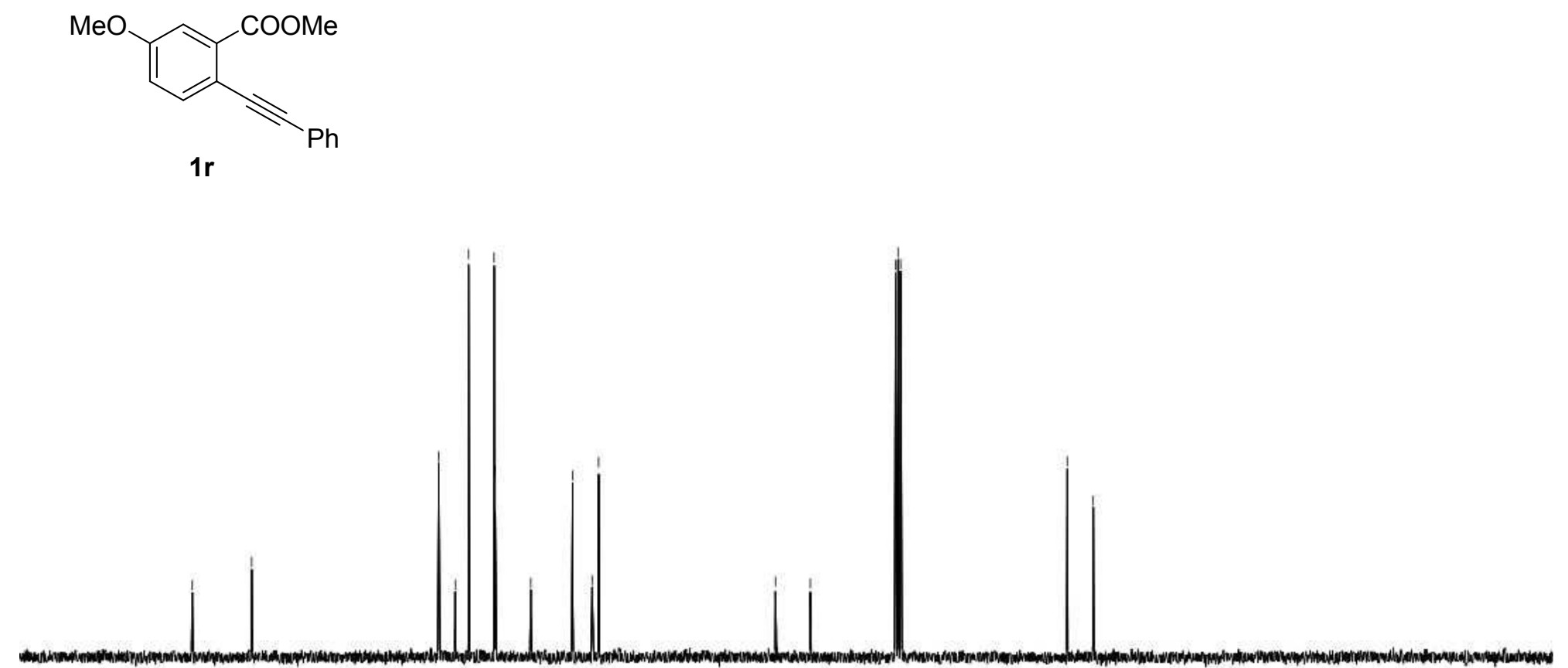

$180 \quad 170$

$160 \quad 150$

140

$30 \quad 120$

$110 \quad 100 \quad 90$

70

$60 \quad 50$

40

20 $1 0 \longdiv { 1 }$ 
II. ${ }^{1} \mathrm{H}-\mathrm{NMR}$ and ${ }^{13} \mathrm{C}-\mathrm{NMR}$ Spectra of Products 2 and 3

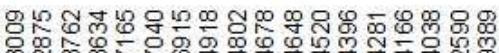

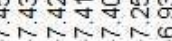
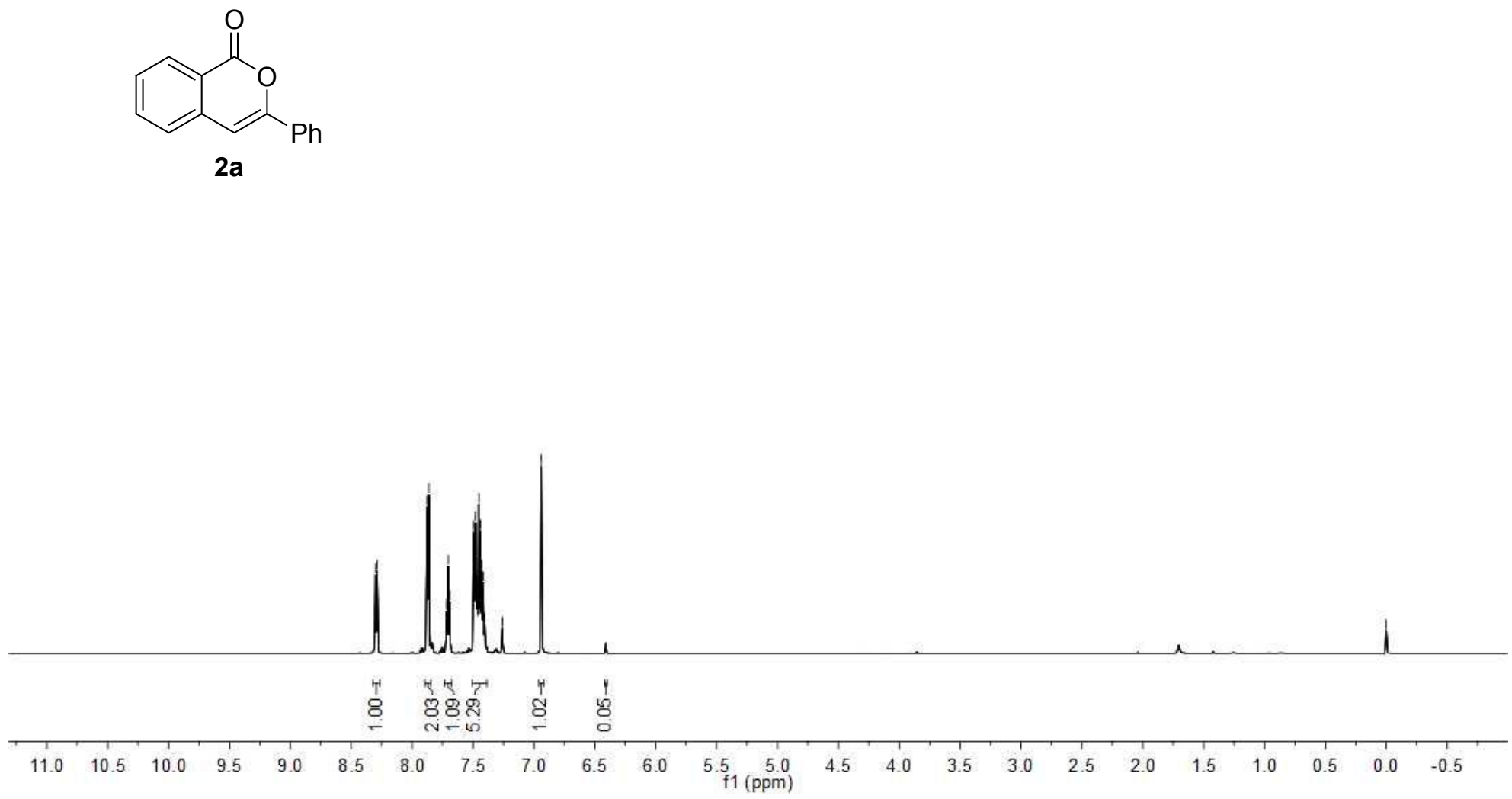

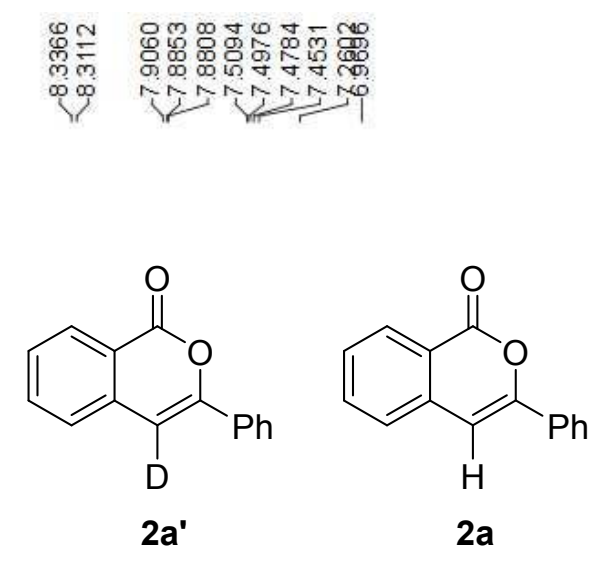

(10:1)

crude ${ }^{1} \mathrm{H}$ NMR of reaction mixture

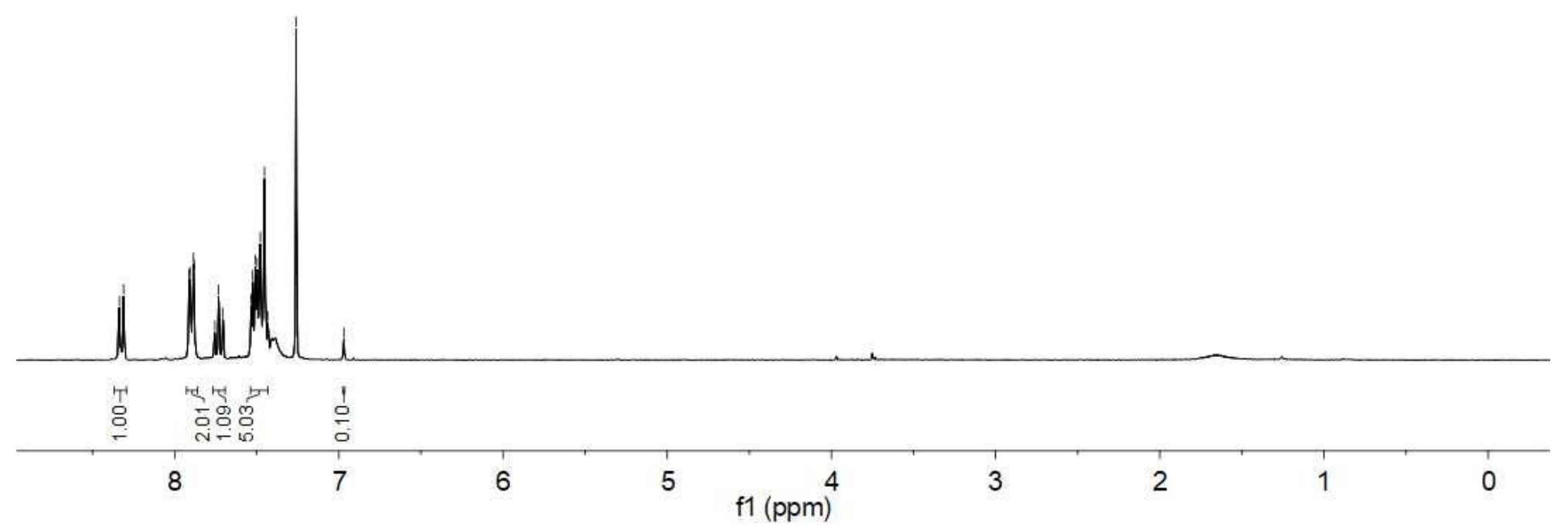




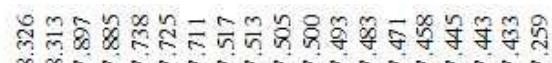

कo

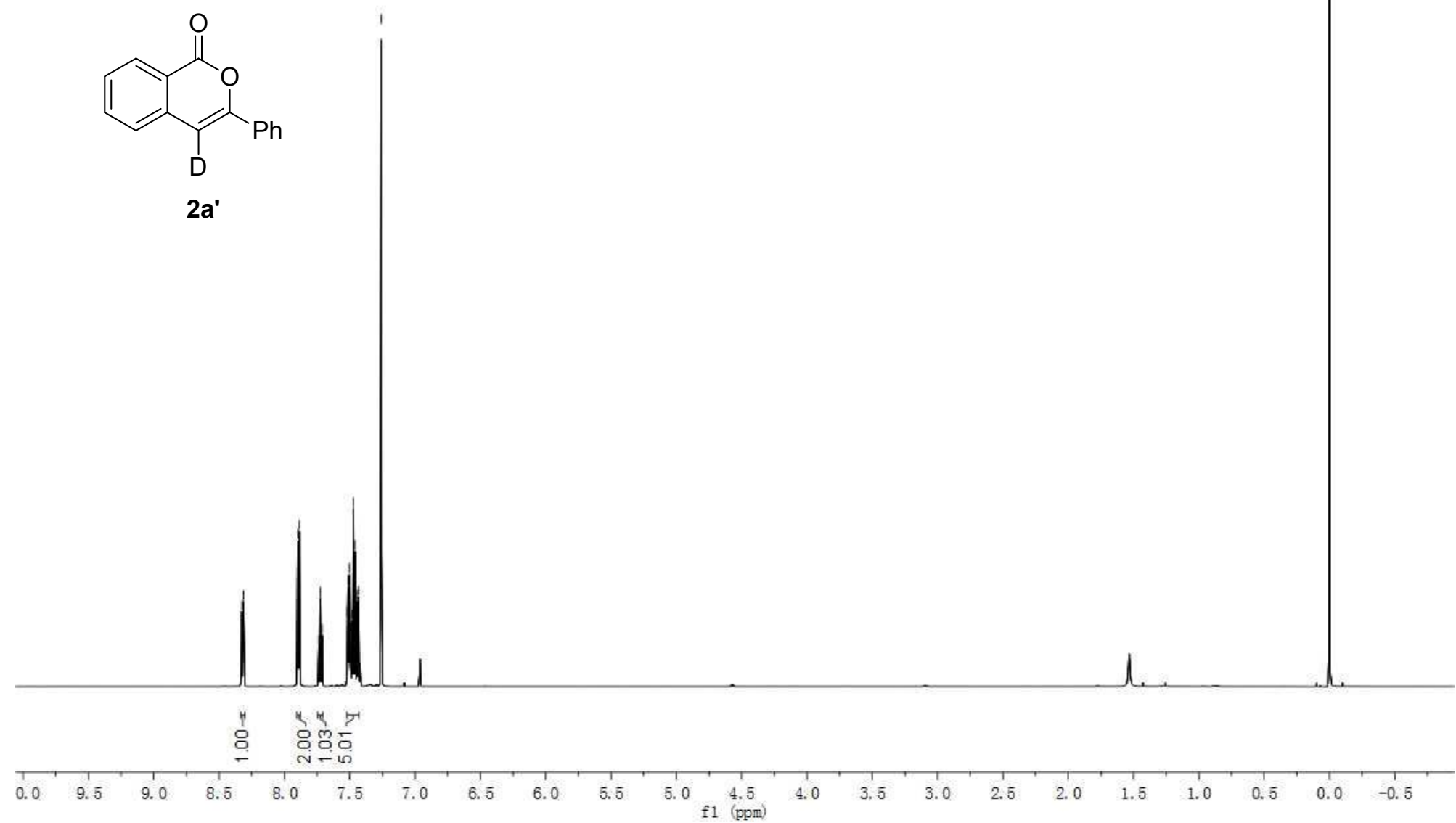



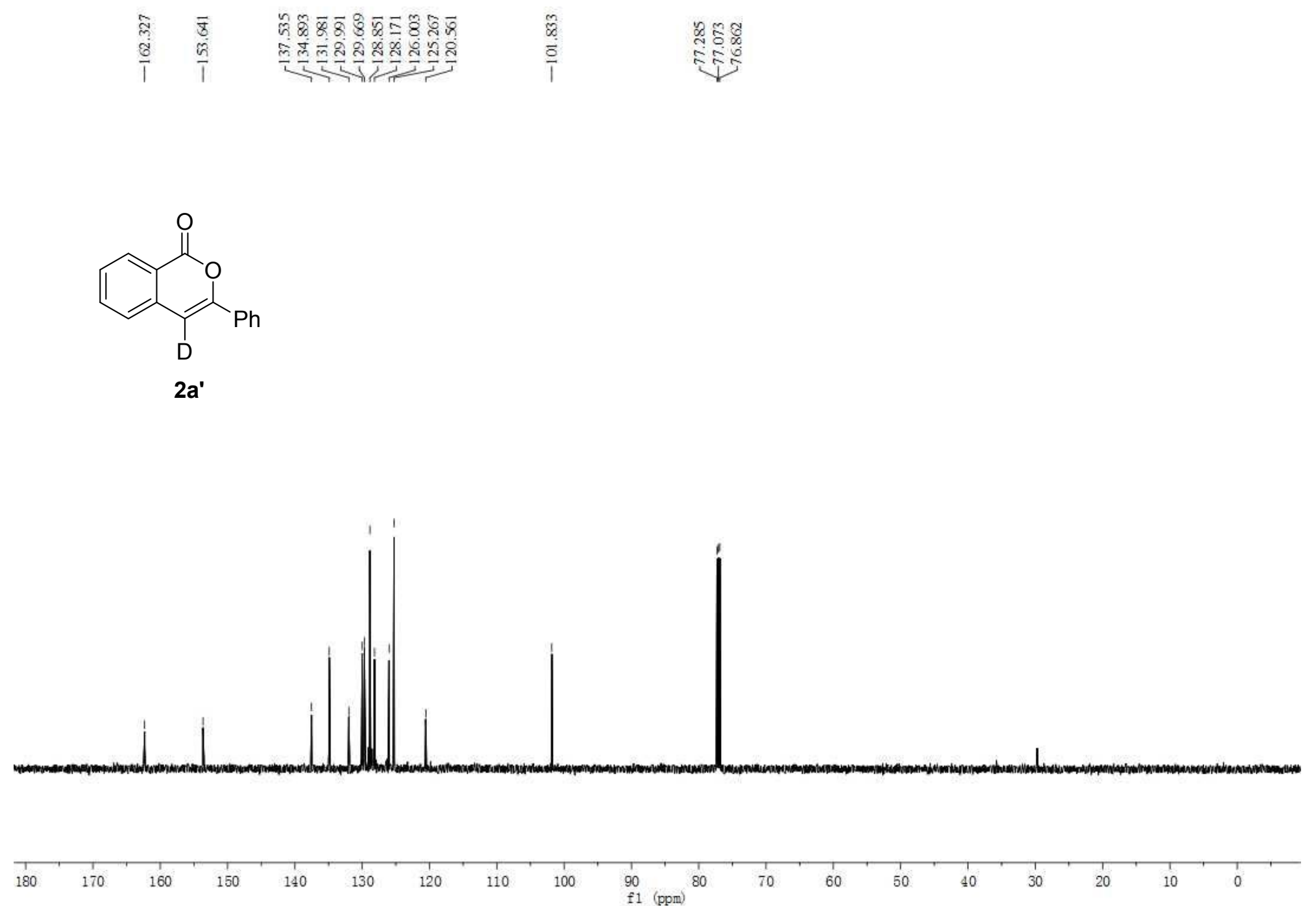


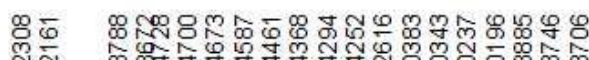

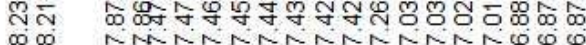

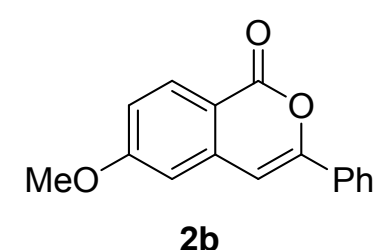

$2 b$

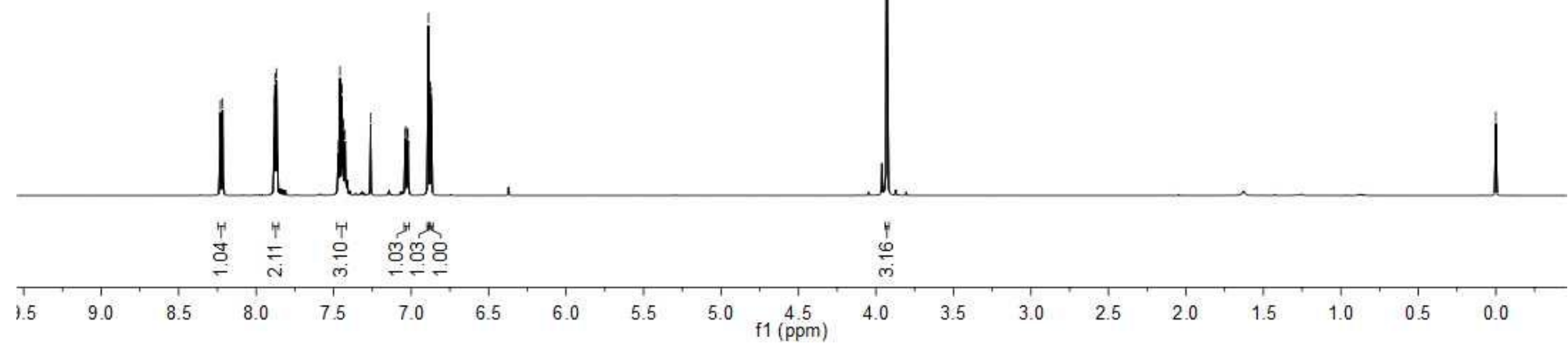




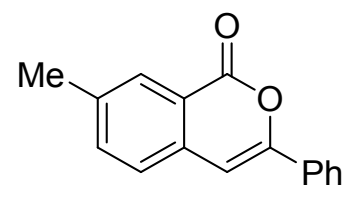

2c

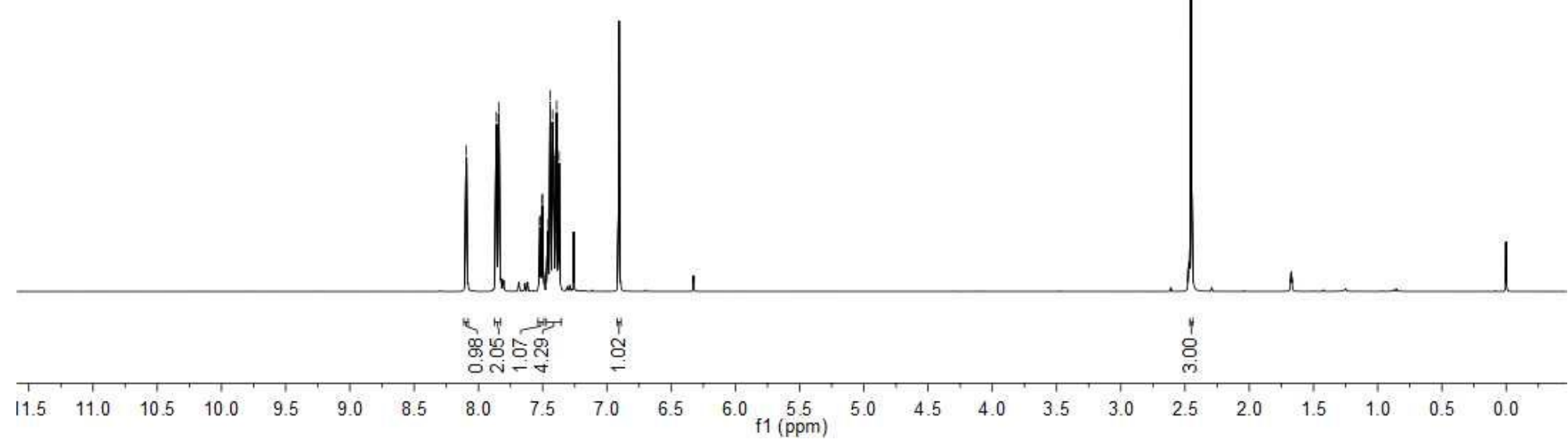



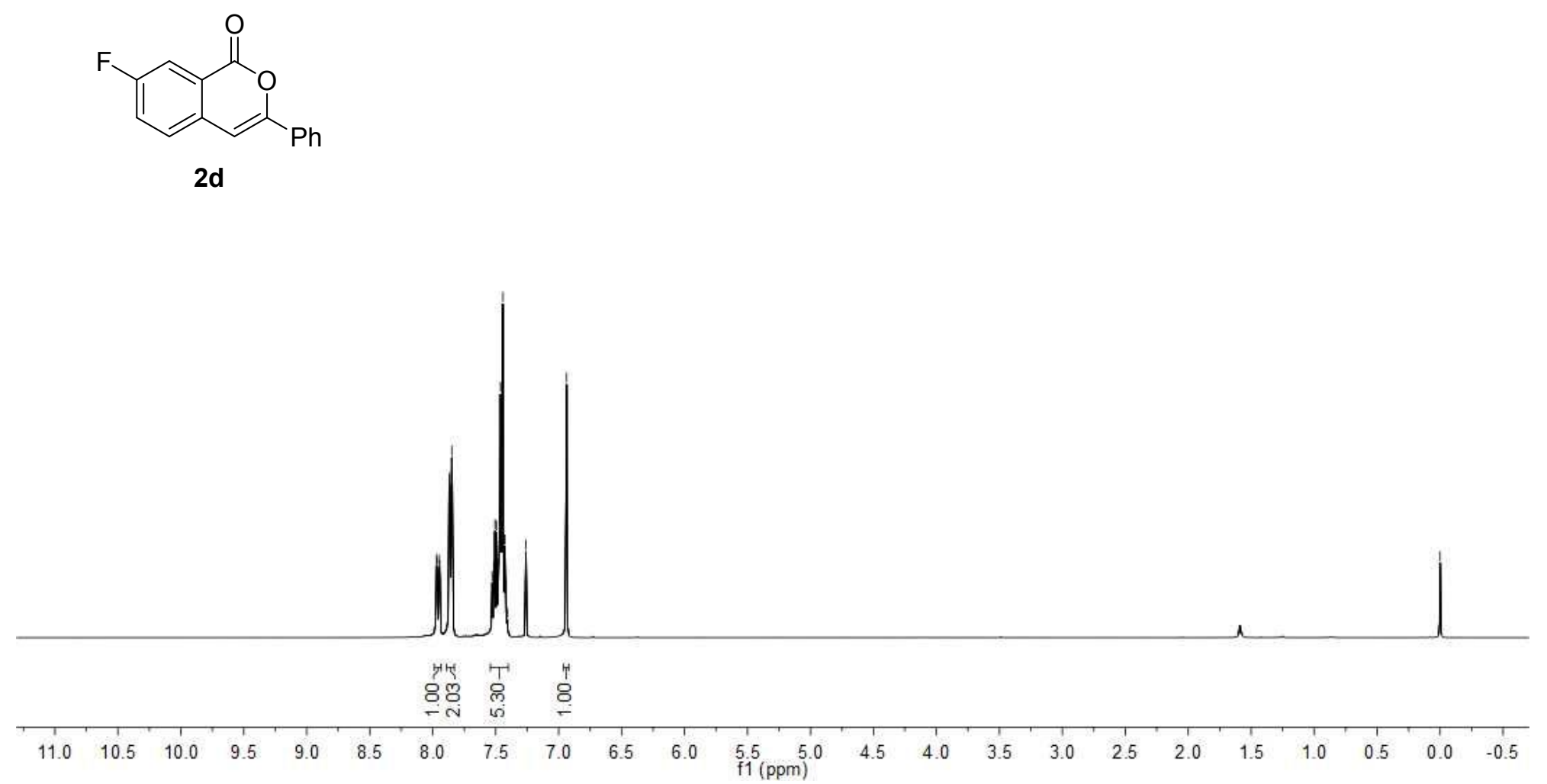

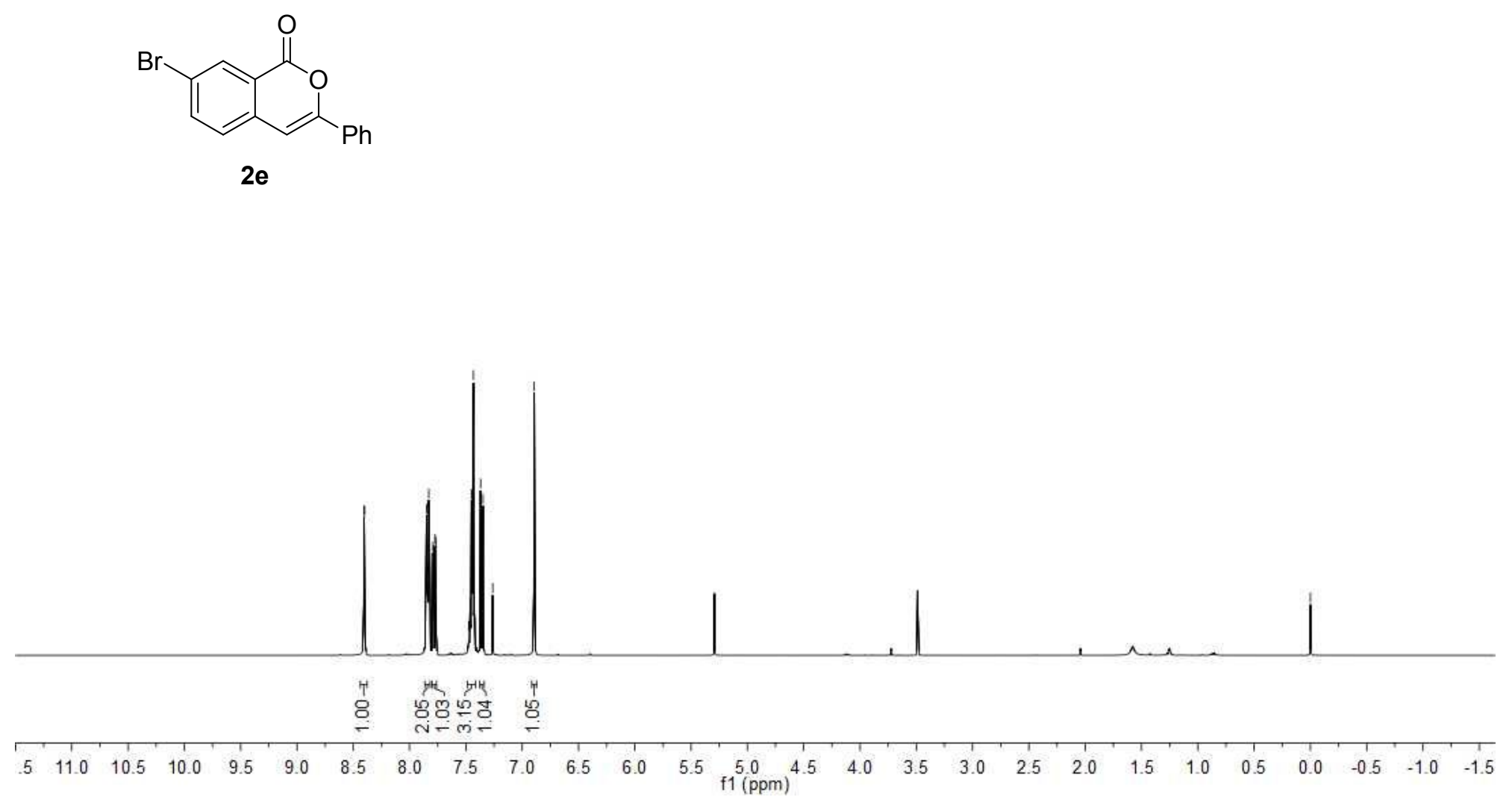


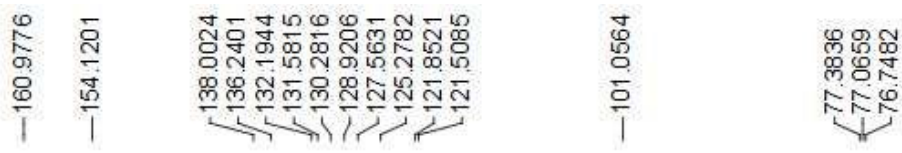

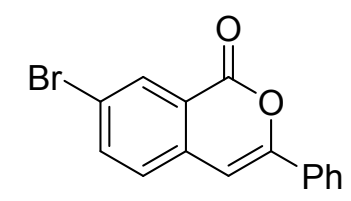

$2 e$

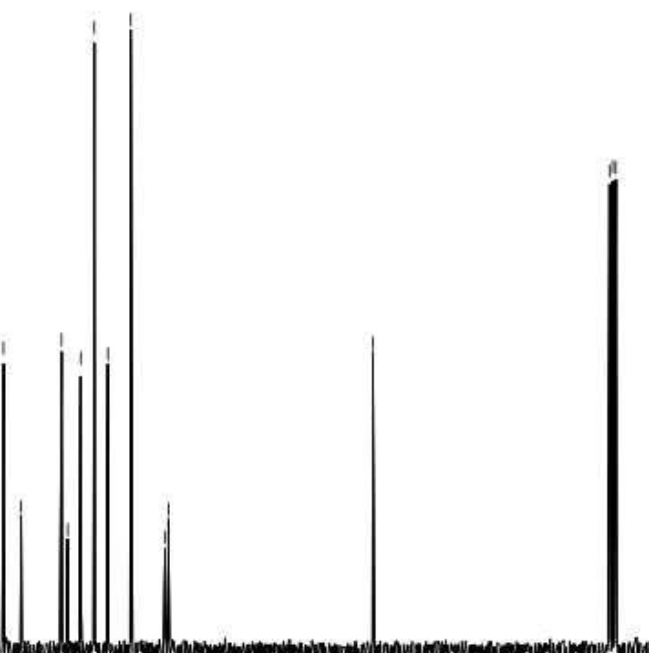

D.

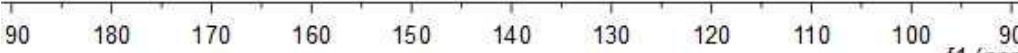

90
$91(\mathrm{ppm})$ 


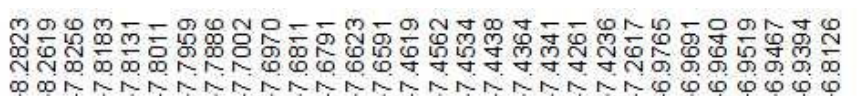

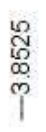

용<smiles>CCCCCCCCCCOc1ccc(-c2cc3ccccc3c(=O)o2)cc1</smiles>

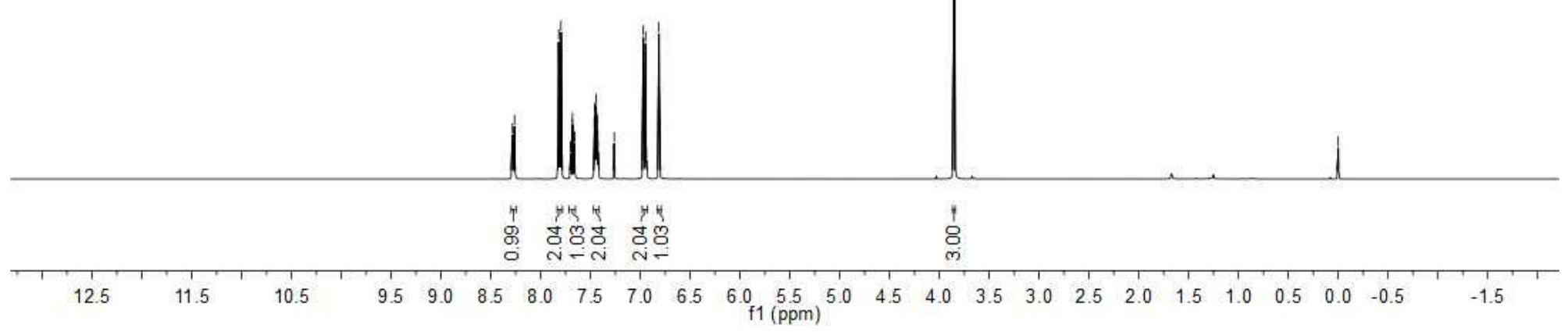

S37 

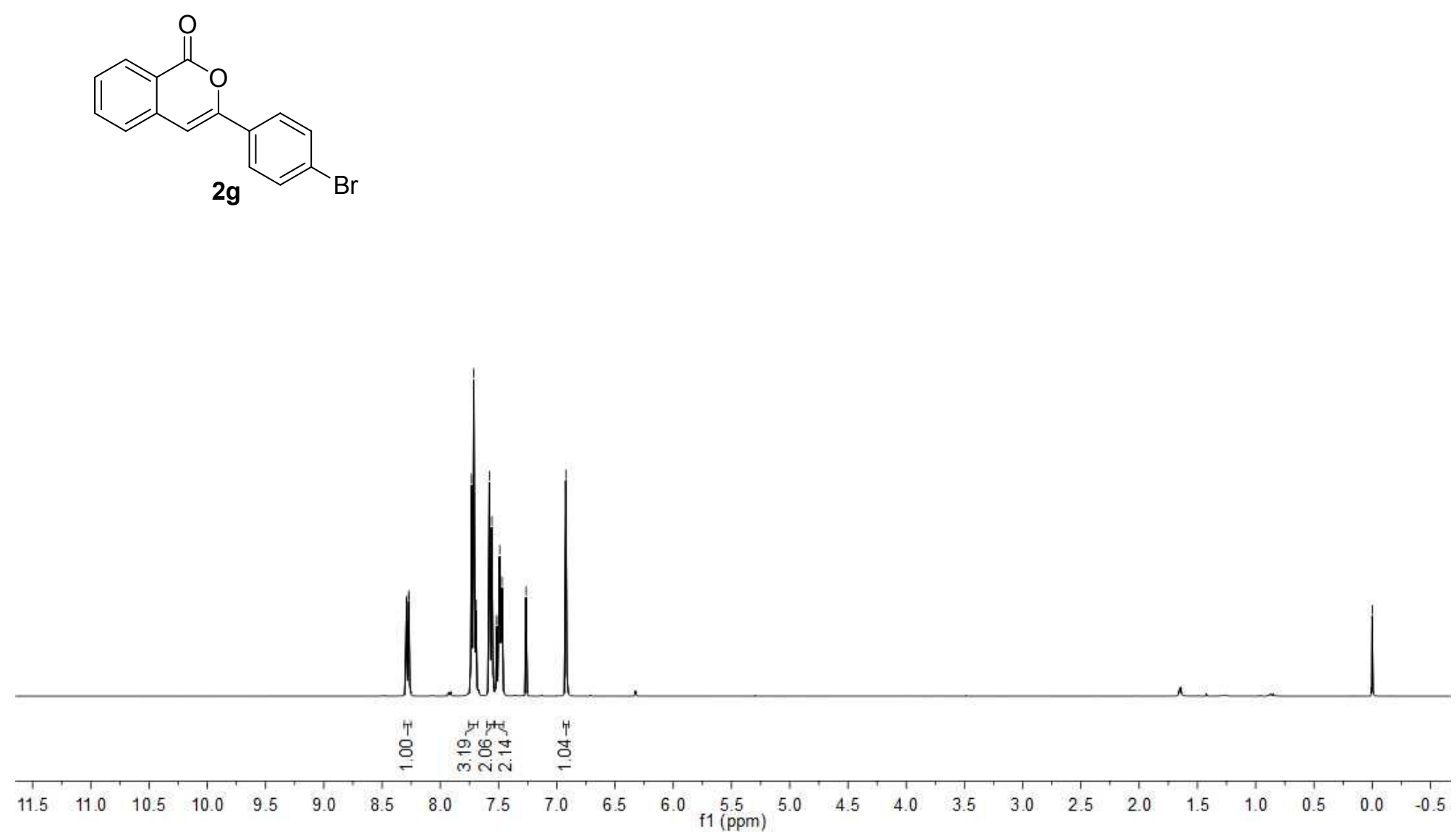

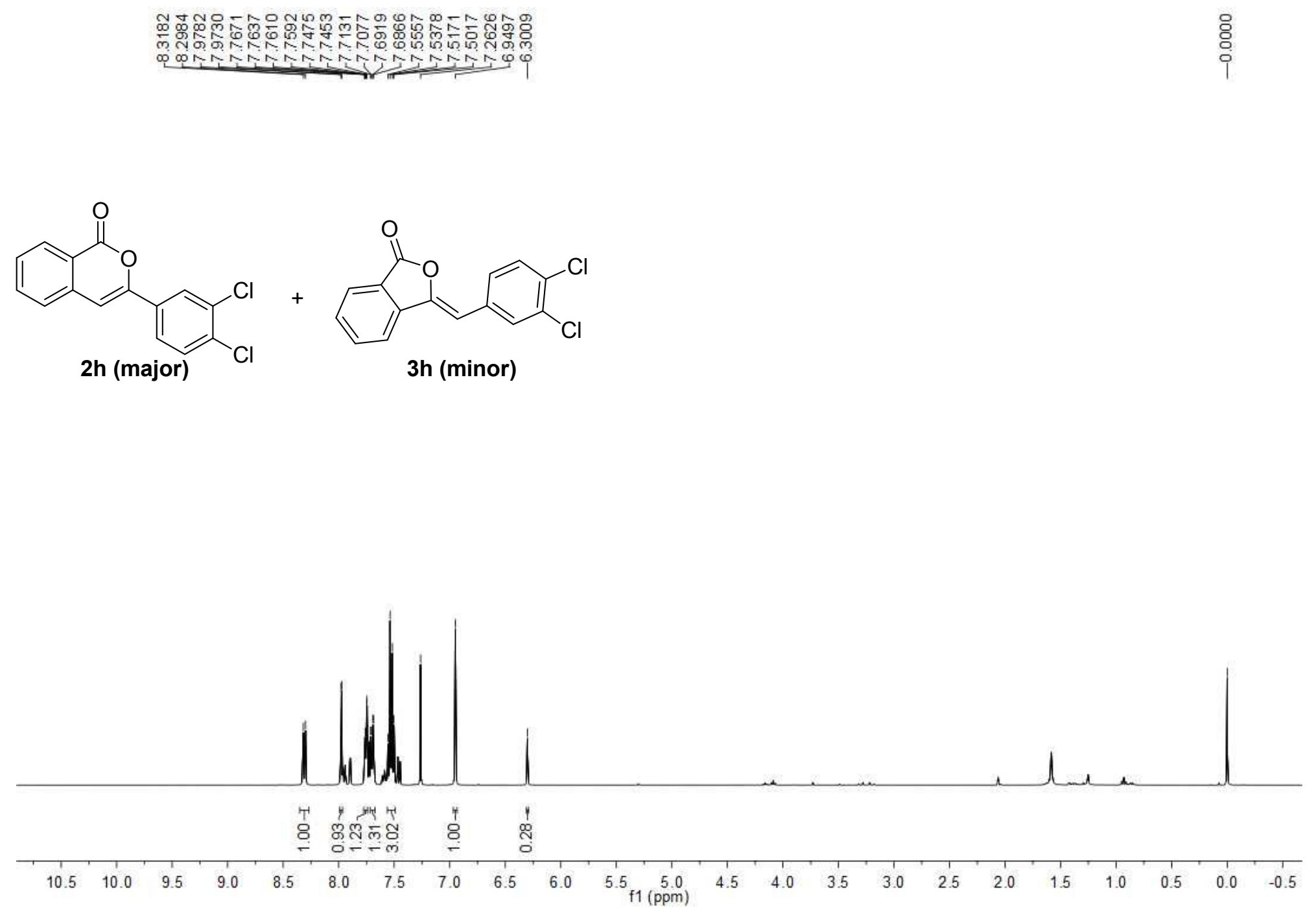


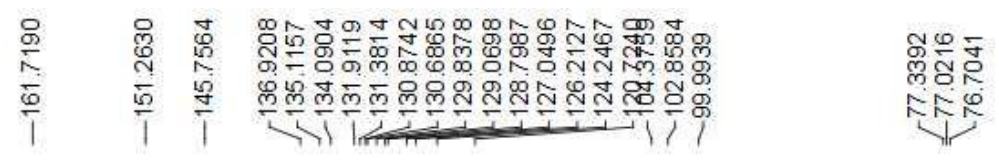

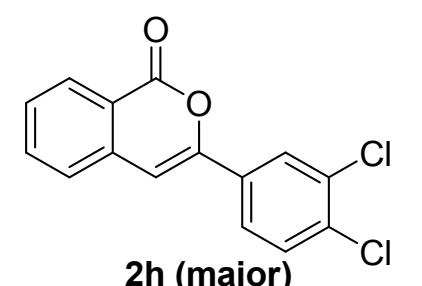

2h (major)
$+$<smiles>O=C1O/C(=C\c2ccc(Cl)c(Cl)c2)c2ccccc21</smiles>

3h (minor)

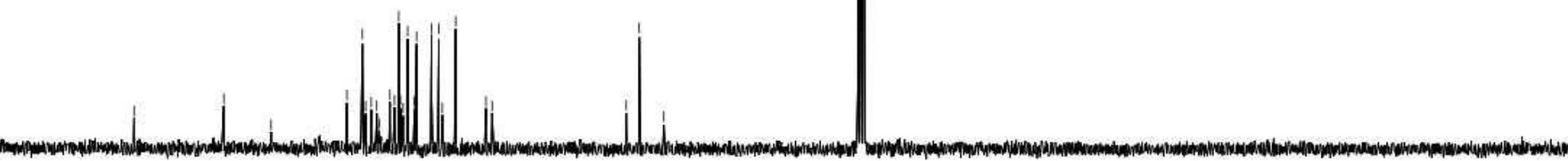

\begin{tabular}{rllllllllllllllll}
1 & 1 \\
170 & 160 & 150 & 140 & 130 & 120 & 110 & 100 & $\underset{\mathrm{f} 1(\mathrm{ppm})}{1}(10$ & 70 & 60 & 50 & 40 & 30 & 20 & 10 & 1 \\
\hline
\end{tabular}



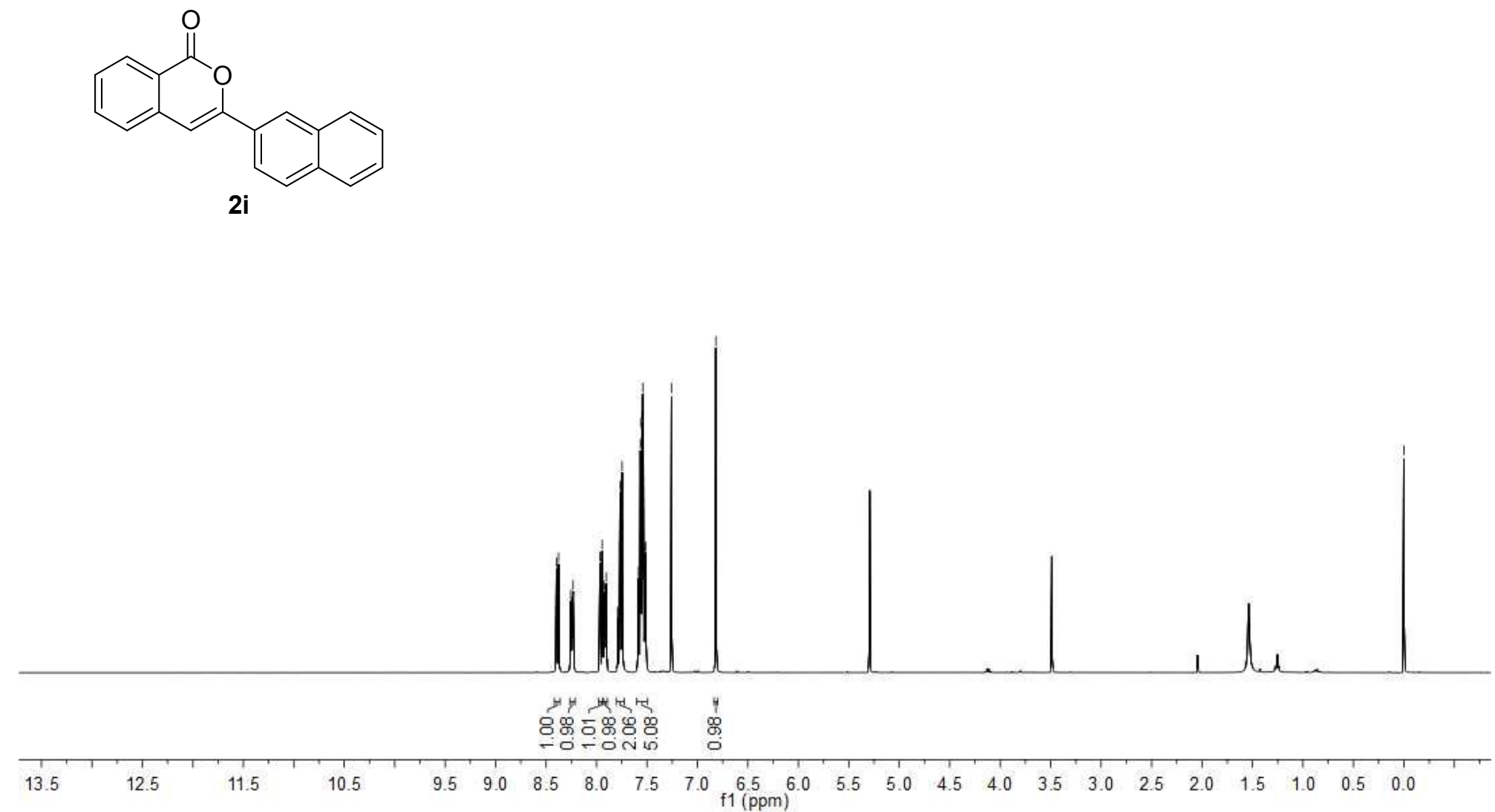


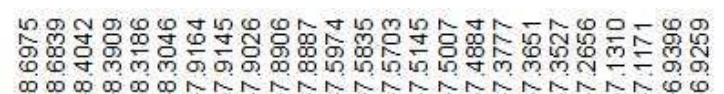

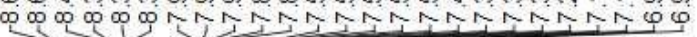
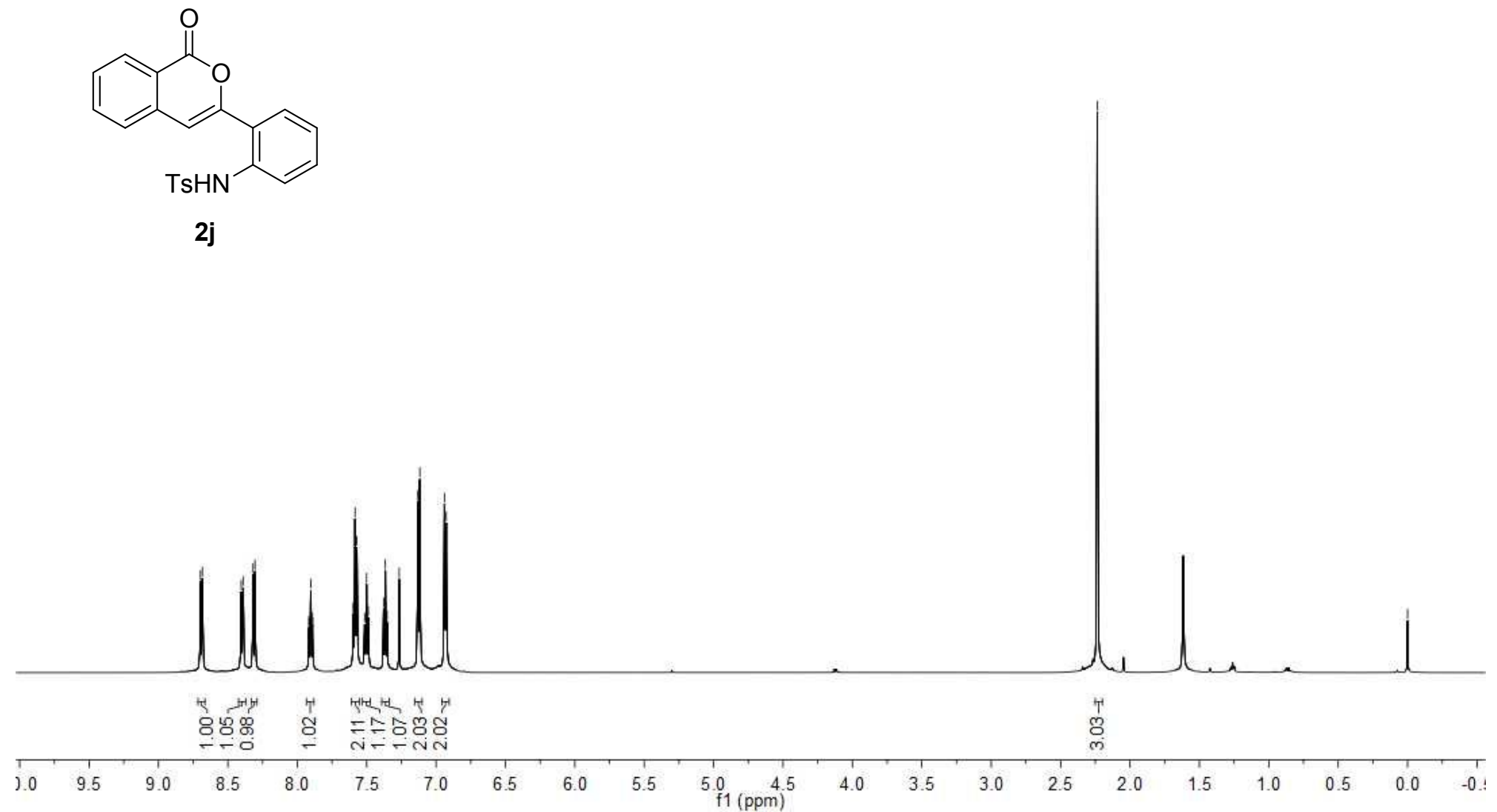


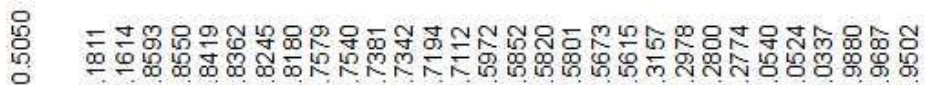

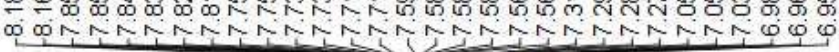

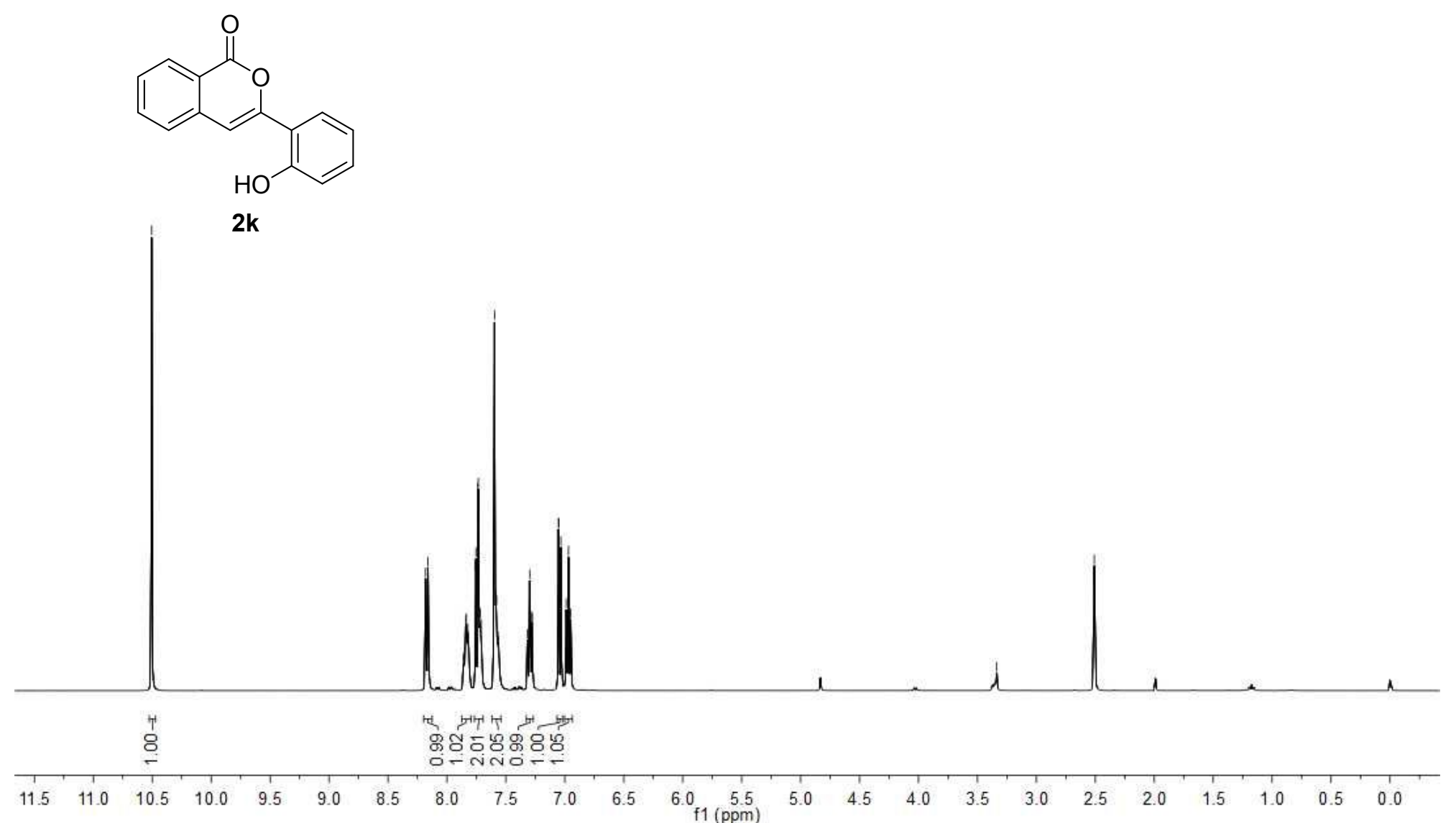



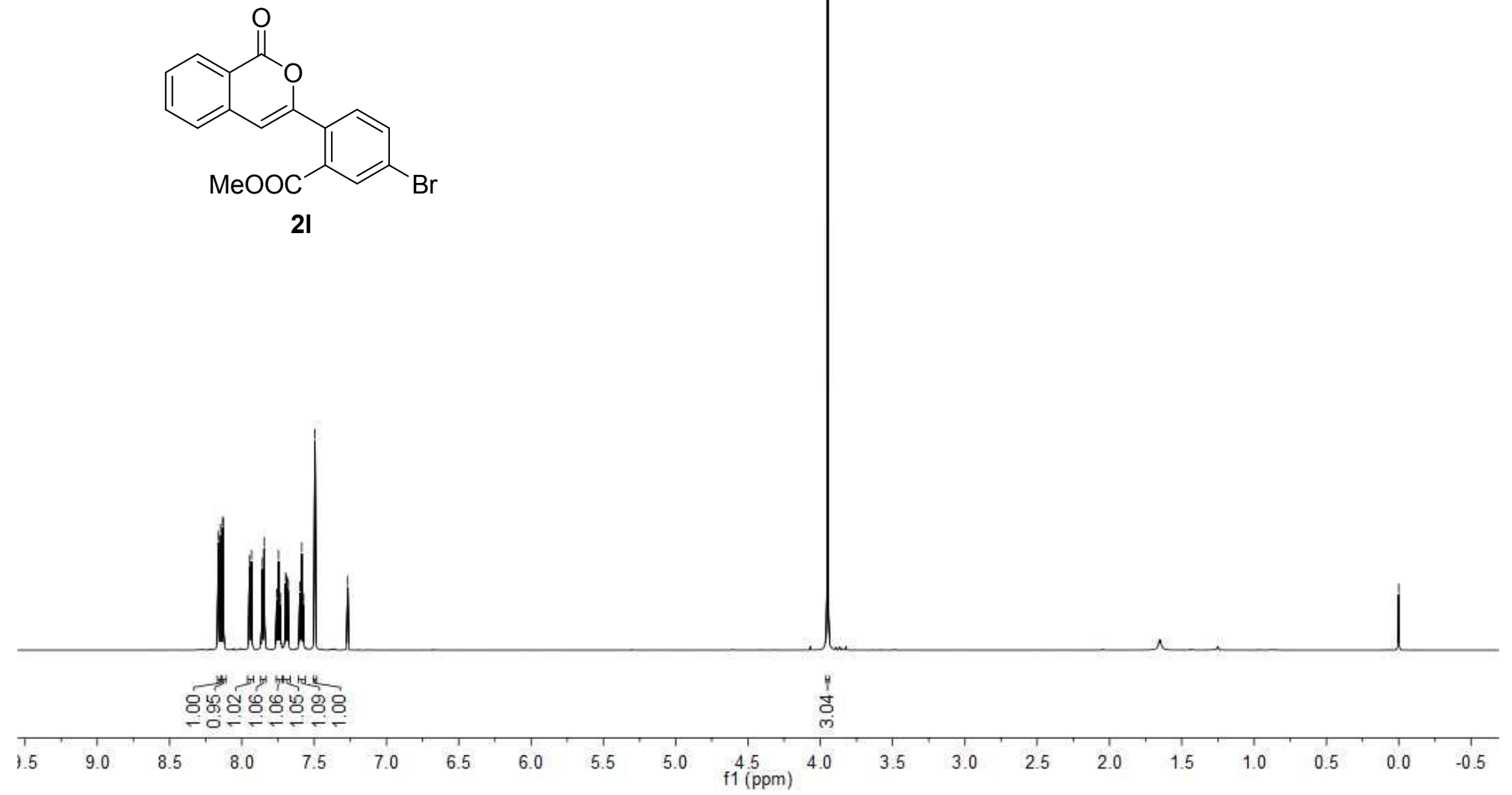

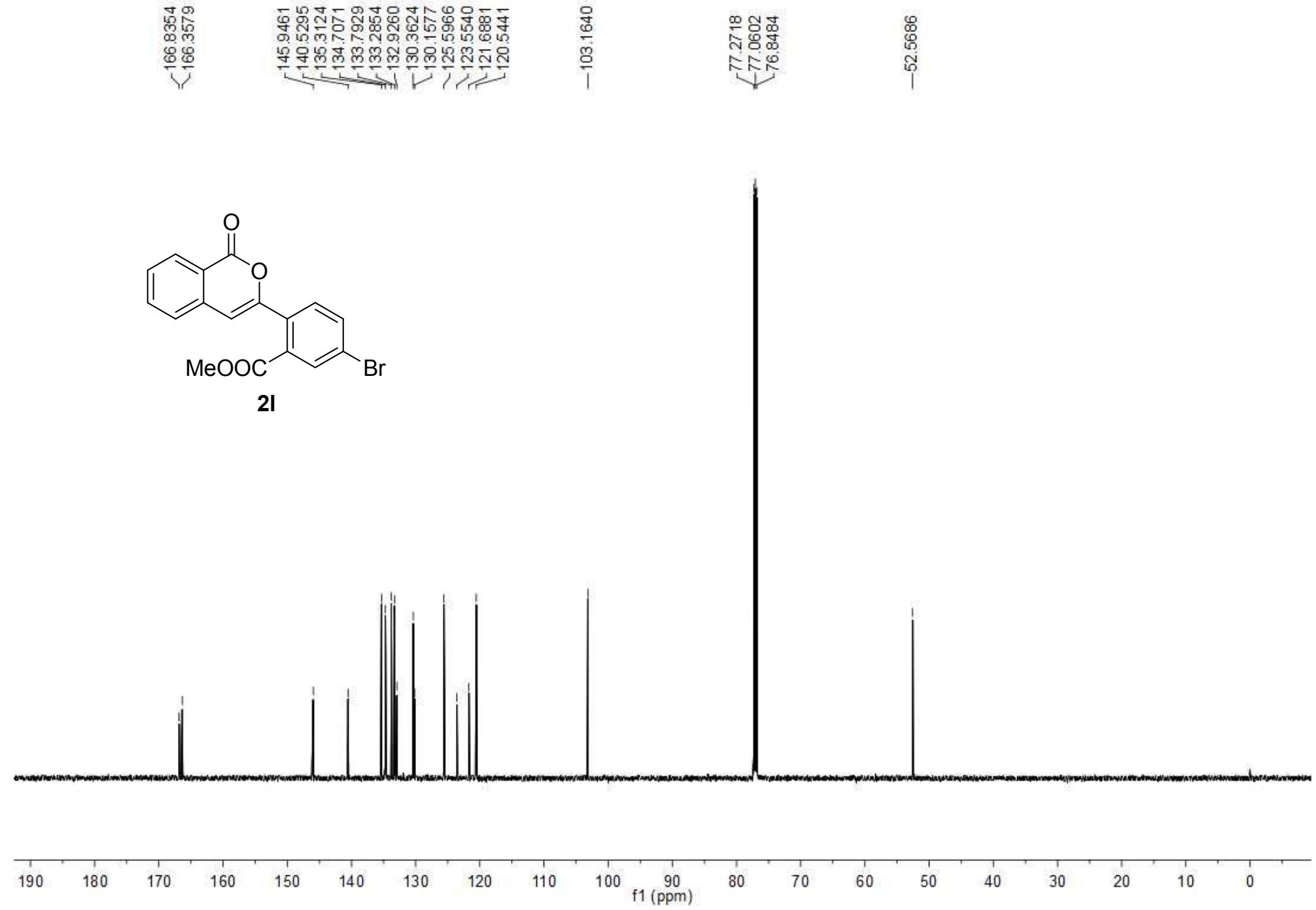

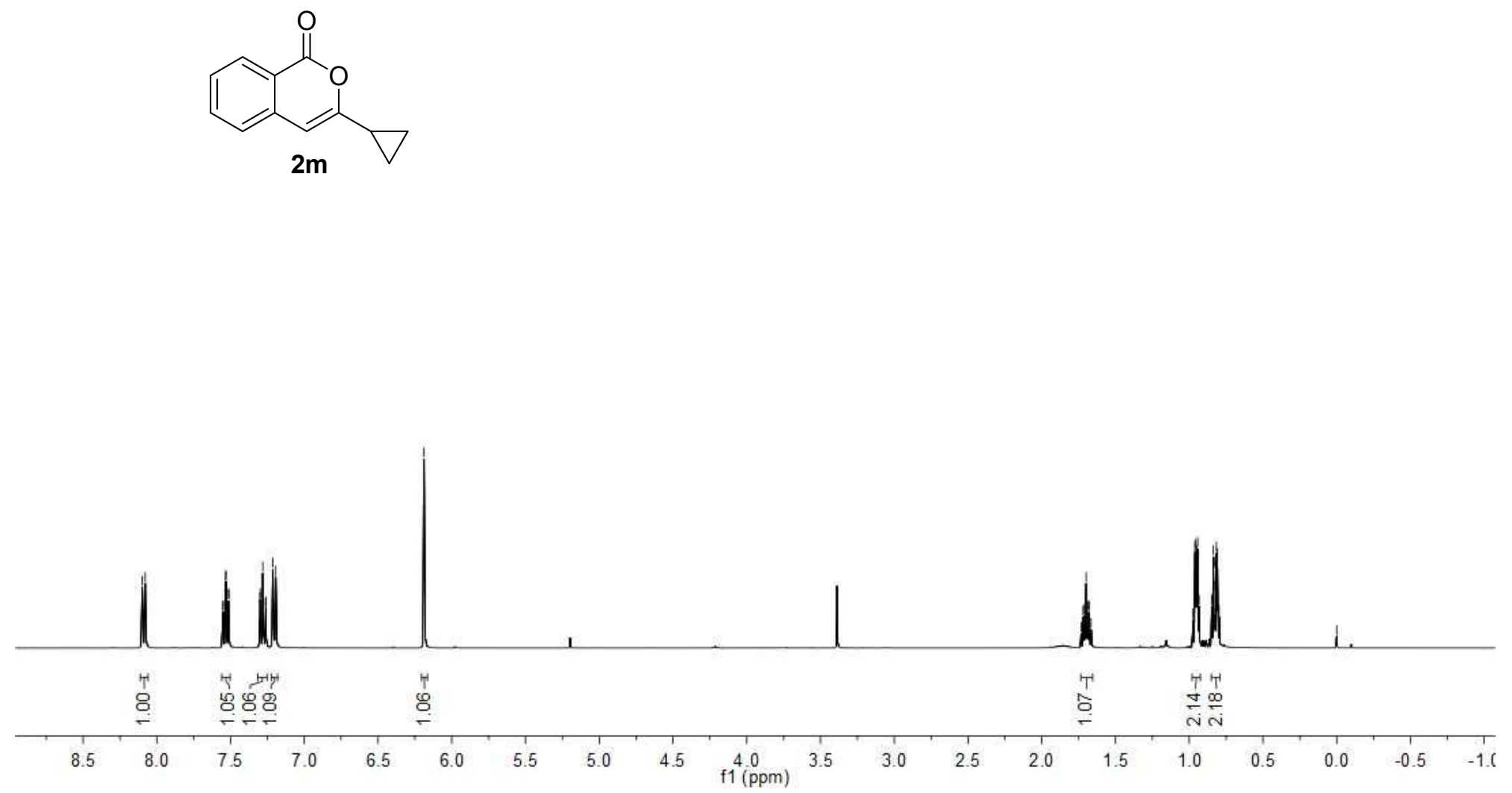

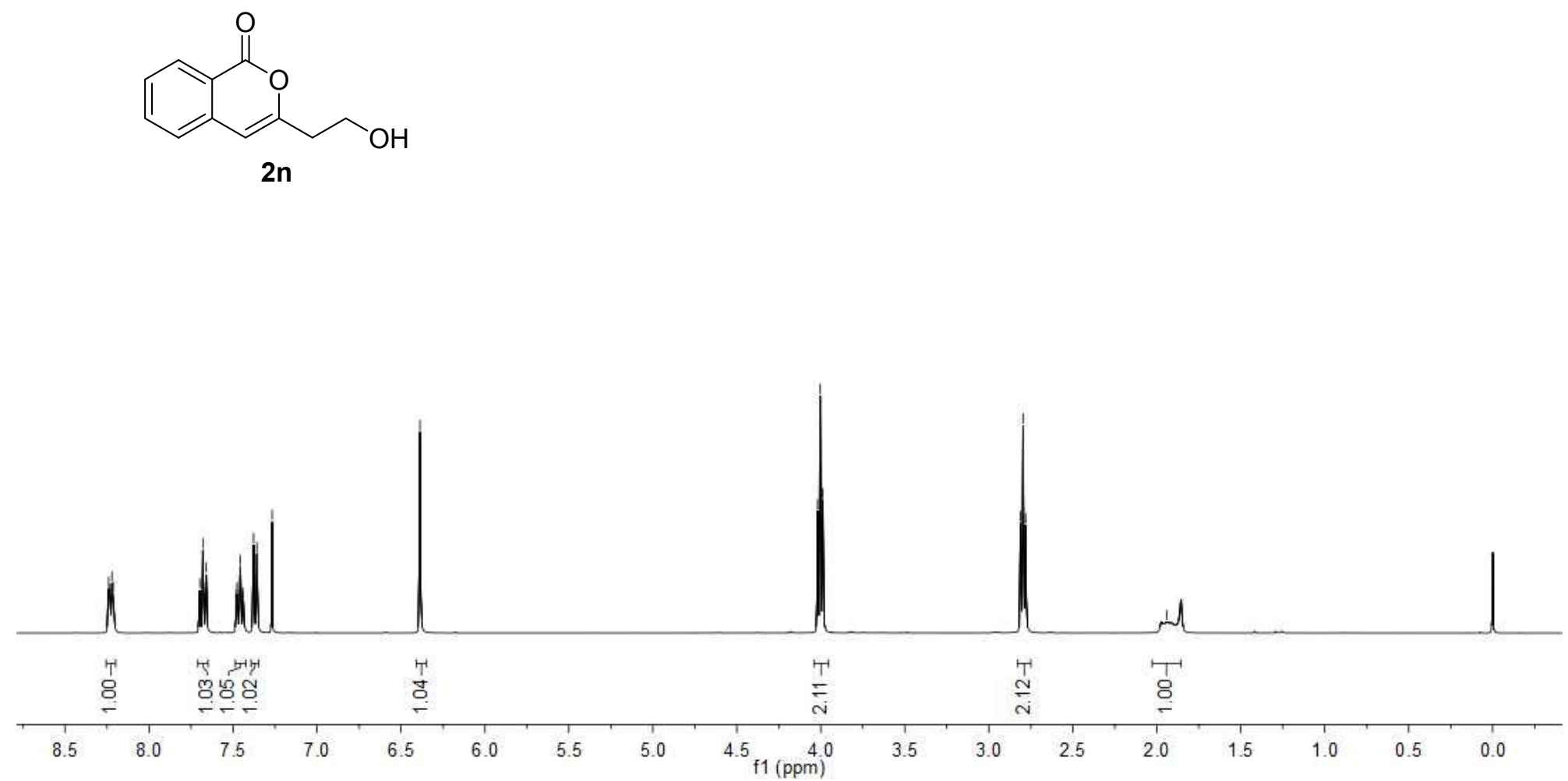


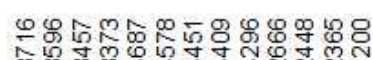

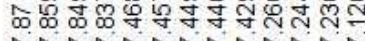

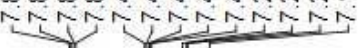
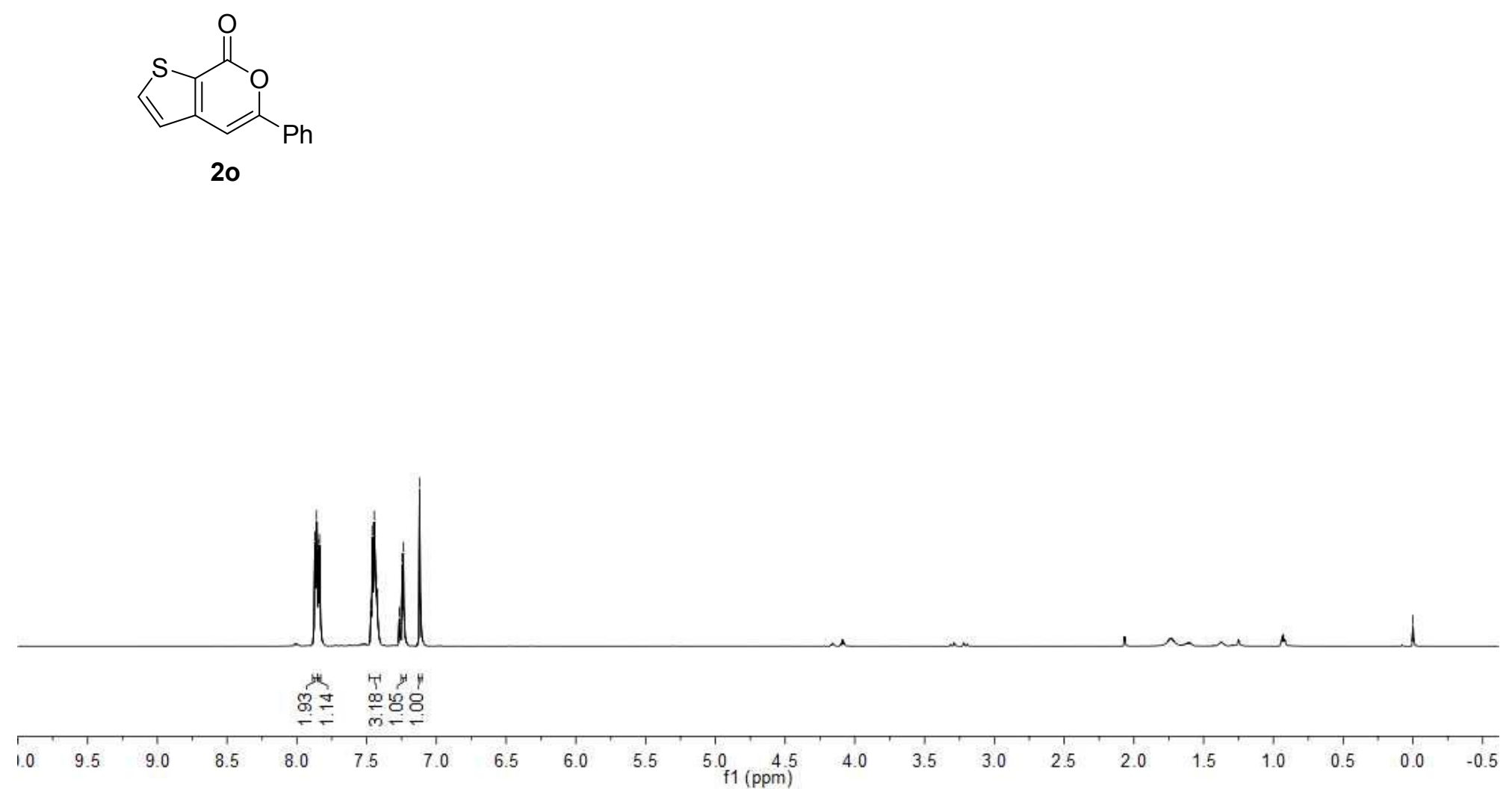


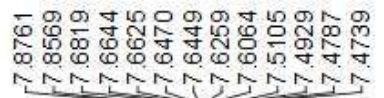

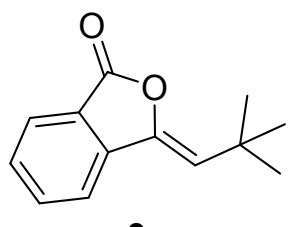

$3 p$

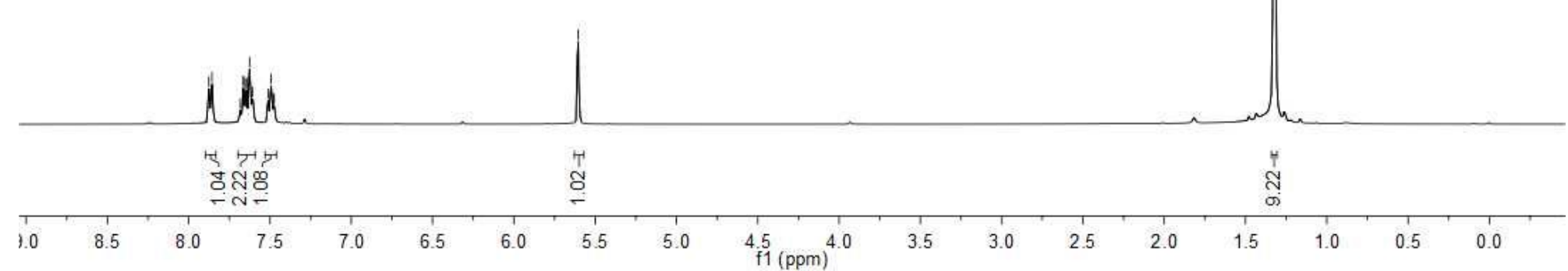

S49 

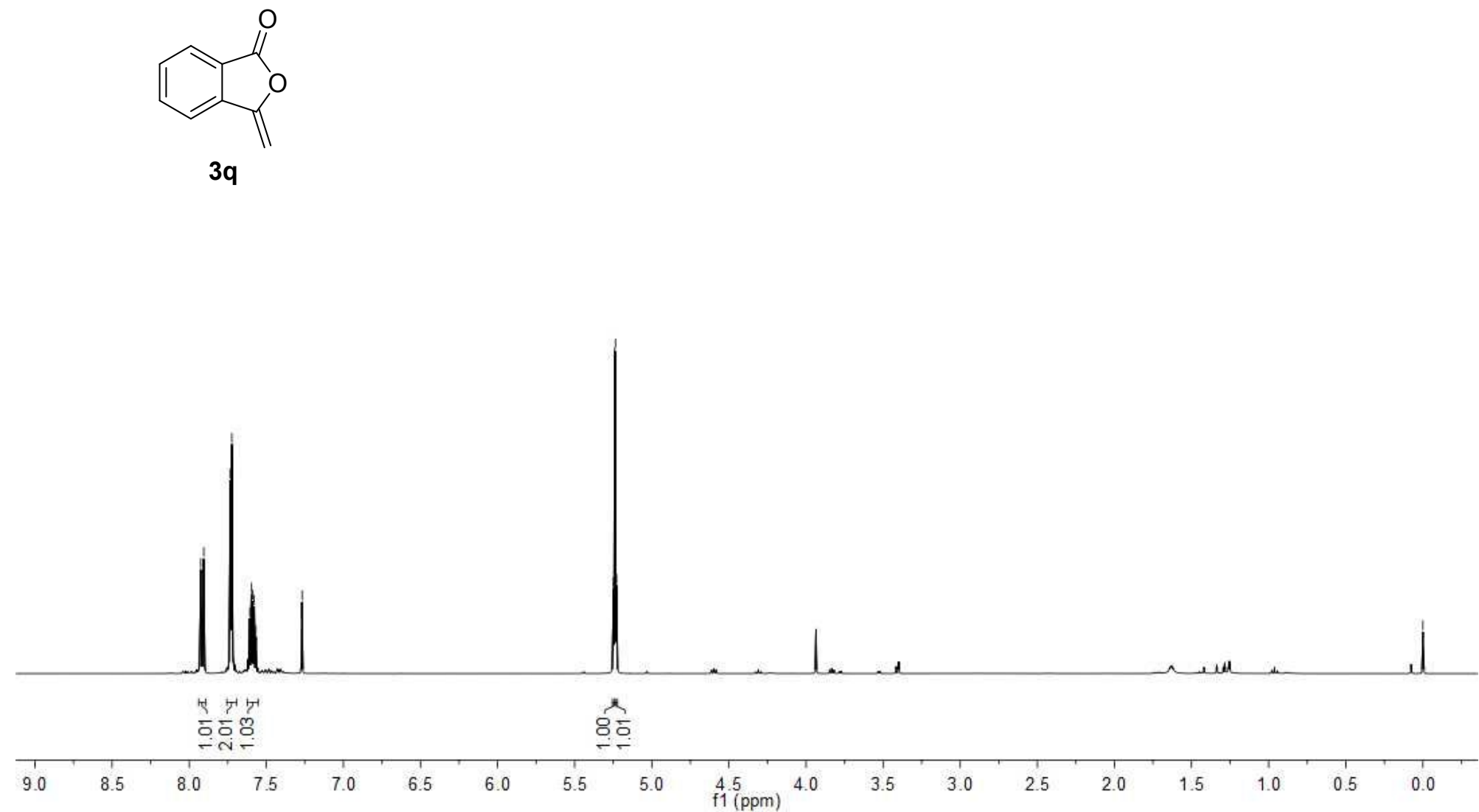

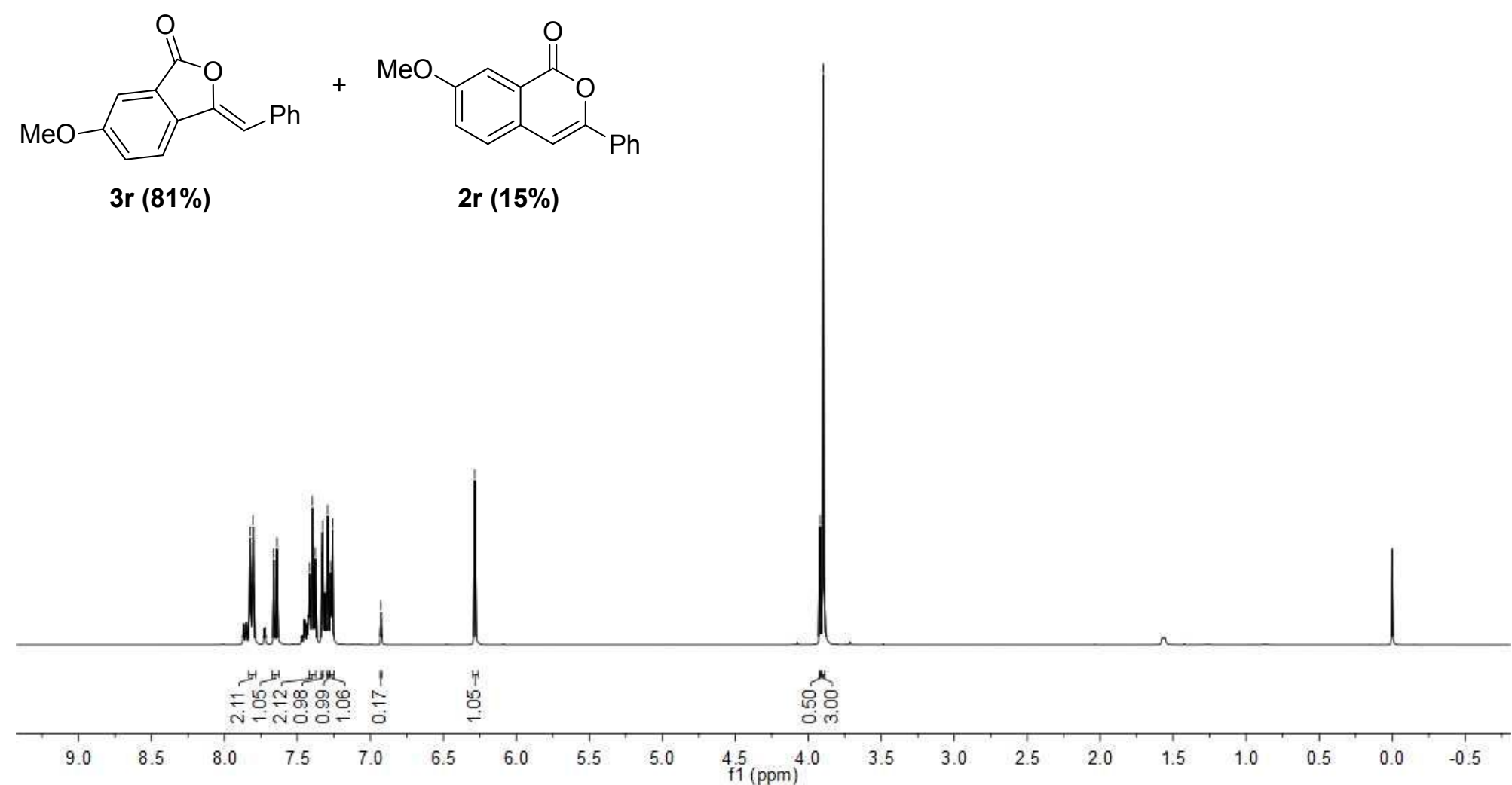

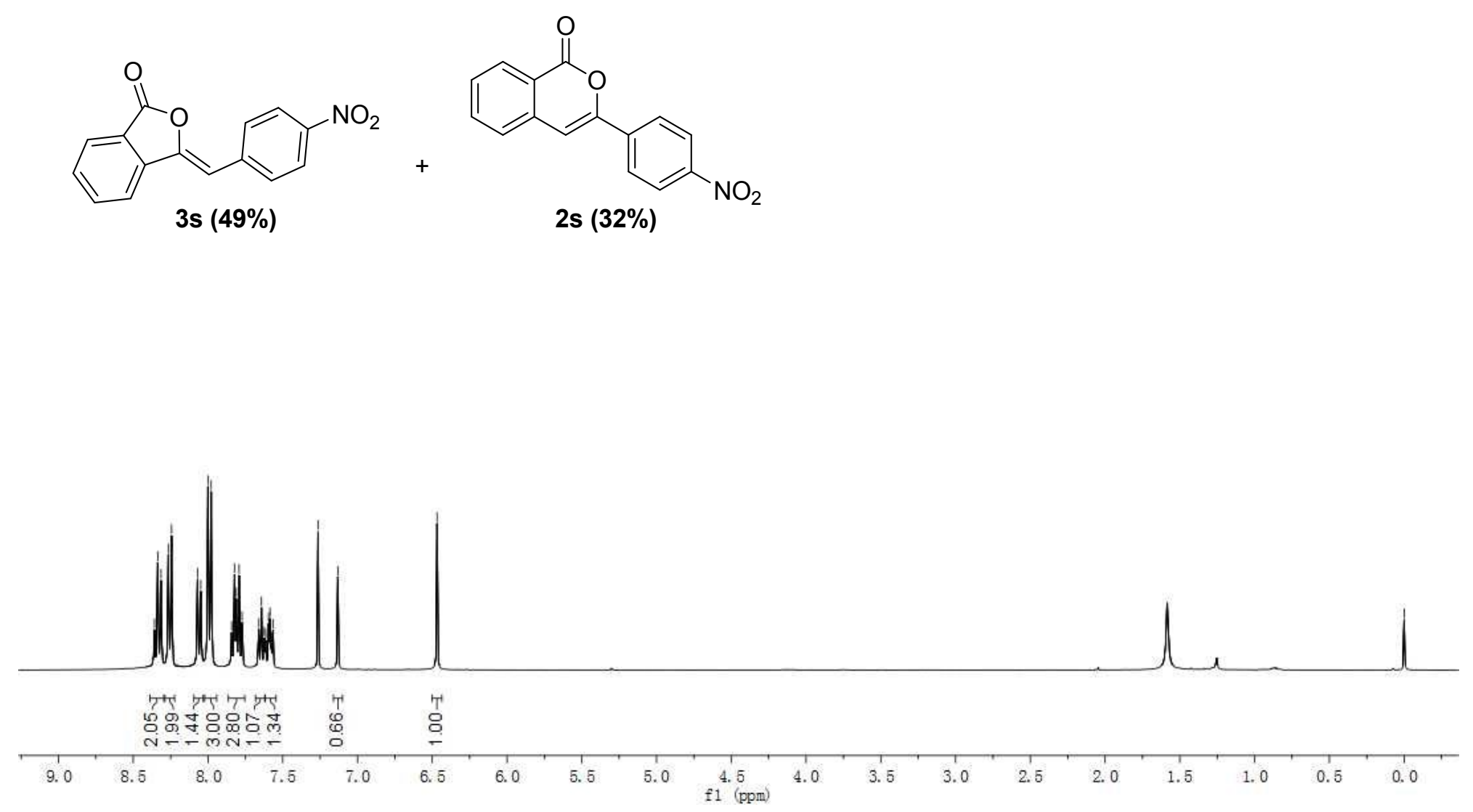
III. ${ }^{1} \mathrm{H}-\mathrm{NMR}$ and ${ }^{13} \mathrm{C}-\mathrm{NMR}$ Spectra of Products 4

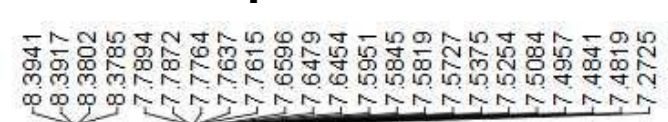

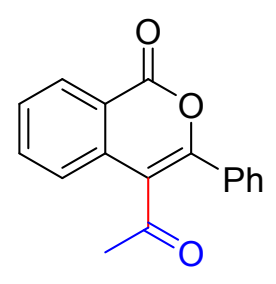

$4 a$

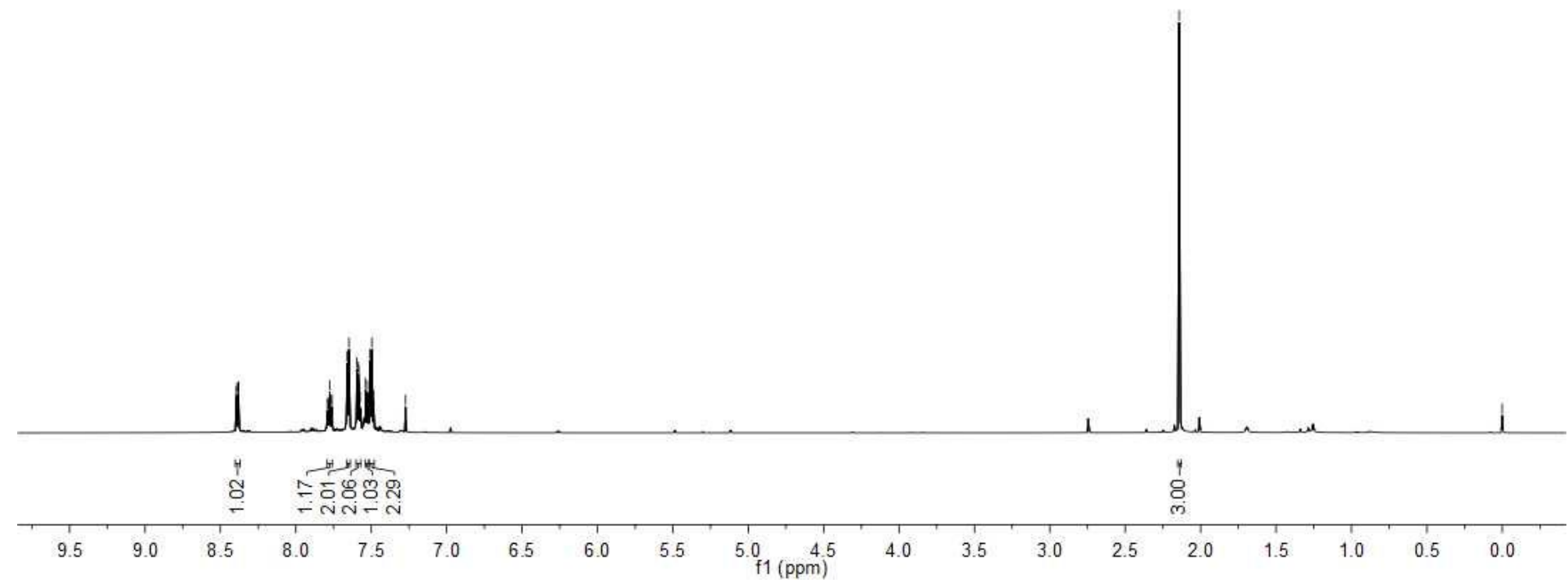




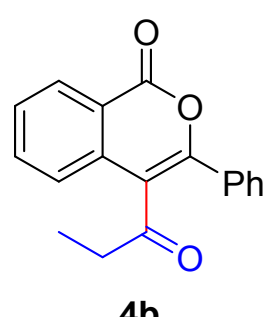

$4 b$

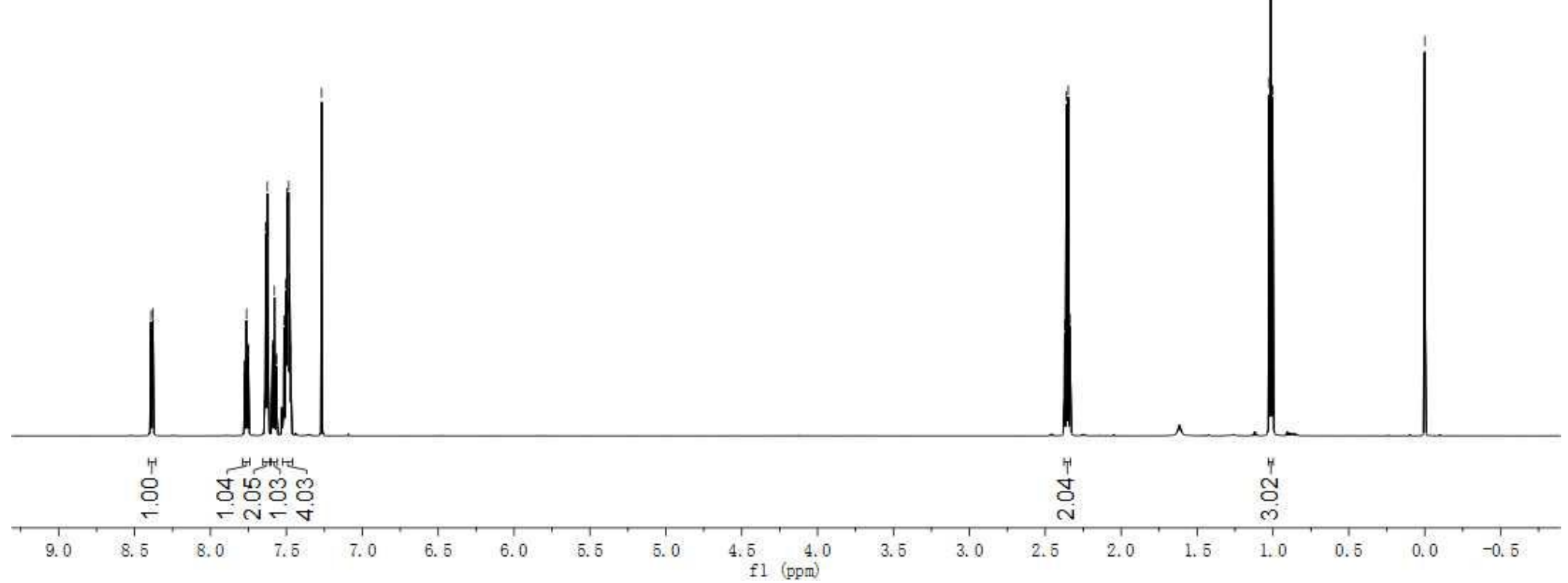




$$
\text { Il }
$$




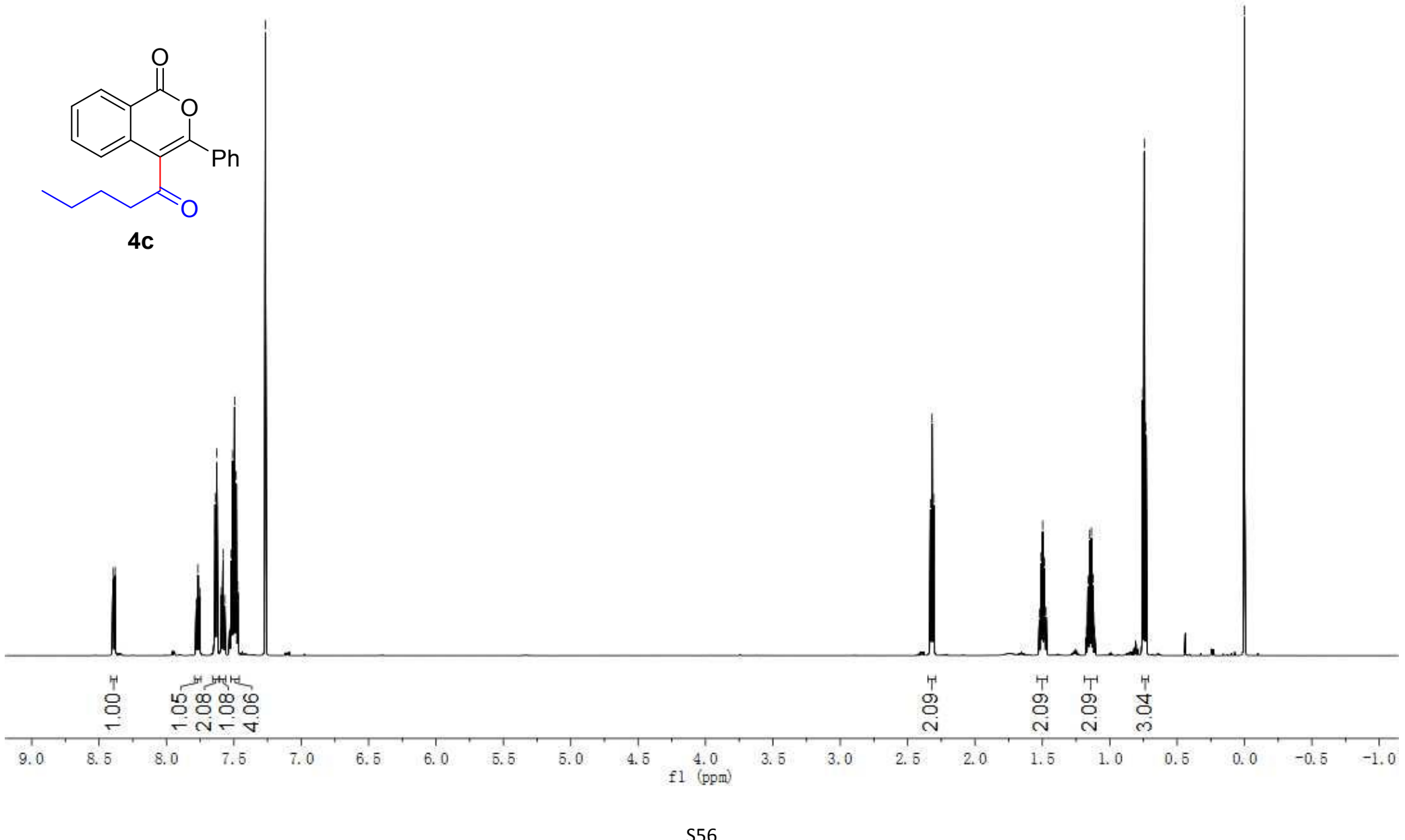



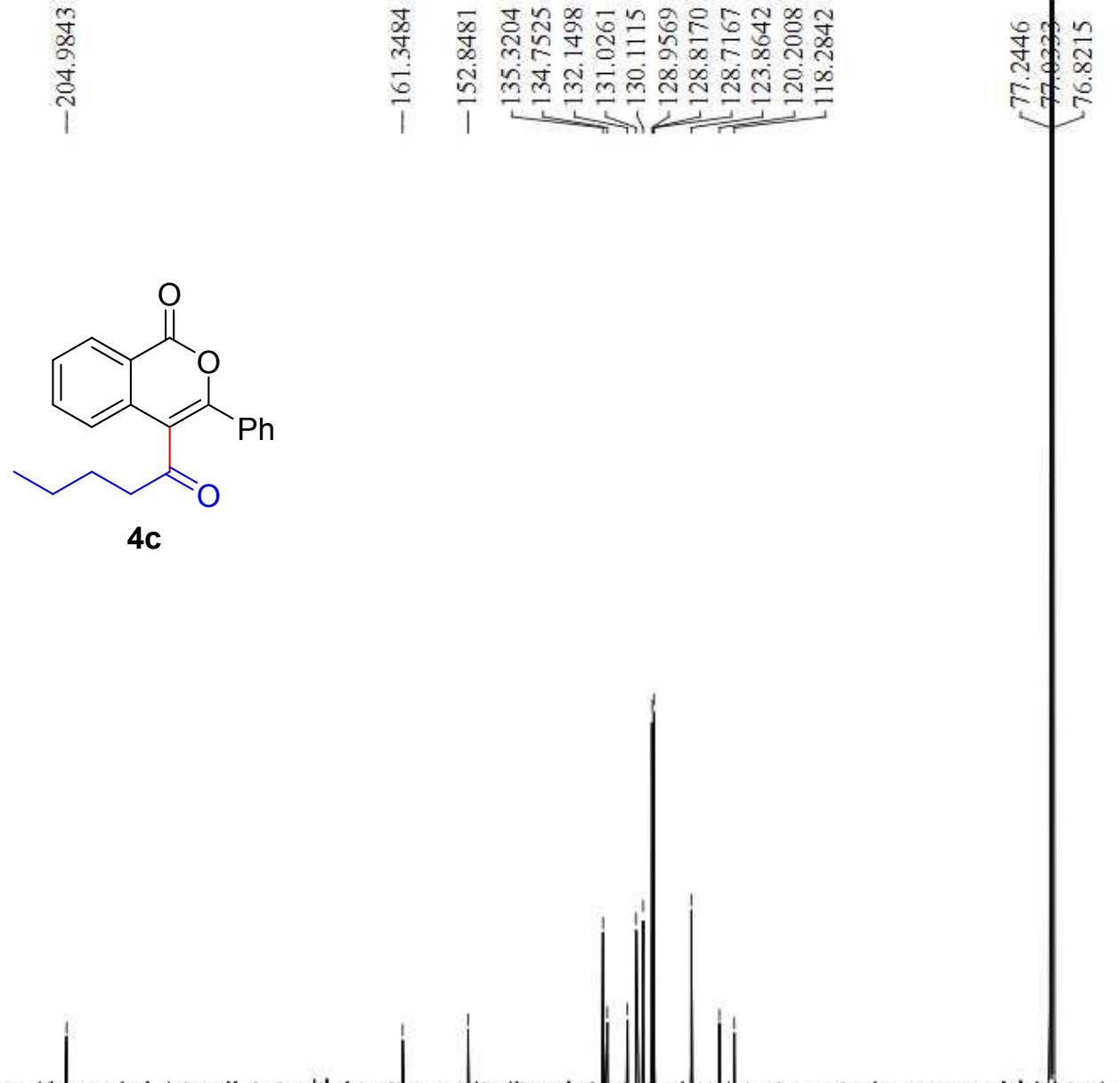

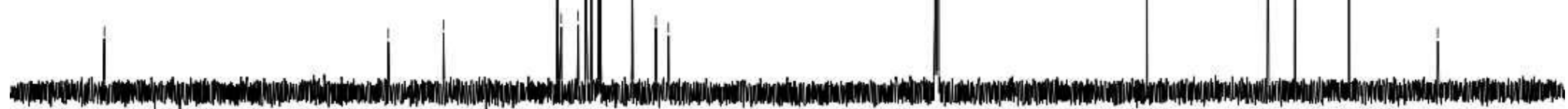

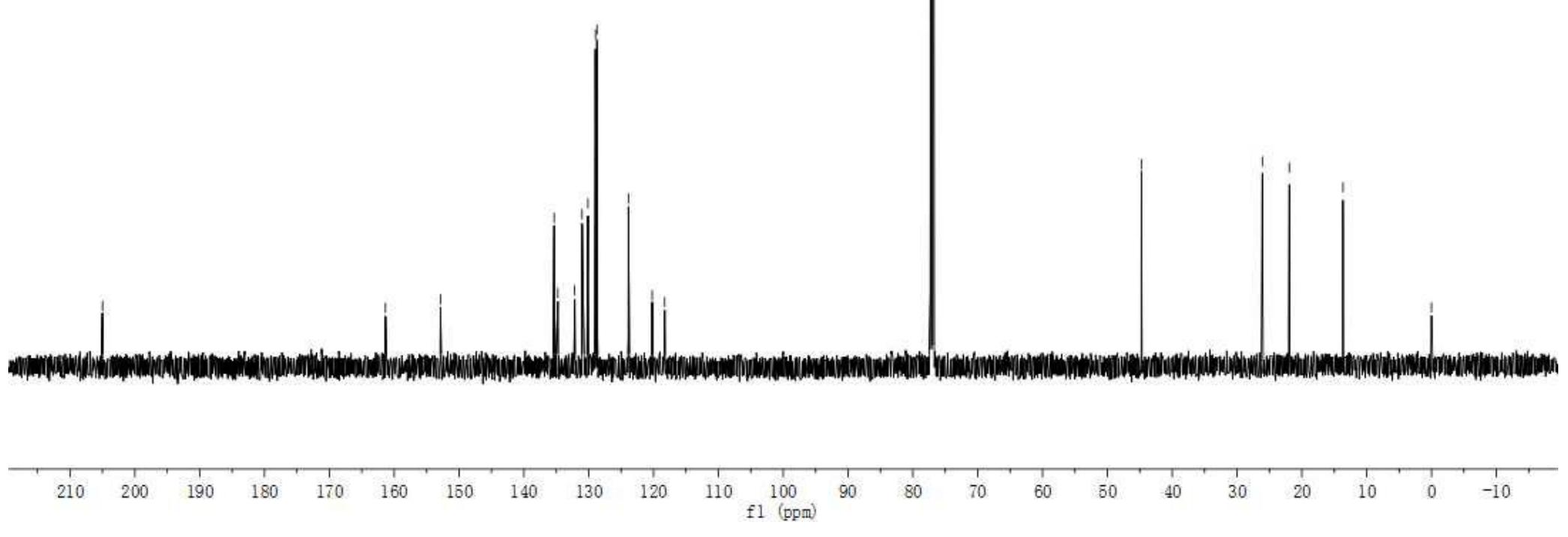




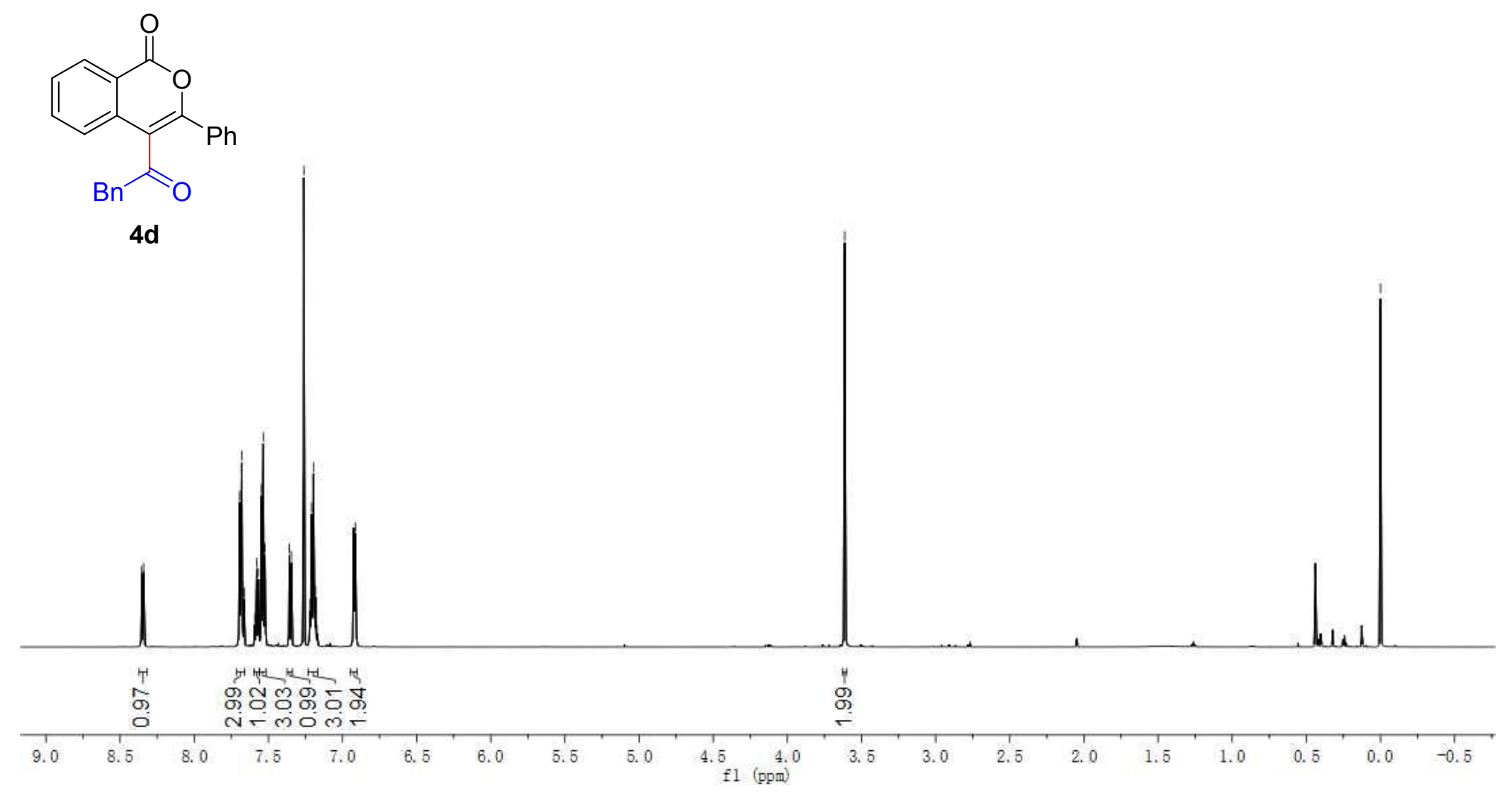



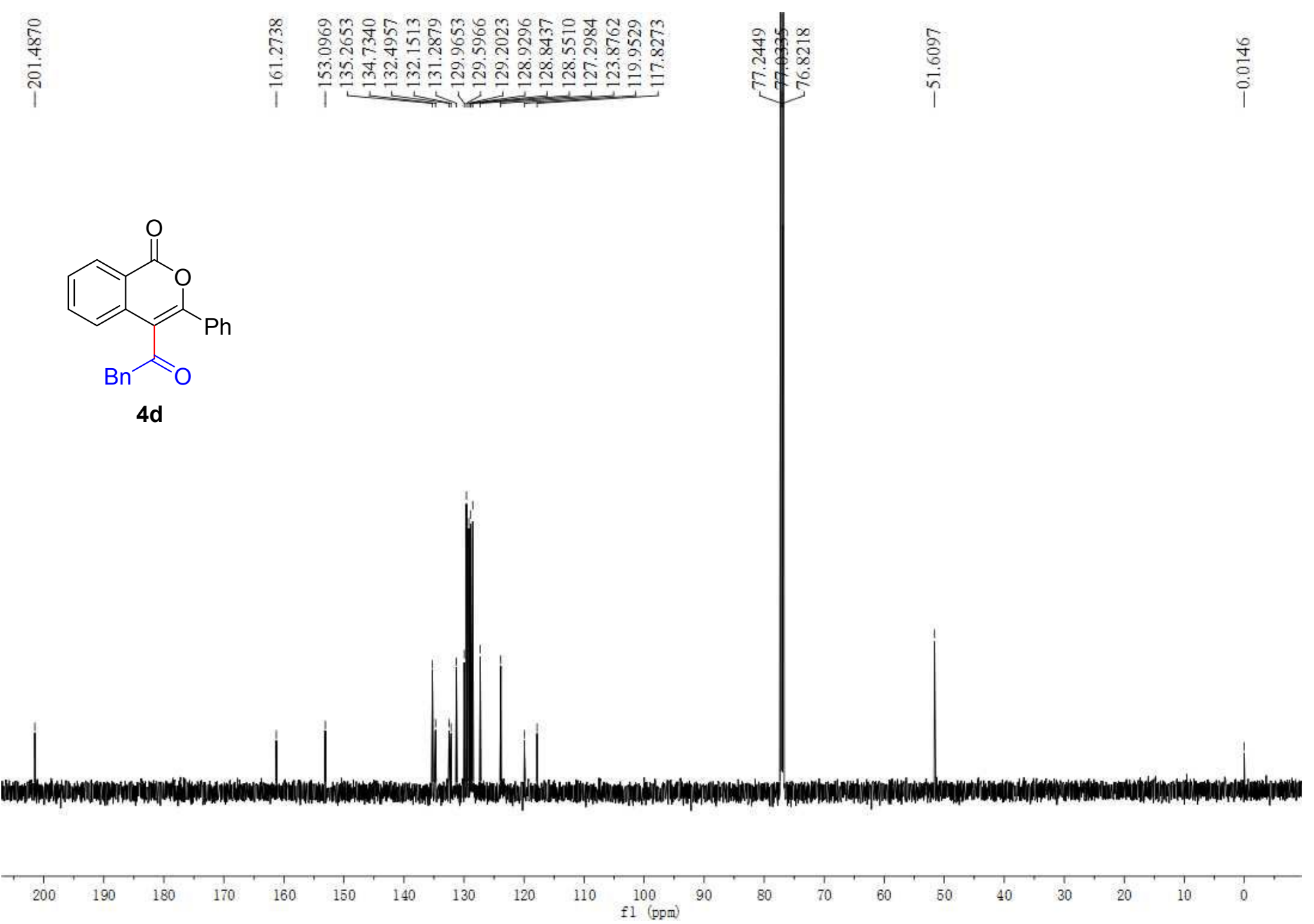

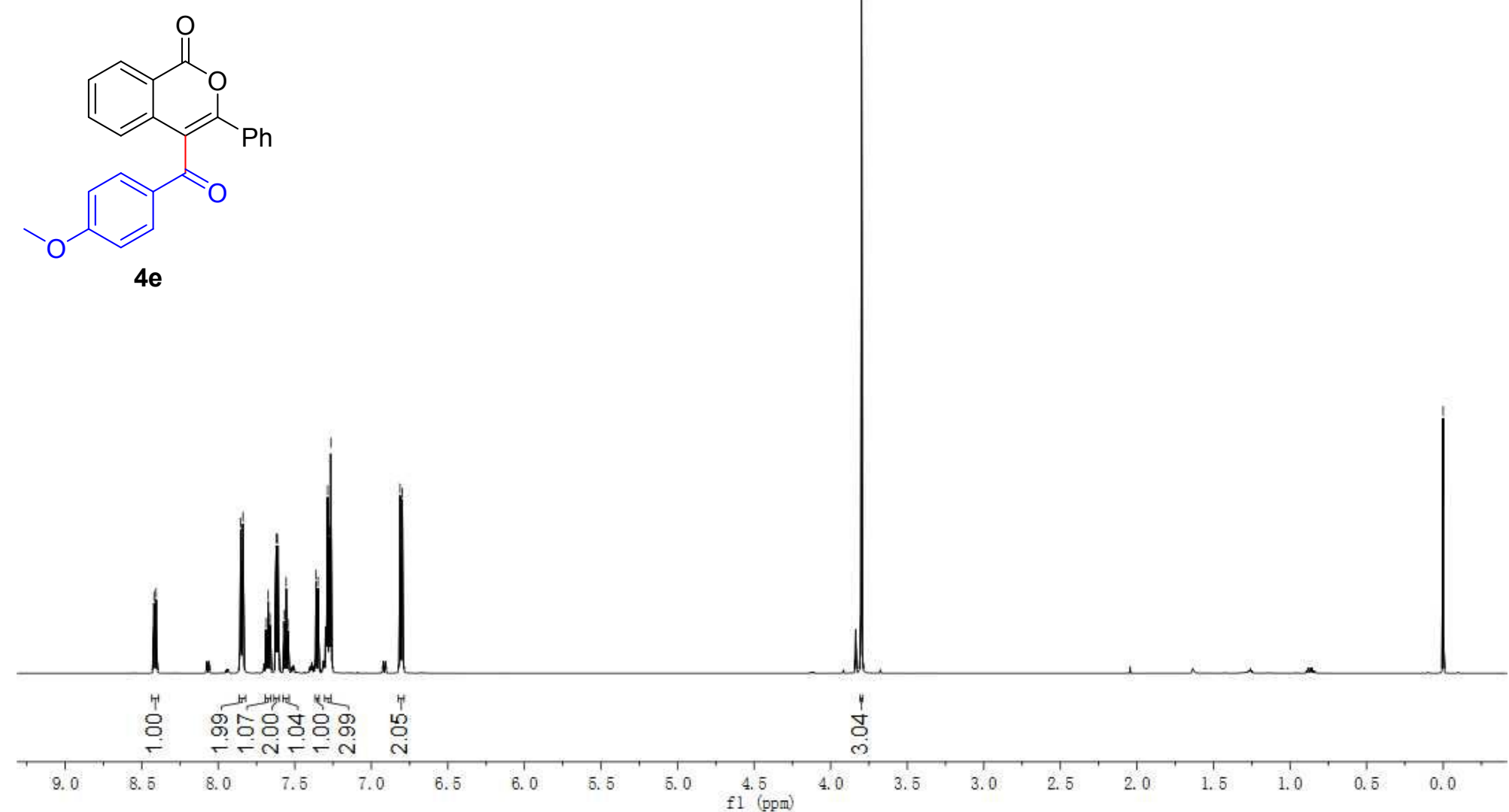

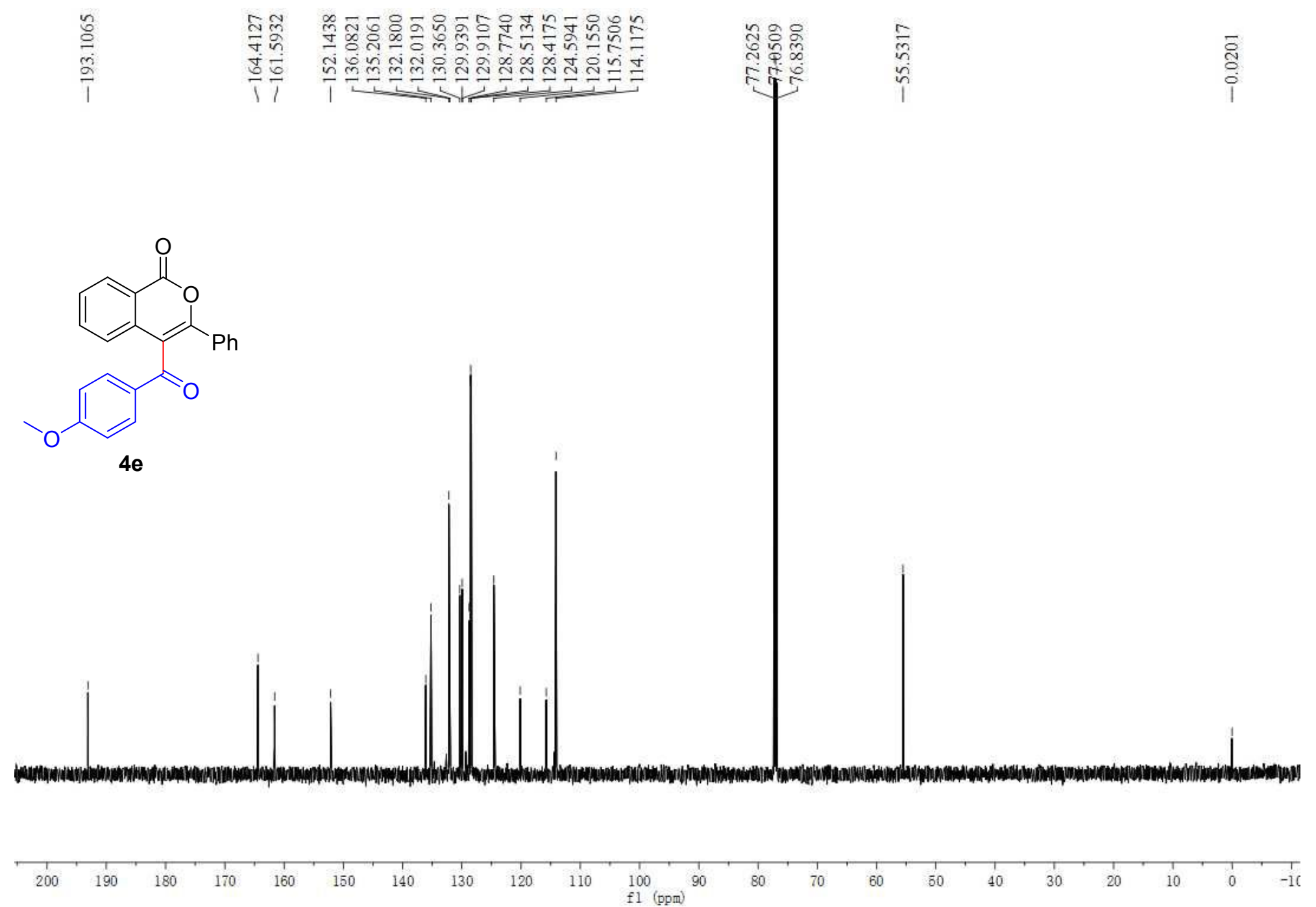


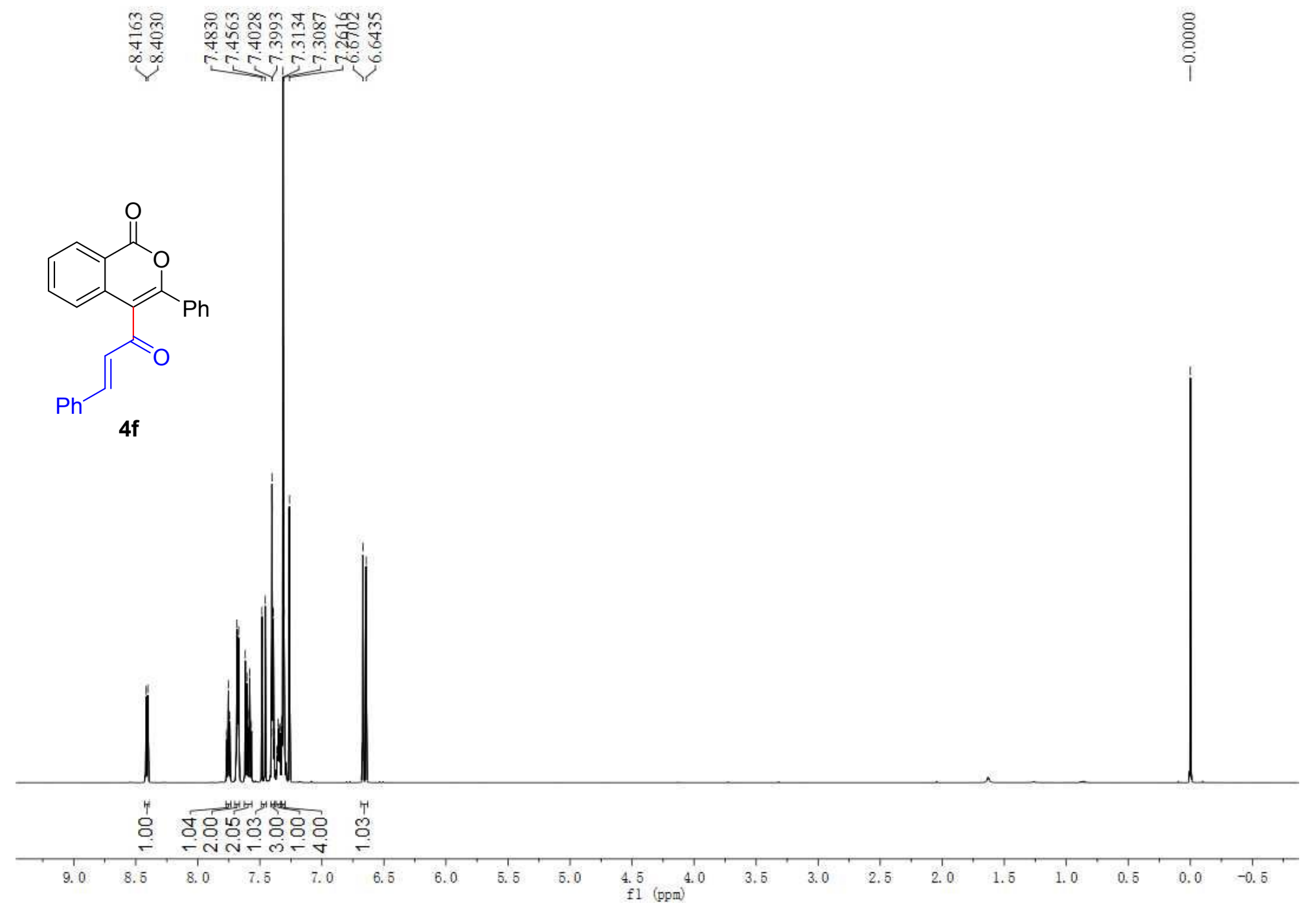




$$
1
$$




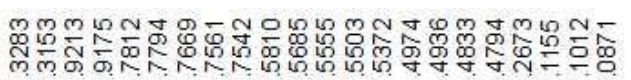

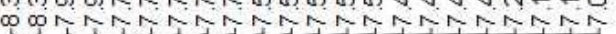
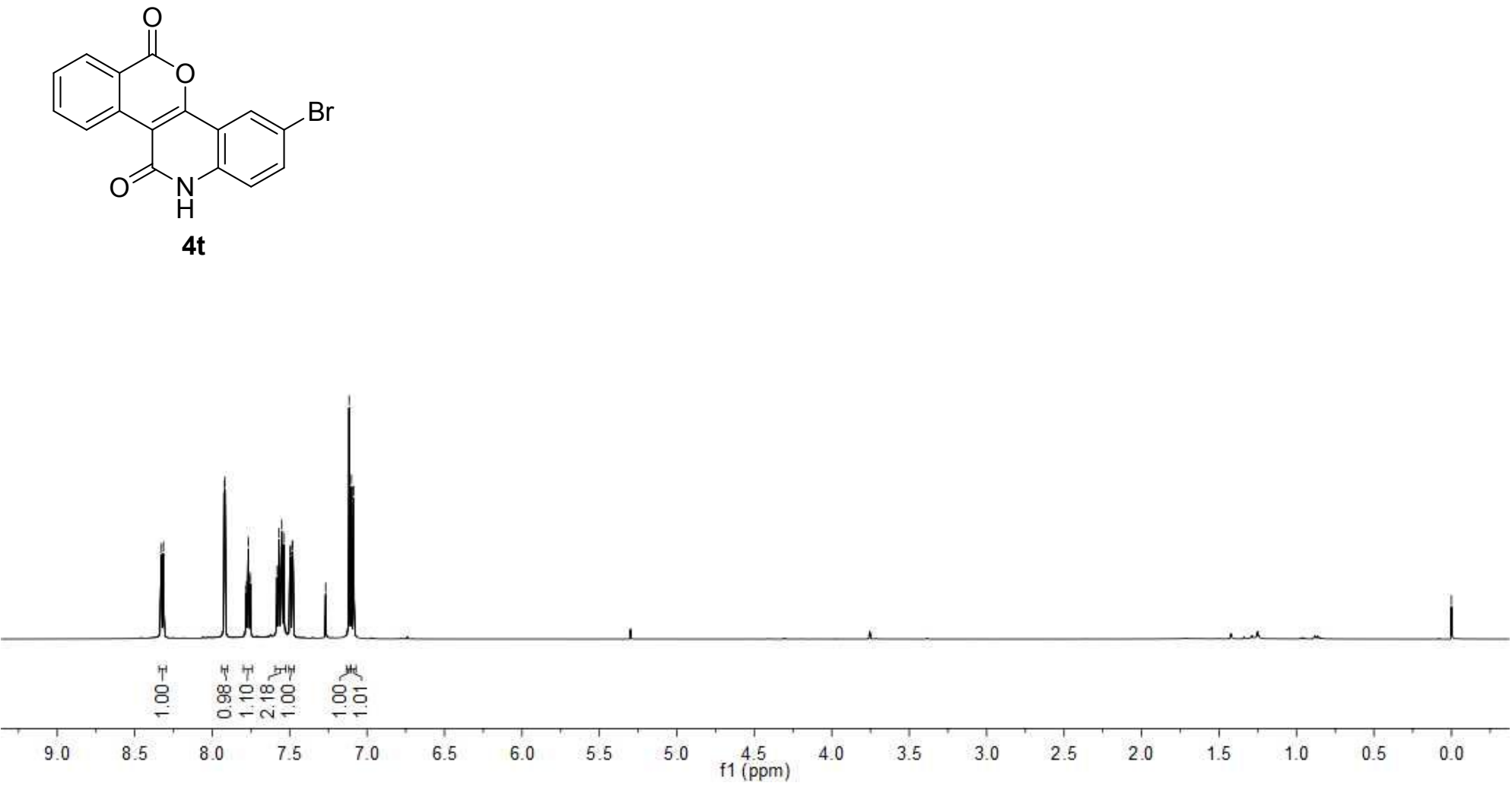


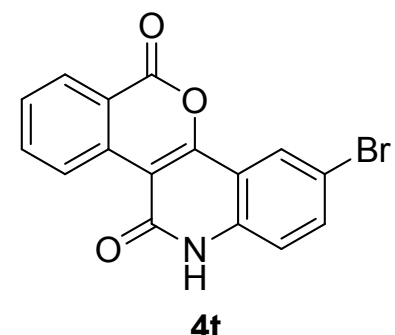

$4 t$

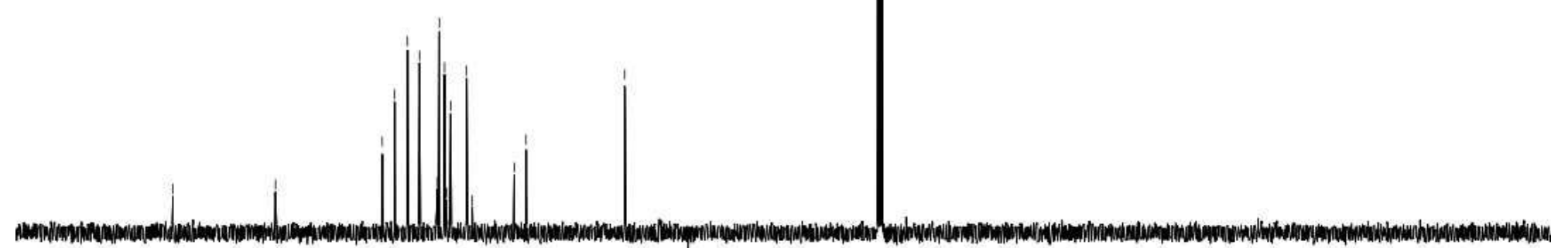

\begin{tabular}{llllllllllllllllllll}
\hline 80 & 170 & 160 & 150 & 140 & 130 & 120 & 110 & 100 & 90 & 1 & 1 & 1 & 1 & 1 & 1 & 1 & 1 & 1 & 1 \\
$f 1$ & $(\mathrm{pm})$ & 80 & 70 & 60 & 50 & 40 & 30 & 20 & 10 & 0
\end{tabular}


IV. ${ }^{1} \mathrm{H}-\mathrm{NMR}$ and ${ }^{13} \mathrm{C}$-NMR Spectra of Compounds 6 and 7

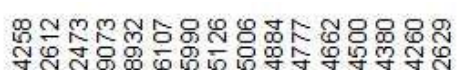

oivañNañNas
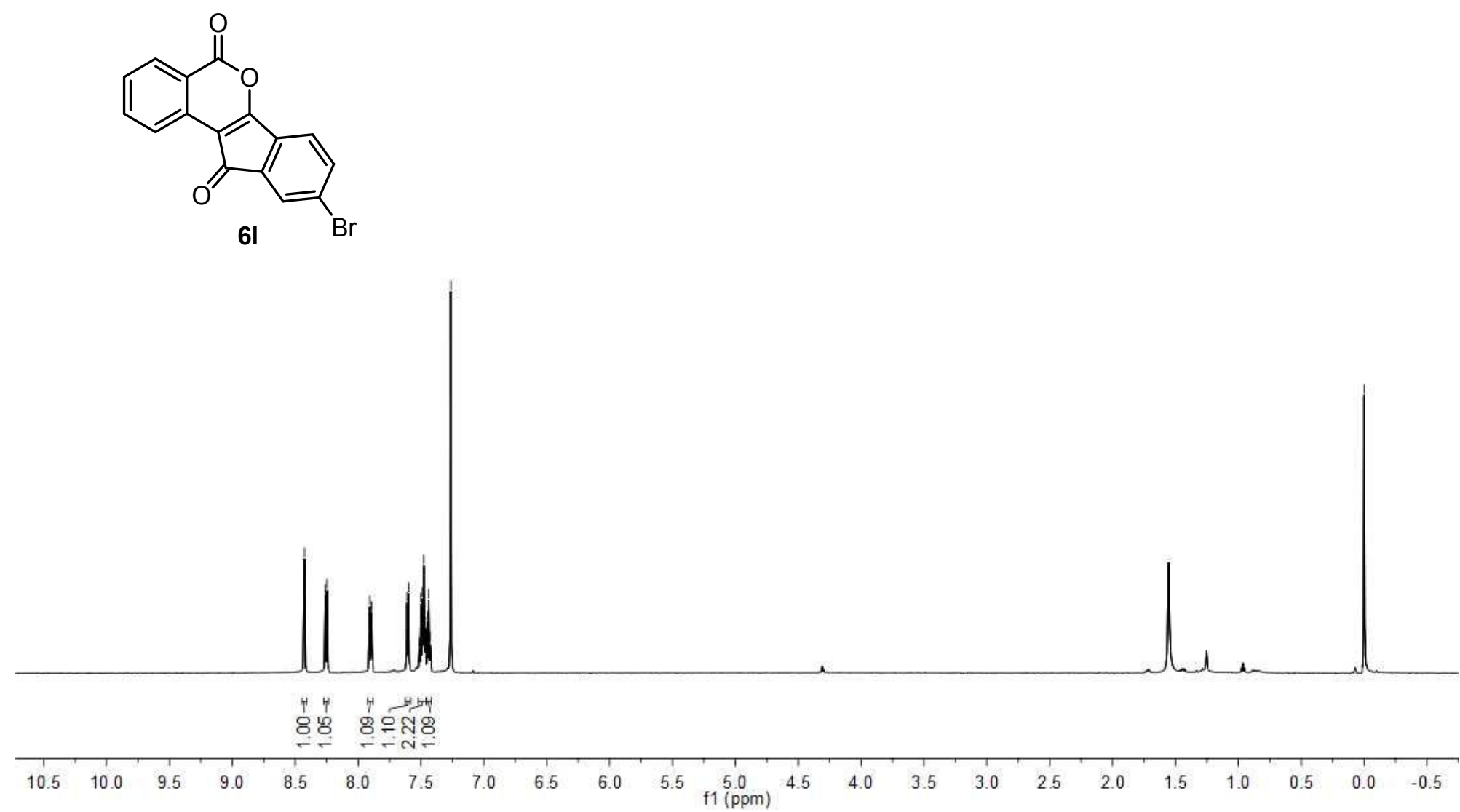


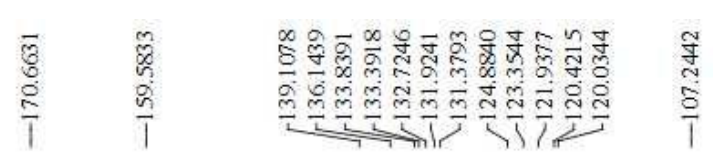

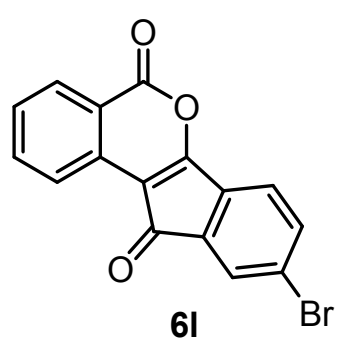

mumanom.

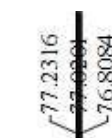

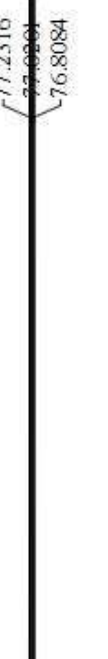

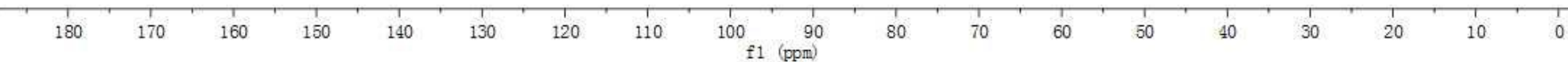




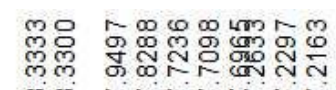

io rivinasin

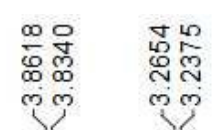
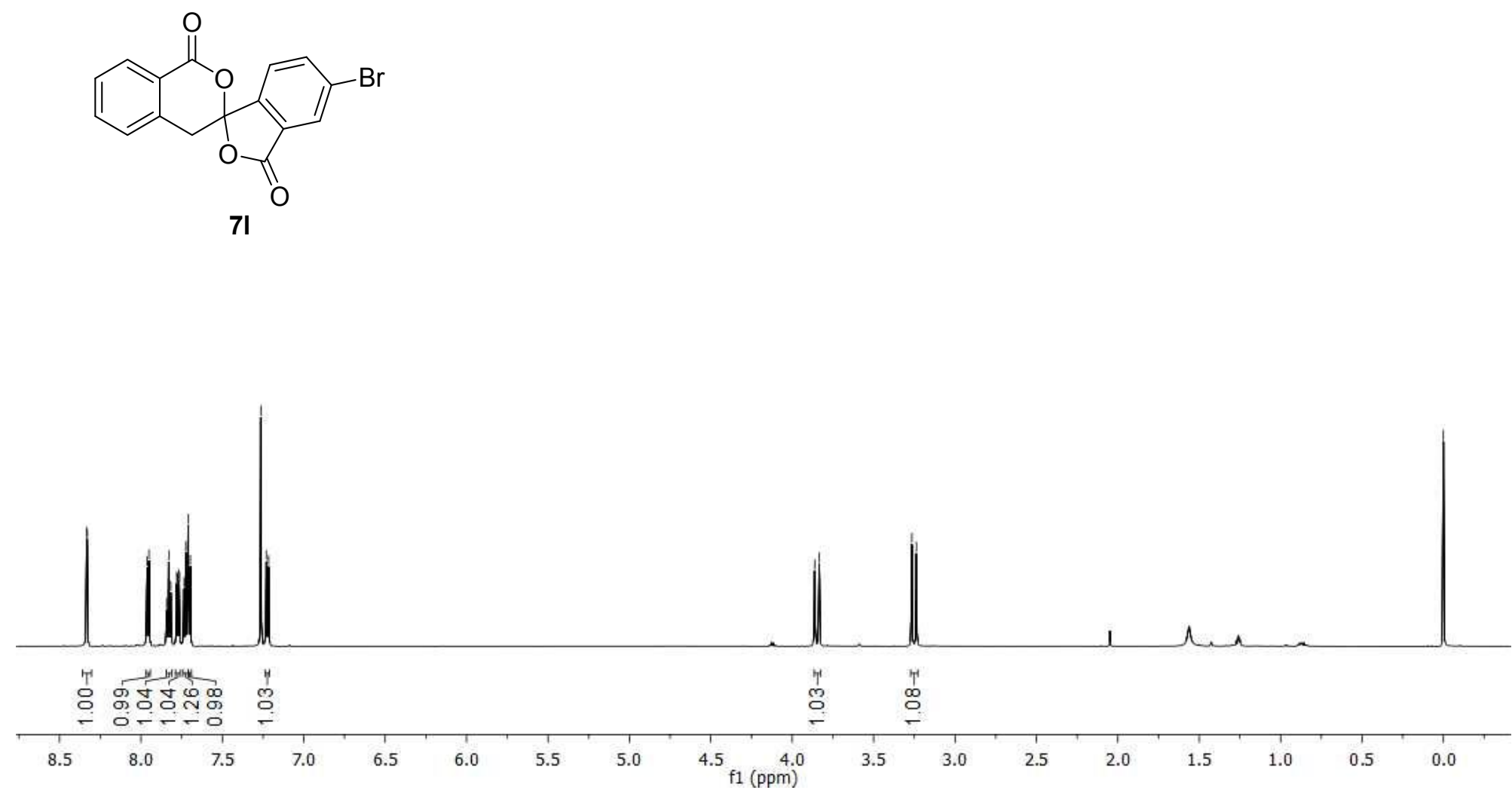


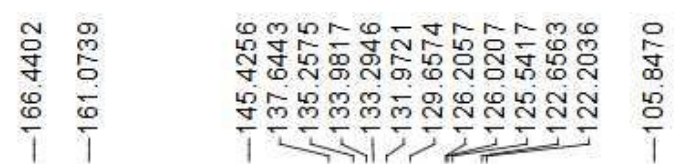

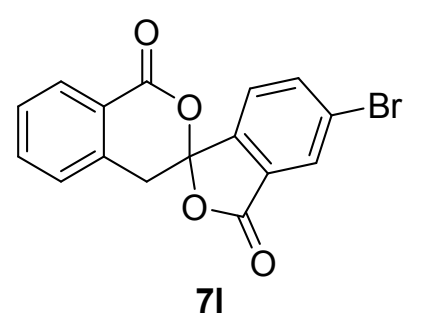

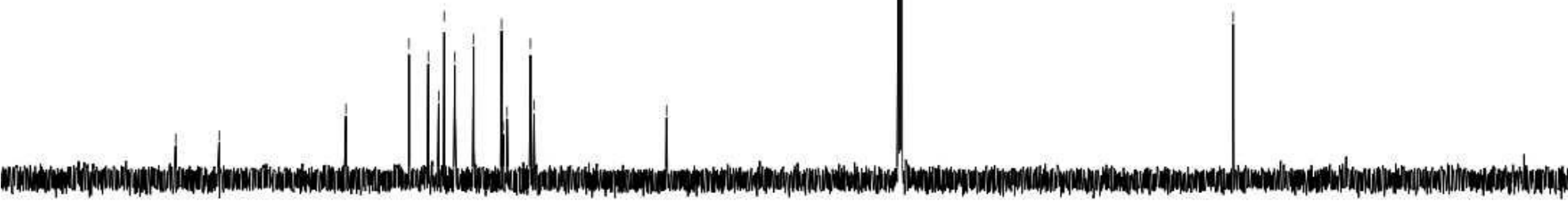

